University of Redlands

\title{
VGI and Twitter for Event Feedback; A Case Study for the Arts Council for Long Beach
}

A Major Individual Project submitted in partial satisfaction of the requirements

for the degree of Master of Science in Geographic Information Systems

by

Numa Gremling

Ruijin Ma, Ph.D., Committee Chair

Mark Kumler, Ph.D.

December 2013 
VGI and Twitter for Event Feedback;

A Case Study for the Arts Council for Long Beach

Copyright () 2013

by

Numa Gremling 
The report of Numa Gremling is approved.

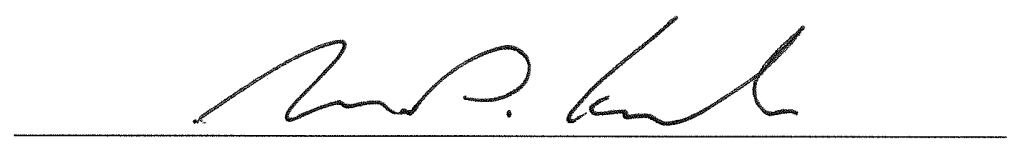

Mark Kumler, Ph.D.

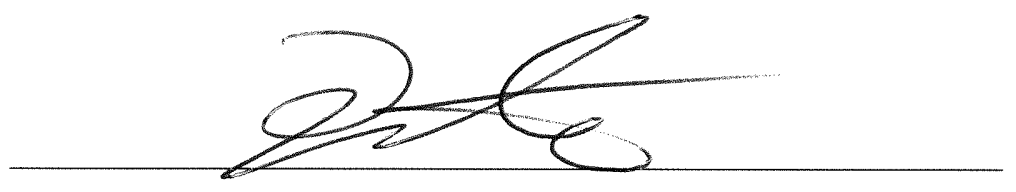

Ruijin Ma, Ph.D., Committee Chair

December 2013 



\section{Acknowledgements}

This project is dedicated to mom, dad, brother, grandma, the four turtles, as well as the endless blue in the Southern California skies.

Robbyn Abbitt, my number one reason for being in GIS. Without you I would never have realized how amazing this field is.

My cohort, the past cohort, and the new cohort. I will not list my favorites here; you know who you are :-)

Brandon, Pon, Vani, Sean, Lisa, who have given me great advice, or helped me to some extent or another with this project. Thank you for pushing me, Ruijin; it was needed and it taught me a lot about not giving in. Getting these birds to tweet was doable, indeed.

My best friends from Luxembourg: Tatiana, Béa, Tom, Yves.

My best friends from Ohio: Brett and his family, Lisa, JaMalle, Logan, Fern, Mike \& Sam, Liz, Matt, Emma, Mary, Molly, Natalia, Amy, Ana, Clancy.

The faculty for sharing so much great data, information, knowledge, and sometimes even wisdom. An especially big thank you to Mark Kumler. You are one of the best teachers I have ever had. Your passion, dedication, and support were incredibly inspiring and a major reason why I was able to finish this program successfully.

Marco from the Arts Council. Vielen Dank für Deine Geduld und Unterstützung.

The Grateful Dead, Cream, The Doors (R.I.P. Ray), Bruce Springsteen, The E Street Band, The Beach Boys, Leonard Cohen, Neil Young, Judas Priest, Pink Floyd, John Lee Hooker, Led Zeppelin, Beethoven, The Velvet Underground \& Nico (R.I.P. Lou), Paul Butterfield Blues Band, Kris Kristofferson, Hank Williams, JJ Cale (R.I.P. JJ), David Gilmour, Wilson Pickett, Jeff Beck, Air.

The many authors whose books I have read or read again at the pool, in my apartment, or on the road during two fantastic breaks: Jack Kerouac, Ira Levin, Hunter S. Thompson, Arthur Robinson, John Steinbeck, Arthur Clarke, Max Frisch, Goethe, and Ernest Hemingway. This project seemed like the marlin in the Old Man and the Sea, me being the old man, obviously. I am glad to call this degree mine now. I am glad I was able to catch it.

The West Coast in general for its incredible nature, cities, burgers, and insane amount of excellent breweries. Grab an IPA and understand the API, it works!

Oh, and let's not forget about RollerCoaster Tycoon 2, the only game I really had time to play.

Leaves are fallin' all around, time I was on my way

Thanks to you, I'm much obliged for such a pleasant stay

but now it's time for me to go, the autumn moon lights my way

Led Zeppelin - Ramble On 


\section{Abstract \\ VGI and Twitter for Event Feedback; \\ A Case Study for the Arts Council for Long Beach}

by

Numa Gremling

Social networking platforms such as Twitter are playing an increasingly important role in understanding the public's involvement of social activities. Along with GIS and the volunteered geographic information movement, these technologies have great potential in shaping how urban planning can be conducted. This report will provide details about how an interactive web GIS application was used to connect the public with the Arts Council of Long Beach (ACLB), a non-profit organization. The web application provides the ACLB an effective way to evaluate public responses concerning their A LOT Initiative, a project which aims at reviving neighborhoods by hosting events on vacant urban lots. These events draw crowds and stimulate interaction among neighbors. 



\section{Table of Contents}

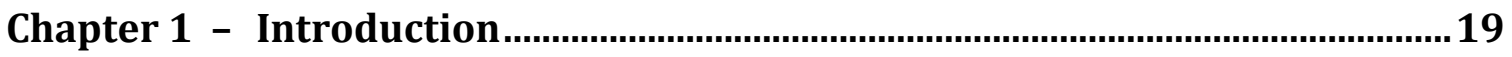

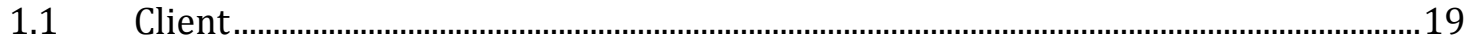

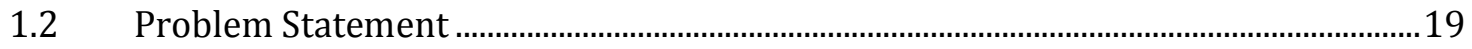

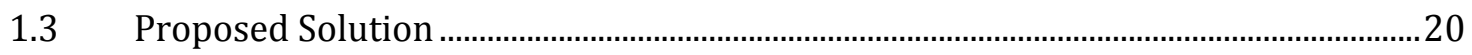

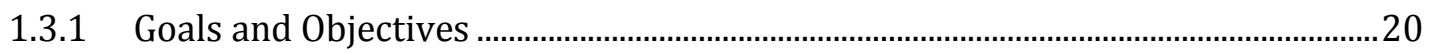

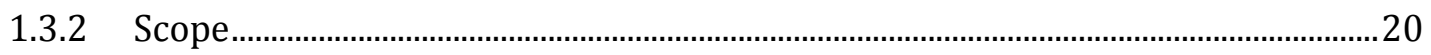

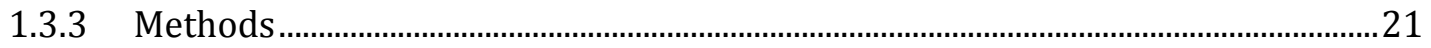

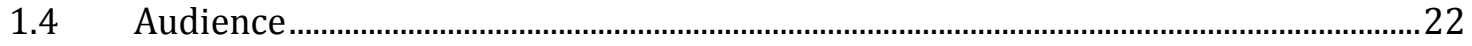

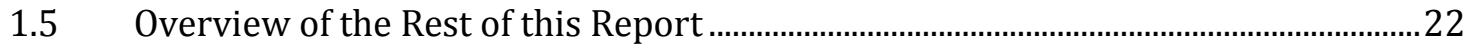

Chapter 2 - Background and Literature Review ...................................................23

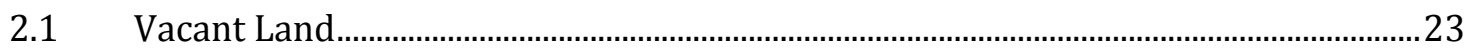

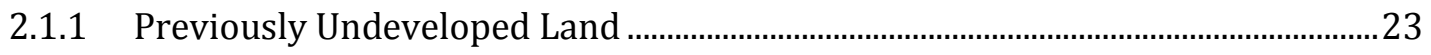

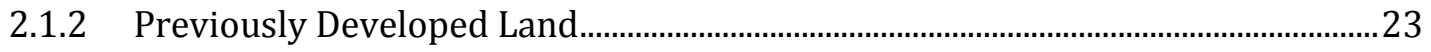

2.1.3 The Issue of Vacant Land in America Cities................................................................24

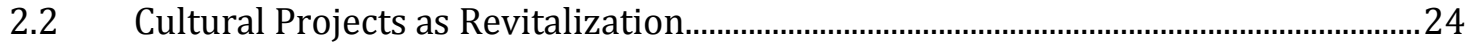

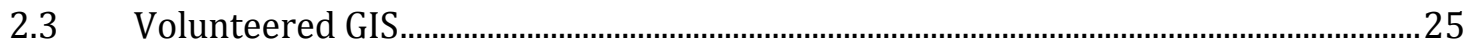

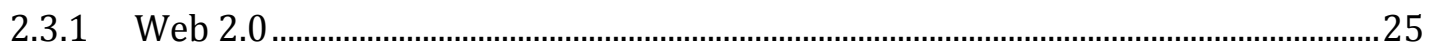

2.3.2 Public Participation GIS and Volunteered Geographic Information ......................25

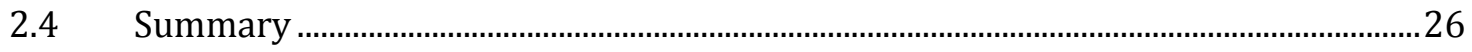

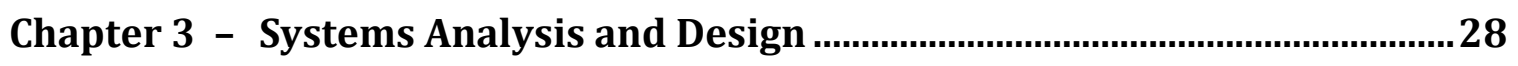

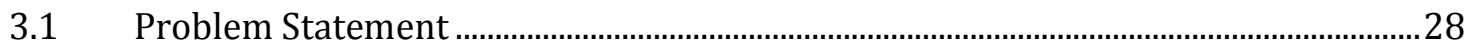

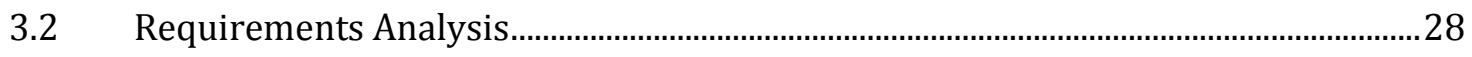

3.2.1 Functional Requirements.............................................................................................2 
3.2.2 Non-Functional Requirements ............................................................................. 29

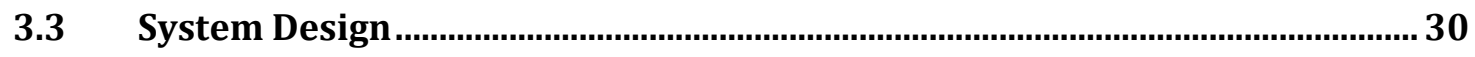

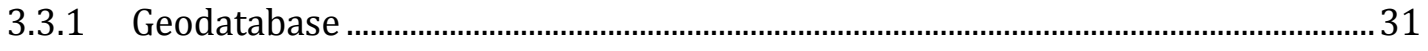

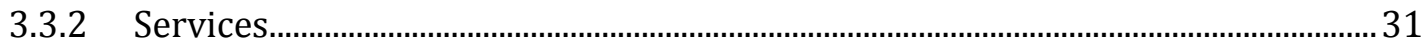

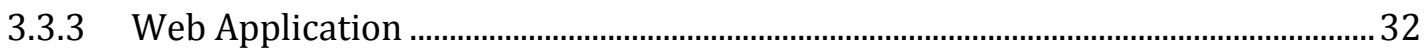

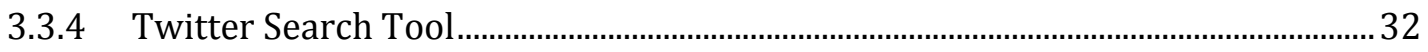

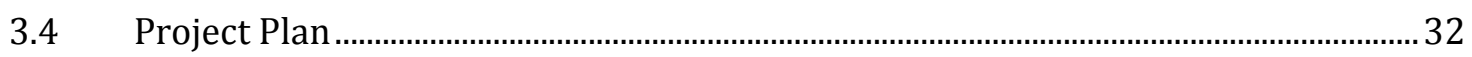

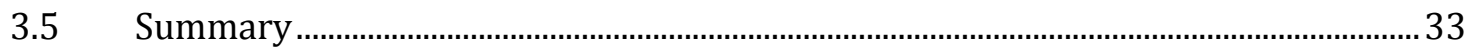

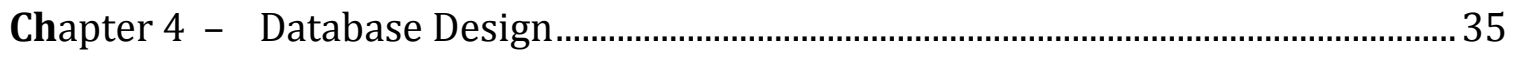

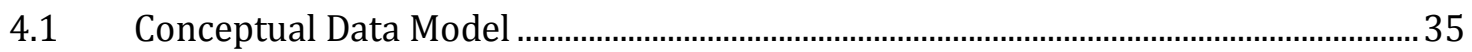

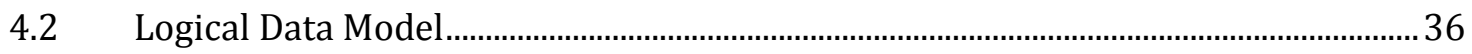

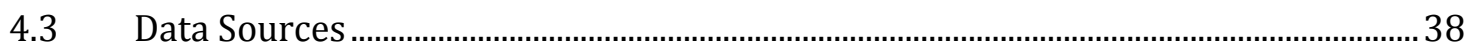

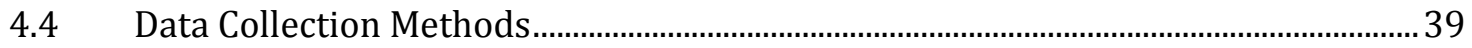

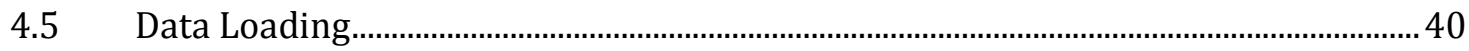

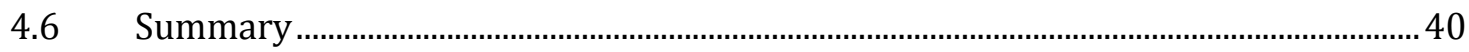

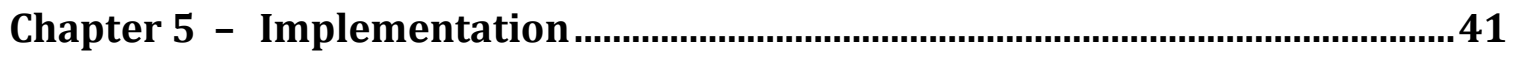

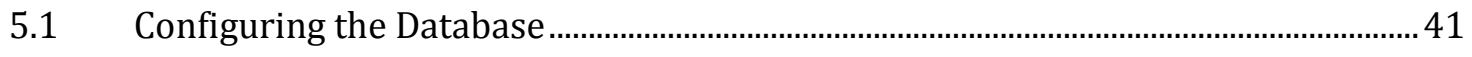

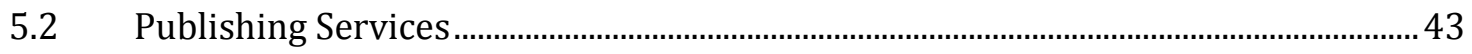

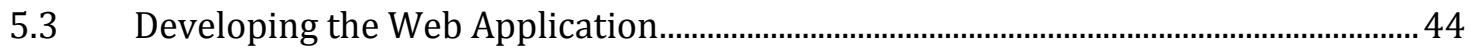

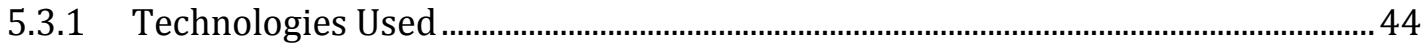

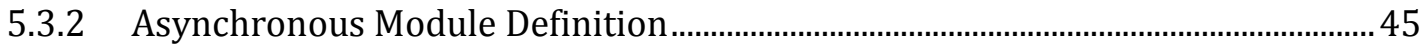

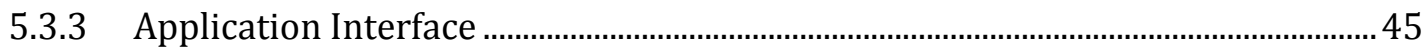

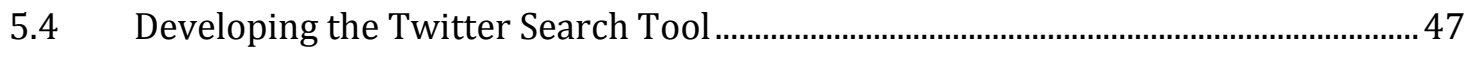

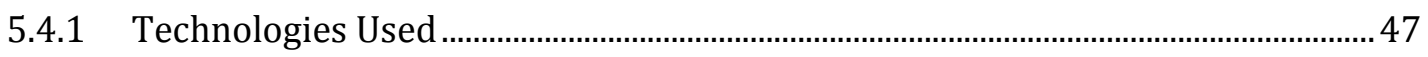


5.4.2 Limitations of the Twitter Search API......................................................................... 48

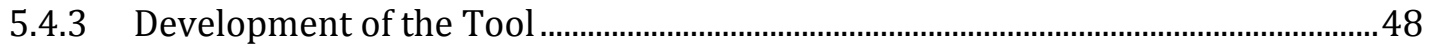

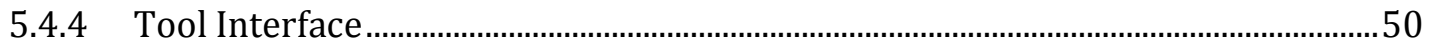

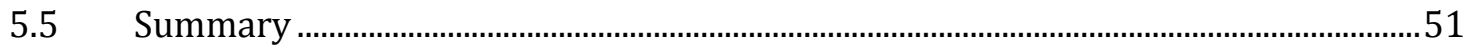

Chapter 6 - Use Cases ..................................................................................................... 53

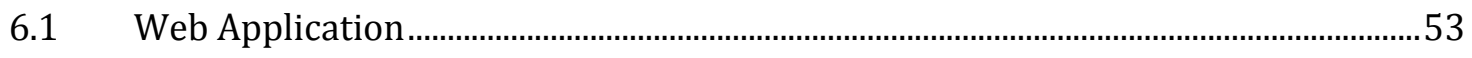

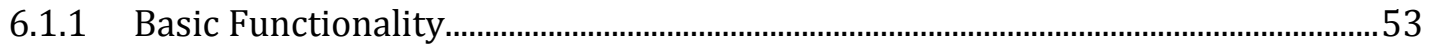

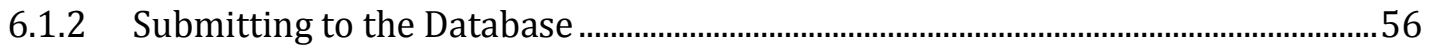

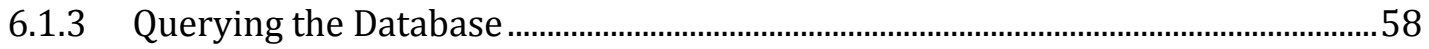

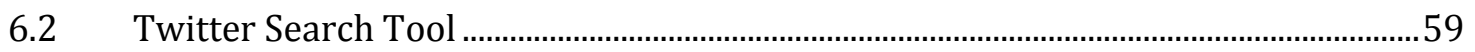

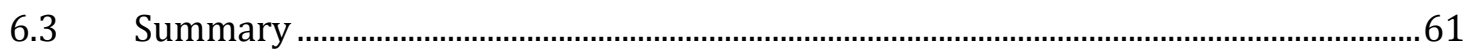

Chapter 7 - Conclusions and Future Work .....................................................63

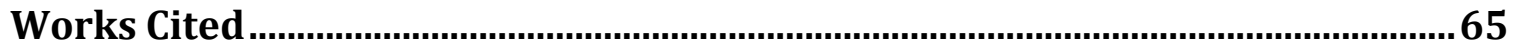

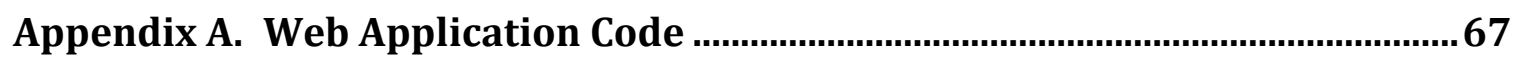

Appendix B. Twitter Search Tool Code 



\section{Table of Figures}

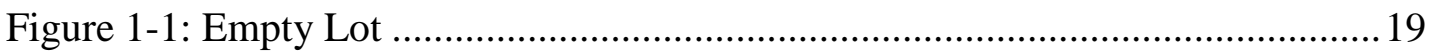

Figure 1-2: Map of Study Area and A LOT Initiative Lots ........................................2

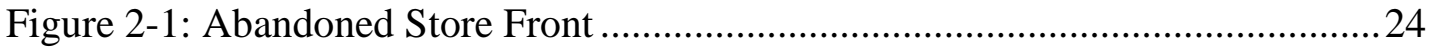

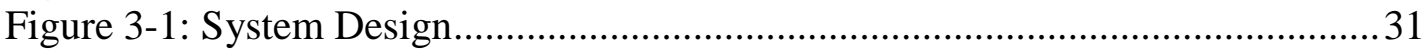

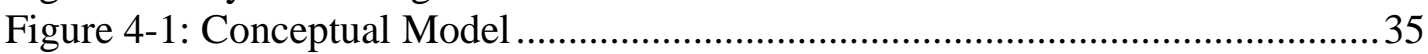

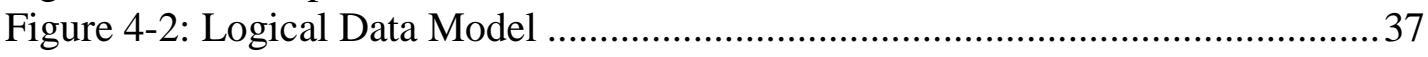

Figure 4-3: City of Long Beach GIS Data Catalog..................................................... 39

Figure 4-4: Inconsistencies between Imagery and Parcels ..........................................39

Figure 5-1: Initial and Final Database ............................................................... 41

Figure 5-2: Choosing a Primary Key .................................................................... 42

Figure 5-3: The ArcGIS Rest Services Directory ……………………….................4 44

Figure 5-4: Graphical User Interface of Web Application ..........................................46

Figure 5-5: Flowchart of the Twitter Search Tool ....................................................49

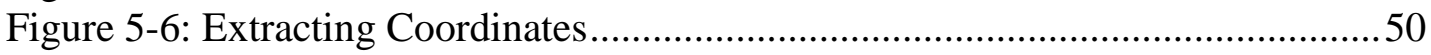

Figure 5-7: Graphical User Interface of Twitter Search Tool.....................................51

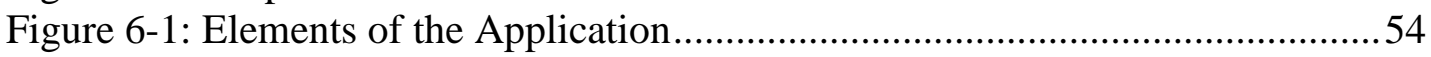

Figure 6-2: The Schedule Pane for the Central Lot ...................................................55

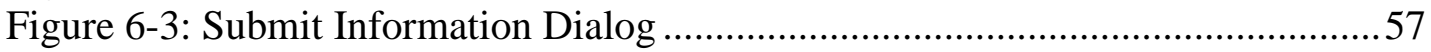

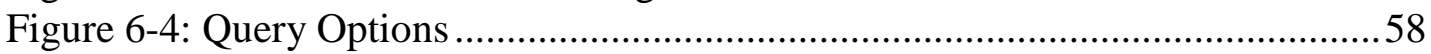

Figure 6-5: Query Results for Carlos Ramirez ……………………........................59

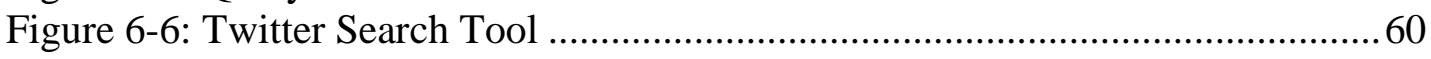

Figure 6-7: Heat Map Result from Searching "Thanksgiving”..................................61 



\section{List of Tables}

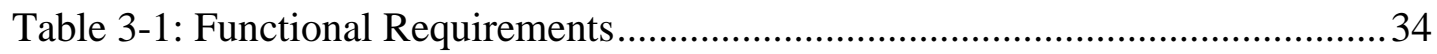

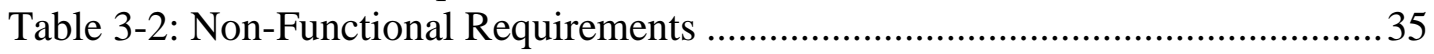

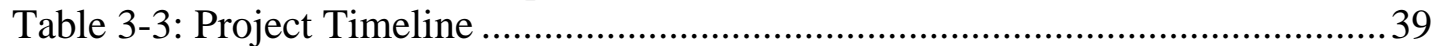

Table 5-1: Maximum Field Values in Table.......................................................51

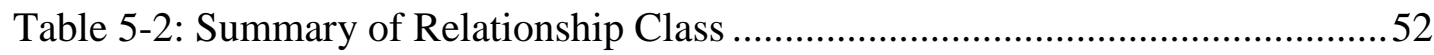

Table 5-3: Technologies Behind the Web Application..........................................55

Table 5-4: Technologies Behind the Twitter Search Tool ......................................59

Table 6-1: Accuracy of Geolocation Methods ........................................................ 71 



\section{List of Acronyms and Definitions}

ACLB

API

CSS

GUI

HTML

IIS

NEA

VGI
Arts Council for Long Beach

Application Programming Interface

Cascading Style Sheets

Graphical User Interface

HyperText Markup Language

Internet Information Services

National Endowment for the Arts

Volunteered Geographic Information 



\section{Chapter 1 - Introduction}

This project assisted the Arts Council for Long Beach in developing two ways to track the success of its A LOT Initiative, a project that looks at the issue of vacant urban lots in the city of Long Beach. This chapter provides a broad overview of the project by introducing the client and stating the problem, as well as the solution to it. The solution is broken down into specific categories such as the goals and objectives, the scope, and the methods needed for completion of the project. Finally, this chapter introduces the audience this report is addressed to.

\subsection{Client}

The client for this project was the Arts Council for Long Beach (ACLB), a non-profit organization based in Long Beach, California. The ACLB's mission is the support of artists, as well as the promotion of the arts in local communities. The ACLB is recognized by numerous departments of the city, and it has strong ties to these departments, as well as to diverse corporations, foundations, and members of the Long Beach community. Dr. Marco Schindelmann and Shay Thornton were the main contact people who contributed to the successful completion of this project. Dr. Schindelmann helped defining the functionalities and the design of the application and Mrs. Thornton provided the necessary contacts at the ACLB who helped with the technicalities when developing the application.

\subsection{Problem Statement}

The ACLB was engaged in a project, the A LOT Initiative. The A LOT Initiative is an attempt to find a solution to the broader issue of empty urban lots in the city of Long Beach. Figure 1-1 shows a typical empty lot.

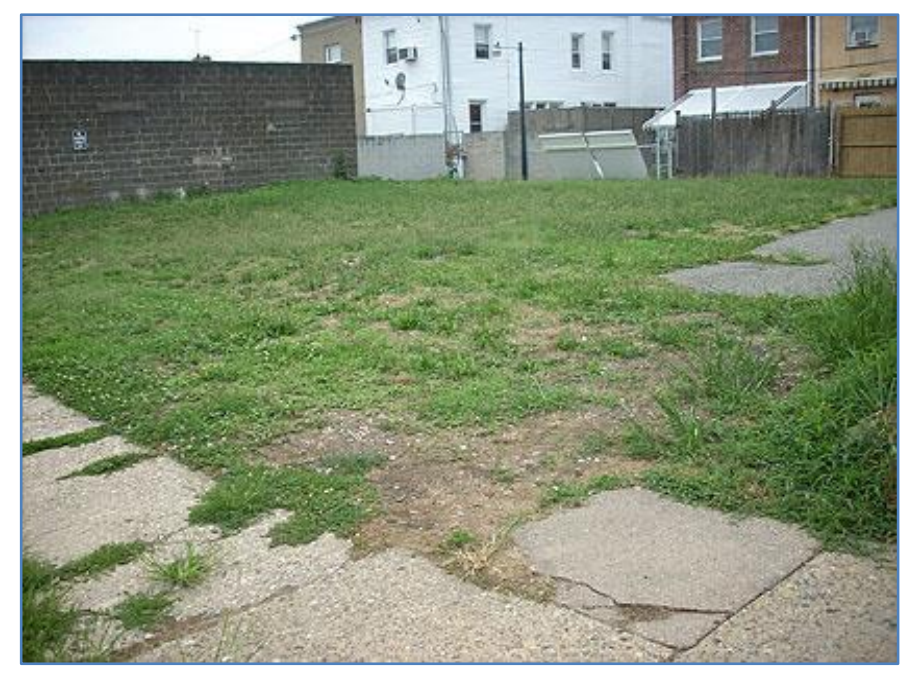

Figure 1-1: Empty Lot 
Three specific empty lots in the city were identified to host events (e.g., concert, theater, comedy) that would attract a wide variety of visitors, ideally stimulating interactions among the visitors and, in the long term, improving conditions in the neighborhood (e.g., reduced crime rates, redevelopment). The project was supported by a $\$ 150,000$ grant from the National Endowment for the Arts (NEA), a grant which only nine cities across the United States had received in 2012. Because of the importance of receiving the grant, the ACLB needed an effective way to track the success of the A LOT Initiative. It was crucial that the effects of the A LOT Initiative could be evaluated so the ACLB could draw conclusions for future projects.

\subsection{Proposed Solution}

To track the effects of the A LOT Initiative, this project proposed two tools. First, an interactive web GIS application to provide the public an opportunity to express its opinion about specific events and submit or retrieve information from a variety of sources, such as YouTube, the press, or blogs. Second, a tool that queries Twitter databases based upon specific keywords and then maps out the resulting tweets. The number of tweets regarding a specific event was used as an indication of the event's impact.

\subsubsection{Goals and Objectives}

The main goal of this project was to find a way for the ACLB to apply GIS to evaluate the A LOT Initiative. To achieve this goal, an interactive web application that lets users submit and retrieve information about the A LOT Initiative was proposed. More specifically, users could post feedback about the A LOT Initiative so the ACLB would have information that can be analyzed and used in further decision making. In addition to the public application, a tool that searches Twitter databases was proposed. The tool should detect what visitors of an event were saying regarding the event.

\subsubsection{Scope}

This project had a three-tiered scope: geographic, temporal, and technological. Geographically, this project was confined to the city of Long Beach, California (Figure 1.1). Although the three parcels in the ACLB's A LOT Initiative take up a minimal geographic area, their implications can potentially be felt across the city, so the entire city was considered in the analysis. The temporal scope refers to the time span that the web application will be used. The A LOT Initiative is a two-year project which started in September 2013, requiring that the developed application be running until September 2015. Technologically, the main deliverable of this project was restricted to the online environment. Users will, in most cases, only come in contact with the application and its results via the internet. Although the datasets are stored in a database hosted on a server, most users will not ever see that. The second part of the technological scope was that users become an interactive part of the project, meaning that users can input information regarding ACLB-supported events. The technological scope of the second deliverable was desktop-based. The tool can only be run by the ACLB and its results are not meant to be shared in the online application. 


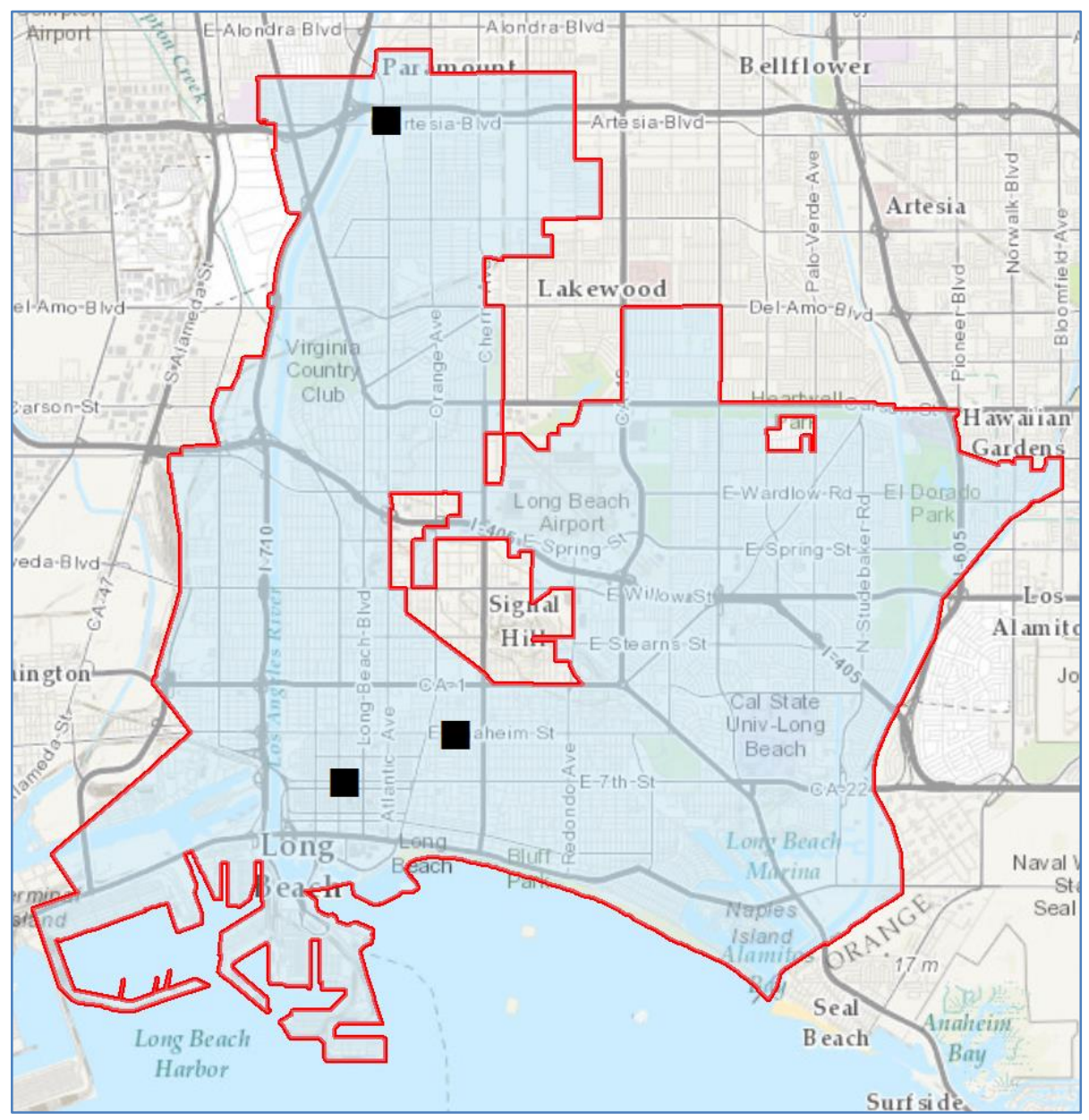

Figure 1-2: Map of Study Area and A LOT Initiative Lots

\subsubsection{Methods}

The application provides ways for users to submit information about A LOT Initiative events. Information that can be submitted are personal reviews and ratings, links to blogs, links to newspaper articles, and links to YouTube videos. These pieces of information were written to an esri multiuser geodatabase, with each piece pertaining to a specific parcel and performance. After the information was written to the database, users were able to retrieve that information using predefined queries. The second part of the analysis uses Twitter to geolocate tweets specific to an A LOT Initiative event. Searching keywords and specifying a temporal scale detects relevant tweets. If available, the locations of these tweets can be mapped and used in a kernel density analysis. This provides a way to quickly visualize patterns and shows which areas of the city are most influenced by performances. JavaScript was used for all of the coding behind the web application and Python was used to develop the Twitter tool. 


\subsection{Audience}

This report was written mainly to help the ACLB understand the technology behind the application, as well as to explore research areas that might be helpful in future projects. However, anyone who uses the website might potentially be interested in reading this document. Therefore this document is addressed to city departments, city officials from other cities, users of the application, or anyone who is curious if the A LOT Initiative has had an effect on the empty lot issue. The report is also addressed to software and web developers who might be interested in creating similar applications.

\subsection{Overview of the Rest of this Report}

The rest of this report provides the reader with additional information about the project. Chapter Two presents the literature review that lead to the decisions that were undertaken to build the application, Chapter Three elaborates on the design of the system, and Chapter Four explains the design of the database. Chapter Five shows how the elements from previous chapters have been used to build the actual applications. Chapter Six lays out a scenario, showing how a typical user would use the applications. The last chapter concludes this project and suggests what could have been done differently or what can be added to it in the future. 


\section{Chapter 2 - Background and Literature Review}

This section presents the academic research that was important in understanding the issue of this project. This chapter is divided into three parts, each part belonging to a specific topic. Section 2.1 defines empty lots and presents the issue of empty lots in American cities, Section 2.2 shows how the arts can be used in urban revitalization, and Section 2.3 elaborates on the technologies and the movements whose understanding was essential when building the application.

\subsection{Vacant Land}

The main factor driving the A LOT Initiative is the empty lot issue, which has affected many cities across the United States. The following subsections will differentiate the two main categories of empty lots - previously undeveloped and previously developed lots and then elaborate on the issue of vacant land in American cities.

\subsubsection{Previously Undeveloped Land}

Northam (1971) distinguished five types of vacant urban land: remnant parcels, parcels held for speculation, tracts, corporate reserves, and institutional reserves. This project focused on remnant parcels and parcels held for speculation. Remnant parcels are generally defined to be between a few hundred to a few thousand square feet in size, and characterized by an often irregular shape. Because of their inconvenient shape as well as their limited size, such parcels are often not favored for development and remain empty over time. Parcels held for speculation are parcels that will not be developed until the owner sees a clear benefit in doing so (e.g., the surroundings become popular). Northam emphasized that vacant parcels were parcels that have never been developed.

\subsubsection{Previously Developed Land}

One type of vacant urban land, greyfields, is often cited in urban planning literature. Greyfields, as coined in 1998 by the Congress for the New Urbanism, a non-profit organization, "can be used to describe any redevelopment project that is not significantly contaminated" (McKay, 2007, p.2). Although the term is usually used to describe larger areas, such as parcels occupied by shopping malls, it is also used to describe smaller parcels of land, such as a parcel that was occupied by a neighborhood store which has closed.

The broken windows theory, as laid out by Kelling and Wilson (1982), emphasizes that certain factors - such as the condition of a building - greatly influence citizen behavior and crime rates. Figure 2-2 is an example of an abandoned building that has not been taken care of and is likely to make the passerby feel uneasy. In the long term, such buildings could increase crime rates, especially if the number of similar buildings multiplies in a neighborhood. The A LOT Initiative is an attempt to have neighborhoods come together. Over time this interaction can stimulate people to invest into their neighborhoods (e.g., repainting facades and planting flowers in front yards) and change their neighborhood's appearance. 


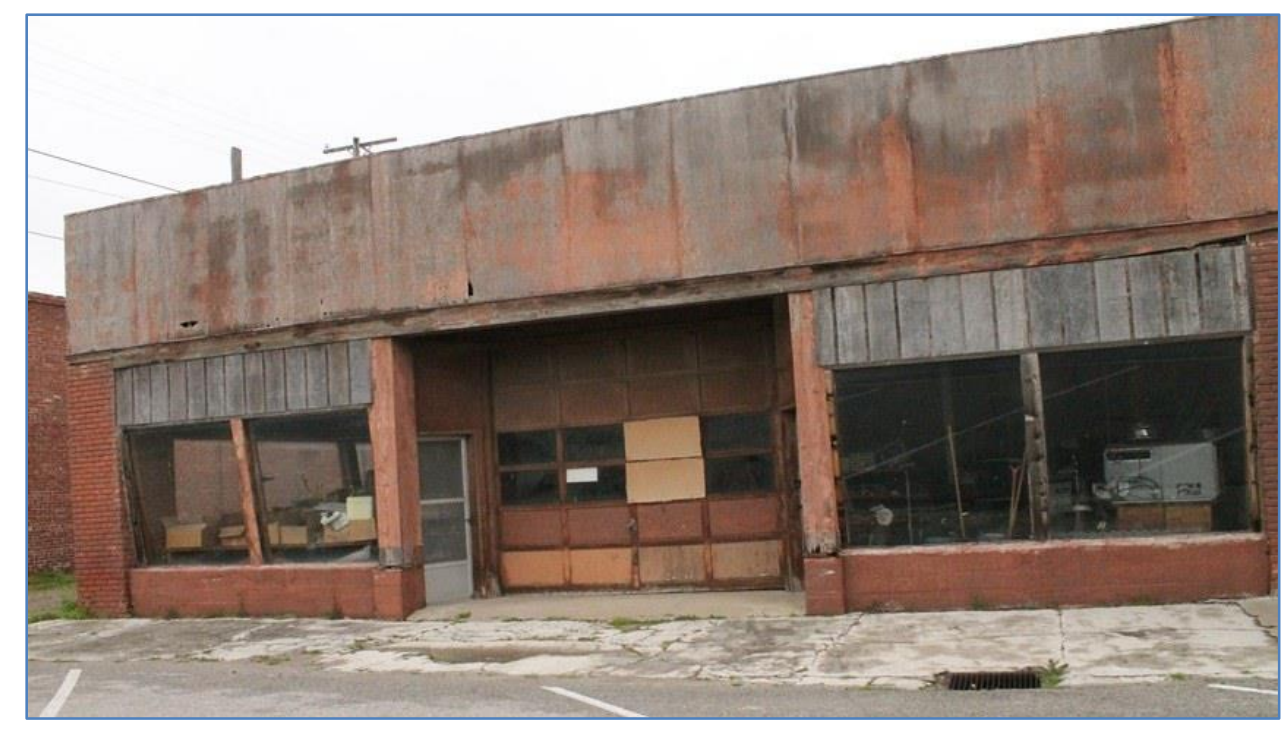

Figure 2-1: Abandoned Store Front

\subsubsection{The Issue of Vacant Land in America Cities}

Pagano and Bowman (2000) found that on average 15\% of land in American cities was considered vacant. These findings, however, should be considered with care as they only surveyed 70 cities. Kunstler (2008) cited the American system of property taxes as the main reason why there was an abundance of vacant lots in most American cities. Buildings are taxed more heavily than the land that they are built upon, meaning that a piece of land does not become expensive until a building has been built on it. This leads to the fact that land is often held in speculation. Economically it is cheaper to build on the outskirts of a city rather than to develop existing land in the center of a city, leading to the decay of city centers while at the same time increasing urban sprawl. Kunstler suggested alternative ways that could potentially reverse the issue. One of them was the option that land should be taxed much heavier. Others argue that developing infill can confront many of a city's problems, including neighborhood revitalization (Steinacker, 2003).

\subsection{Cultural Projects as Revitalization}

Through different approaches artists were able to turn dilapidated areas into flourishing places that attracted investors (Stanziola, 1999). Strom (2002) argues that cultural projects had become a popular way of revitalizing urban areas. Ideally, cultural projects benefit the city by creating jobs and revenue, and by putting a city or a neighborhood back on the map. One major benefit of cultural developments is that they are often driven by non-profit organizations and therefore draw little or no opposition, as opposed to large scale projects undertaken by the city and relying on the taxpayer's money. Small organizations were viewed as more efficient and less expensive than the public sector and 
they had progressively gained influence in urban decision-making (Elwood \& Leitner, 2003). Strom also noted that measuring the success of revitalization projects usually became complicated as it was hard to pin down exact variables. Most notably, determining what terms like "impact" and "community" mean was commonly cited as the root of the problem (Guetzkow, 2002).

Markusen and Gadwa (2010) concluded that the use of arts in planning was often hindered by unclear goals, little input from the public, or the omission of project evaluation. Furthermore, their study suggested that higher equity could be obtained by using certain methods, such as surveys, to determine which piece of art or performance went into which neighborhood. To avoid these two common issues, the ACLB suggested an interactive web application to track the success of their A LOT Initiative. The web application would allow the ACLB to see if the A LOT Initiative is a success among the public.

\subsection{Volunteered GIS}

The reason the application could be built and how it accepts user input goes back to two concepts: Web 2.0 and volunteered geographic information. Both phenomena have led to the success of many well-known websites.

\subsubsection{Web 2.0}

As pointed out by Fu and Sun (2011), Web 2.0 enabled users to interact with a website in a way that they can submit their own content, which is different from Web 1.0 that provided exclusively read-only content. The term Web 2.0 was coined by Darcy DiNucci in 1999, but it has since become associated with the O'Reilly Media Web 2.0 Conference, which took place in San Francisco in October 2004 (O'Reilly, 2007). Many influential websites are a result of Web 2.0. For instance, reviews on Amazon, articles on Wikipedia, or products on eBay are all provided by people who were not initially engaged in designing the respective websites. Web 2.0 is also the underlying process that drives the web application developed for the A LOT Initiative. The application is entirely dependent on users who collect data and submit data to the website.

\subsubsection{Public Participation GIS and Volunteered Geographic Information}

Sieber (2006) pointed out that technological inventions and movements could greatly engage the public in decision-making. GIS, like previous inventions such as rural electrification and telephony, has played an important role in connecting the general citizen to those who decide the future of communities. Although GIS is sometimes considered another tool for the powerful to gain more control, and some would go as far as calling it elitist and antidemocratic, it cannot be denied that GIS has opened many doors to the public (Peng, 2001). Carver and others (2001) pointed out two important aspects of web-based participation: the fact that meetings do not have to be tied to a strict geographic location, and the fact that meetings can be joined at any time during the day. Whereas a typical town hall meeting would take place at a specific location and a specific time, most likely disabling a portion of the public to attend, the internet eliminates these concerns. Peng (2001) added that traditional town hall meetings were often dominated by 
individuals who had extreme views and strive towards getting their views accepted and implemented. All in all, web-based participation has become an important player in modern urban planning and decision-making.

With the inclusion of GIS in these processes, the term Public Participation GIS, most often referred to as PPGIS, was coined in 1996 at various meetings of the National Center for Geographic Information and Analysis (Sieber, 2006). Whereas the beginning years of PPGIS focused on developing software, hardware, and training manuals, and were aimed towards people with advanced technical skills, the field has moved towards simpler solutions requiring the understanding of only basic concepts of geographic information sciences (Peng, 2001). Goodchild (2007) used the term volunteered geographic information (VGI) to describe this movement that lets people with little to no qualifications in mapping or geographic information sciences collect and distribute data. Tasks that for centuries had been reserved to official agencies can now be accomplished by average citizens. Goodchild pointed out the usefulness of VGI as it is an effective way to create data for places where it is scarce. For instance, he described the example of cities that had been lacking digital maps until the rise of VGI. Specific websites or projects, such as WikiMapia and OpenStreetMap, are entirely dependent on VGI. Their datasets are frequented by millions of users each day. Although the quality can vary, since VGI is majorly driven by people with no formal background, it can be said that most of the datasets are appropriate and qualitatively sufficient if high precision or accuracy is not required. This project relies on VGI because data will not be collected by the ACLB; all of the data is provided by public who finds an interest in feeding the application with useful information.

\subsection{Summary}

This chapter showed that most American cities have vacant lot issues and that there is no clear consensus about what works to revitalize urban spaces. One school of thought suggests that art could be the solution to many urban problems, which is the underlying assumption of the ACLB's A LOT Initiative. The web application that supports the ACLB in tracking the success of its project is dependent on user-created data, which is made possible by the concepts of Web 2.0 and VGI. 


\section{Chapter 3 - Systems Analysis and Design}

This chapter introduces the major components of the final products. Section 3.1 provides a brief overview of the problem, followed by the requirements analysis which describes the main components of the online application and the Twitter Search tool, as well as the software needed for developing these tools. Section 3.3 presents the system's design, an explanation of the physical components of the application, and the tool. Finally, Section 3.4 reviews the project plan, a timeline that was used to complete the different parts of this project on time.

\subsection{Problem Statement}

The ACLB is conducting a project called the A LOT Initiative, which is attempting to look at the issue of vacant urban lots. The ACLB organized events in three empty lots throughout Long Beach, but lacked a way to evaluate the effects of these events. It is essential that the effects of the A LOT Initiative are evaluated so that the ACLB can learn how to improve future events.

\subsection{Requirements Analysis}

While doing research and defining the method, certain requirements were considered necessary for the successful completion of this project. There are two kinds of requirements: functional and non-functional. The former are the essential components and functions of the deliverables, and the latter are the technologies necessary for using the application and the tool.

\subsubsection{Functional Requirements}

Eight functional requirements were defined in this project. All of these requirements, listed in Table 3-1, describe the necessary components of the final application and tool. 


\section{Table 3-1: Functional Requirements}

Web Application
\begin{tabular}{|r|l|}
\hline \multicolumn{1}{|c|}{ Requirement } & \multicolumn{1}{c|}{ Description } \\
\hline Basemap selection & Lets users change basemaps (imagery, street network) \\
\hline Geocoding & Lets users enter an address and finds it on the map \\
\hline User Locator & Zooms users to their position \\
\hline Zoom to Parcel & Centers map around a parcel \\
\hline Schedule & A calendar which displays performances per parcel \\
\hline Query Parcel Information & Shows information of each parcel \\
\hline $\begin{array}{r}\text { User Feedback } \\
\text { Collection }\end{array}$ & $\begin{array}{l}\text { Lets users submit information (YouTube links, links } \\
\text { to blogs, links to press reviews, personal reviews, and } \\
\text { ratings) to tables in the database }\end{array}$ \\
\hline
\end{tabular}

Twitter Search Tool

\begin{tabular}{|r|l|}
\hline Requirement & \multicolumn{1}{c|}{ Description } \\
\hline Input Fields & Lets the user specify parameters to run a search \\
\hline
\end{tabular}

The interactive web map is the main component that a user sees and uses to interact with the data. The map includes standard functionalities, such as panning and zooming. On the map a user can choose from two different esri basemaps: Topo and Imagery. It also includes geocoding functionality; when a user types in an address, it finds the location and zooms the map to that location. To help users position themselves on the map, locate functionality was developed. It will position the map according to the location of a user's device. The Zoom to Parcel widget centers the map and zooms to the desired parcel. Schedules are used to inform users about the A LOT Initiative events taking place. The schedules are directly connected to a server, so live updates can be undertaken. When a parcel in the calendar is clicked, the map centers around that parcel. Three interactive parcels, hosted as a feature service, provide an interface for users to interact with the database. Each parcel is related to a table containing information about events. A user has the option to submit or retrieve information for parcels and events.

\subsubsection{Non-Functional Requirements}

Non-functional requirements describe technological elements that are necessary to guarantee the optimal development and functioning of the final application. Five nonfunctional requirements were defined for this project as listed in Table 3-2. 
Table 3-2: Non-Functional Requirements

\begin{tabular}{|c|c|}
\hline Requirement & Description \\
\hline ArcSDE geodatabase & $\begin{array}{l}\text { Geodatabase that allows multiple users and editing in the } \\
\text { online environment }\end{array}$ \\
\hline ArcGIS 10.1 & The software used to prepare data before publishing \\
\hline ArcGIS for Server & Allows the data to be published \\
\hline IIS & The Microsoft web server which hosts the web services \\
\hline Windows 7 or later & A Windows operating system is required to run esri products \\
\hline
\end{tabular}

All of the data that were used in this project were stored in an esri ArcSDE geodatabase with a multiuser configuration. ArcSDE allows the geodatabase to be set up in a way that multiple users can write to it at the same time. This was an essential factor in this project, as it is likely that multiple users will enter data at the same time. To connect the datasets to the online application and to publish them to a server, ArcGIS for Server was necessary. Datasets were prepared in ArcMap and ArcCatalog, and then were published as feature services, a type of web service that allows editing. To install and run these esri components, a current Windows operating system was needed. The published datasets were hosted by Microsoft's web server, IIS (Internet Information Services).

\subsection{System Design}

Three major components - a database, a web server, and the user - had to be considered to develop the web application that was delivered to the client (Figure 3-1). These three components are linked to each other, and the correct functioning of the final product depends on their interaction. The web application, hosted on a server, was developed with the ArcGIS application programming interface (API) for JavaScript, using different languages and libraries, including HTML, CSS, JavaScript, Dojo Toolkit, and jQuery. The basemaps in the project were from ArcGIS Online, and all of the operational layers were stored in an esri ArcSDE geodatabase with a multi-user configuration. The information written to the operational layers was also stored in the same geodatabase. All of the operational layers from the geodatabase were published as a feature service via ArcGIS for Server and can be accessed through a REST service endpoint. Using the application, a user automatically connects to the server and the database. 


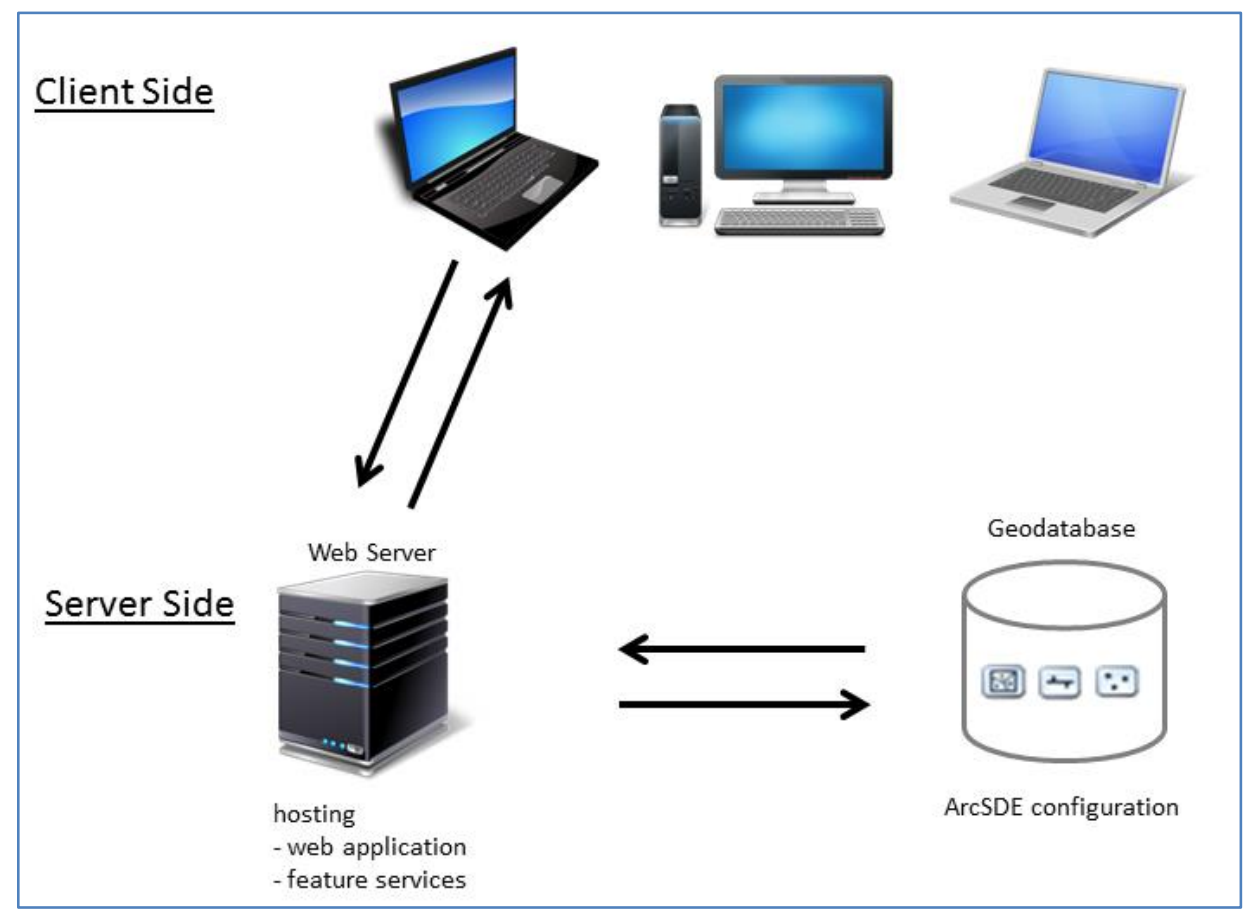

Figure 3-1: System Design

\subsubsection{Geodatabase}

All of the data consumed by the application reside in a database. Esri offers three types of geodatabases: file, personal, and ArcSDE.

ArcSDE offers crucial features that need to be considered when communicating with an online application. Most importantly, it is the only type of database that allows editing of features or tables when connected to a web application. The two other types of databases can be used to publish data but will not allow users to change the data in any way. The second important capability is the multiuser configuration. ArcSDE allows multiple users to write to and retrieve from a database. This feature is essential when connecting to a web application because it is likely that multiple users will write to the same table at the same time. Instead of creating schema locks (locking tables because two users are trying to edit them at the same time) and potentially crashing the application, ArcSDE handles such scenarios efficiently.

\subsubsection{Services}

The datasets stored in the ArcSDE geodatabase were published to a web server. When publishing data through ArcGIS, different kinds of services can be created. In this project, two kinds of services were created. Any published document automatically adds a map service to a REST Services Directory; depending on which options are checked when publishing, more services can be added to the directory. A map service can be used in various desktop and web applications but its functionality is limited. Since the application was intended to allow editing, it was important that the services were also 
published as a feature service, which is the only type of service that allows editing over the Internet.

\subsubsection{Web Application}

The web application was designed to be used primarily in Firefox. Although its look and functionality are similar to most common browsers, it will produce optimal results in Firefox. The ArcGIS API for JavaScript was chosen to develop the application because of its popularity and cross-platform characteristics. Unlike other APIs, such as those for Silverlight or Flex, it does not require any client-side plugins. Since the application would potentially reach a great number of people, it was recommended that it would be best if it ran without installing any plugins. Because the application uses several different widgets and functions, no template was readily available. It was decided to build the application from scratch, using syntax and templates from the API reference and documentation pages as guidance.

\subsubsection{Twitter Search Tool}

The Twitter Search tool was developed using Python and the Twitter Search API. Two libraries - ArcPy and TwitterSearch - were used. Esri's ArcPy provides ArcGIS geoprocessing functionality to be used with Python, and TwitterSearch is an open-source library that enables the use of the Twitter Search API in Python.

\subsection{Project Plan}

A project plan provided a timeline of the different tasks and when they were supposed to be accomplished. The following Gantt chart shows when tasks were accomplished in 2013 (Table 3-3).

\section{Table 3-3: Project Timeline}

\begin{tabular}{|c|c|c|c|c|c|c|c|c|c|c|c|}
\hline & Jan. & Feb. & Mar. & Apr. & May & June & July & Aug. & Sept. & Oct. & Nov. \\
\hline \multicolumn{12}{|l|}{ Acquire domain } \\
\hline \multicolumn{12}{|l|}{ Acquire data } \\
\hline \multicolumn{12}{|l|}{ Client meeting } \\
\hline \multicolumn{12}{|l|}{ Create data } \\
\hline \multicolumn{12}{|l|}{ Build deliverables } \\
\hline Test & & & & & & & & & & & \\
\hline Go public & & & & & & & & & & & \\
\hline
\end{tabular}

This project started in February, 2013, with the acquisition of a domain name by the ACLB. The A LOT Initiative website was developed after the domain name was acquired, and it was online several months before the GIS application was embedded. The basic datasets, such as the parcel data for Long Beach, were obtained from the City of Long Beach between March and May, although some of the data were created in September. It became obvious that the A LOT Initiative parcels did not entirely coincide with the official tax assessor's parcels provided by the City of Long Beach. Therefore, 
the three parcels were digitized, making sure that the boundaries matched those determined by the ACLB. Crucial to the development of the project was a client meeting at the ACLB headquarters on June 13,2013, where everyone involved in the A LOT Initiative gathered and discussed ideas to design the web application. The web application and the Twitter Search tool were built in September and October, and testing occurred during the development, as well as in November.

\subsection{Summary}

This chapter described the steps that were undertaken to define what was necessary to design the final products. A requirements analysis - defining the functional and nonfunctional steps needed to build the application - was essential to the successful completion of this project. The requirements are the basis of the system design, which defines how the major components fit together. The following chapter elaborates on the database behind the deliverables, followed by a chapter which lays out in detail how the deliverables were built. 



\section{Chapter 4 - Database Design}

This chapter presents the database that was used in this project. The database was designed to hold geographic and tabular files from the A LOT Initiative, and it was connected to both the web application and the Twitter Search tool.

Section 4.1 portrays the conceptual model. The logical model, a demonstration of each feature, field, and data type in the database, is laid out in Section 4.2. Section 4.3 discusses the data sources, and Section 4.4 explains how datasets were altered to be used in the final application.

\subsection{Conceptual Data Model}

The conceptual model is meant to give a broad overview of how the key elements of a project are connected (Figure 4-1). It does not provide explicit detail about files in a database, and it is designed to guide the thinking that leads to database creation.

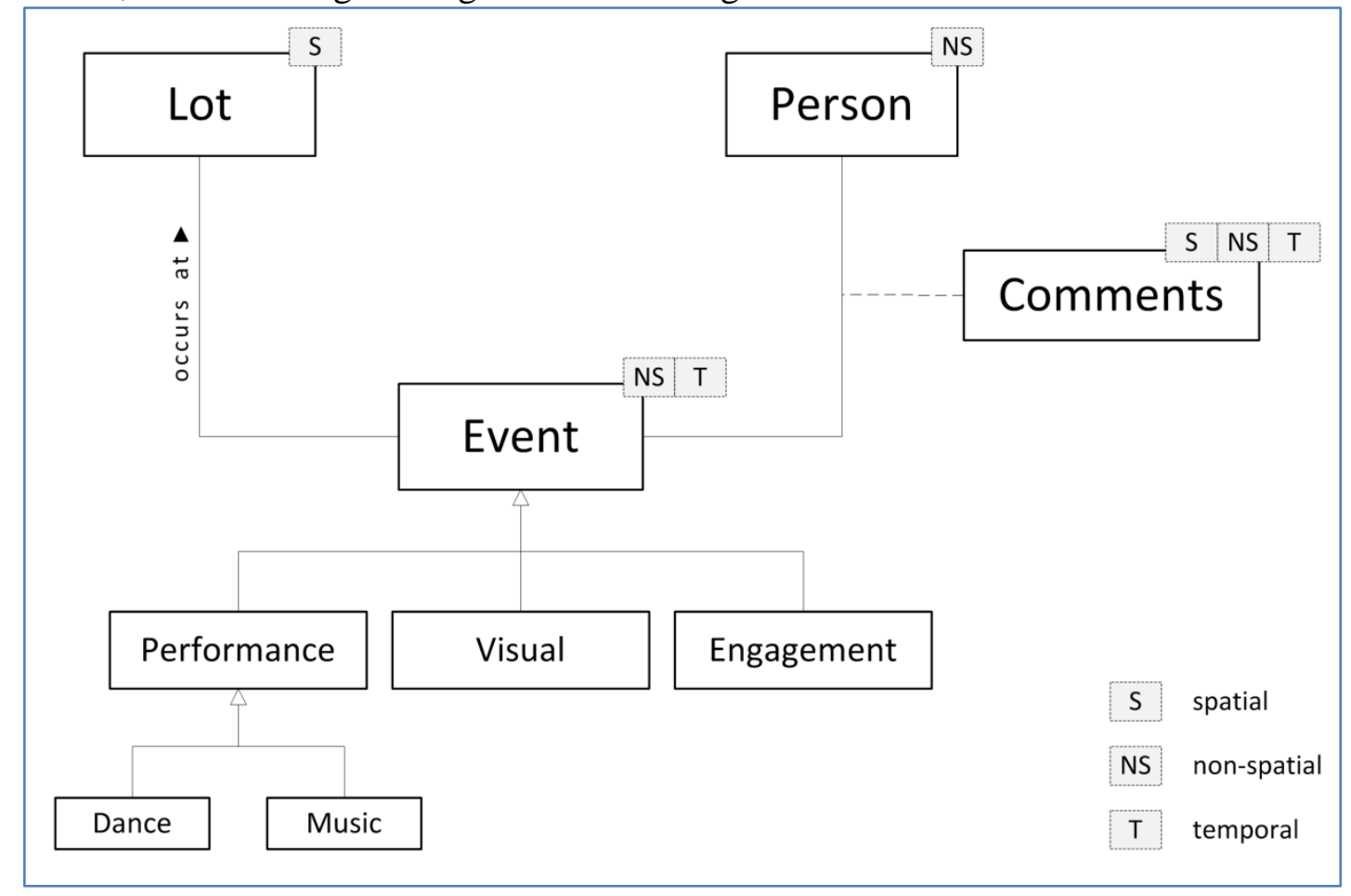

Figure 4-1: Conceptual Model

Three main entities were considered in this project: lots, events, and people. A lot is a place where an A LOT Initiative event takes place. Each lot had a known geographic location, and therefore lots were the only inherently spatial entities in this project. Event is an overarching term to describe three categories: performance, visual, and engagement. Performances were concerts or dances, visual was used to describe the displaying of art, and engagement indicated community programs. Events were temporal: they happened at a specific point in time. An event was not spatial by itself, but because it took place in 
a lot, it could be tied to a geographic location. The person was the component of the model that was used to describe someone who went to or wrote about events. A person was non-spatial in this project as its location was unknown or irrelevant. The purpose of this project was to evaluate the A LOT Initiative, and it was decided to accomplish that task by collecting feedback about events. In this model, that feedback is listed as comments. Each comment was posted or collected at a specific time, but depending on the source it could be spatial or non-spatial. For the purpose of this project a comment was what connected a person to an event. It has to be noted that this project did not keep track of people attending events, nor did it require event attendance: this project was meant to collect information about events, independent of whether the source of the information went to an event.

\subsection{Logical Data Model}

The logical data model presents the files that were stored in the database to implement the conceptual model. The logical model in Figure 4-2 was used to create the database in this project. It shows the files that were both used and generated. 
Permanent Files

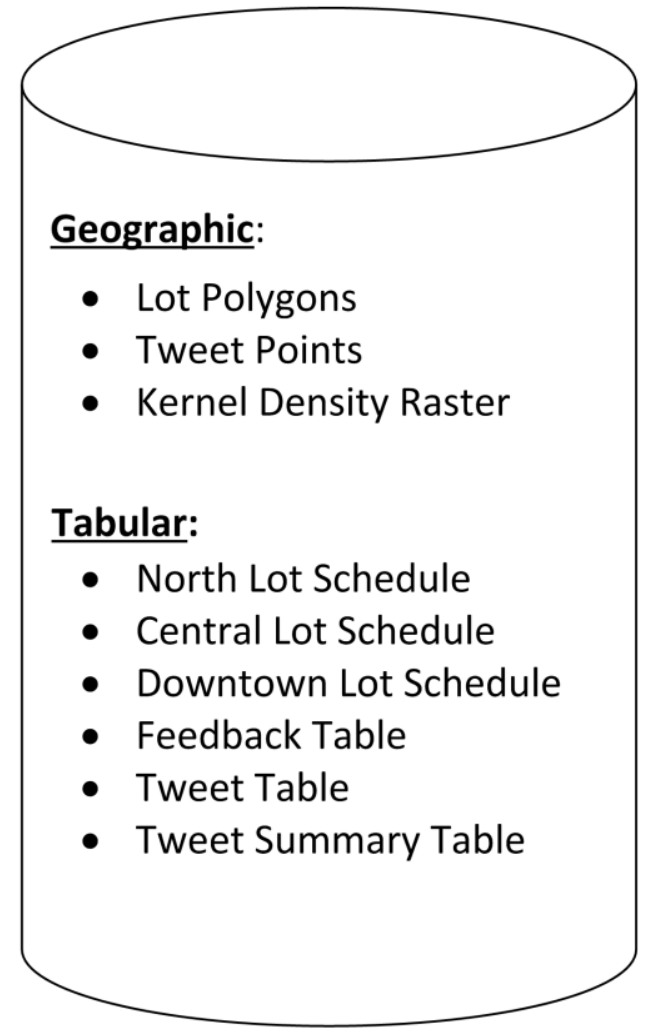

Lot Polygons

\begin{tabular}{|l|l|l|}
\hline Name & Type & Length \\
\hline Lot & Text & 10 \\
\hline Address & Text & 20 \\
\hline
\end{tabular}

Schedules

\begin{tabular}{|l|l|l|}
\hline Name & Type & Length \\
\hline Date & Text & 5 \\
\hline Event & Text & 55 \\
\hline
\end{tabular}

Tweet Table/Tweet Points

\begin{tabular}{|l|l|l|}
\hline Name & Type & Length \\
\hline Username & Text & 15 \\
\hline Time & Text & 21 \\
\hline Coordinates & Text & 50 \\
\hline Latitude & Float & \\
\hline Longitude & Float & \\
\hline Tweet & Text & 201 \\
\hline
\end{tabular}

Figure 4-2: Logical Data Model
Temporary Files

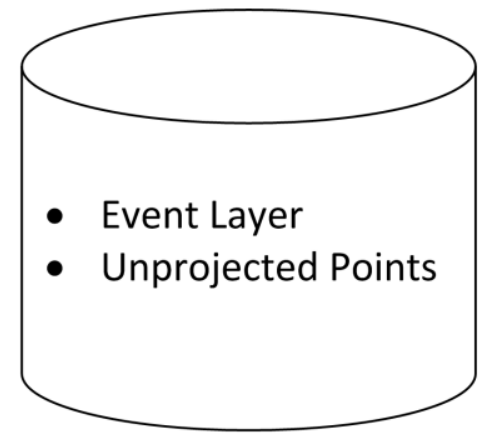

Outside Files

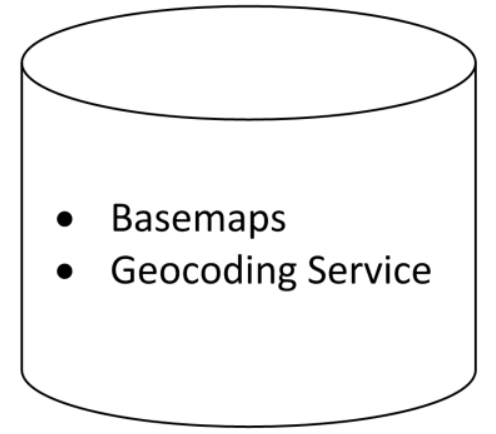

Feedback Table

\begin{tabular}{|l|l|l|}
\hline Name & Type & Length \\
\hline Lot & Text & 10 \\
\hline Event & Text & 25 \\
\hline Date & Text & 15 \\
\hline YouTube & Text & 150 \\
\hline Blog & Text & 150 \\
\hline Press & Text & 150 \\
\hline Review & Text & 250 \\
\hline Rating & Integer & \\
\hline
\end{tabular}

Tweet Summary Table

\begin{tabular}{|l|l|l|}
\hline Name & Type & Length \\
\hline RunOn & Text & 20 \\
\hline Returns & Integer & \\
\hline Keywords & Text & 200 \\
\hline
\end{tabular}


This project used parcel boundaries only for reference, and all of the relevant information the user should see was stored in a table. Because of expected complications, the attribute tables were normalized to an extent that they did not have any information about A LOT Initiative events. Storing all of the information submitted by users in the same feature class would have created unreasonably long fields in the attribute table, slowing down retrieval of information and complicating the display of it. Considering that fields have to be defined with a specific length, it would also have led to the fact that fields would have run out of space at some point, making the application useless. Therefore it was decided to store all the user input in a table which would be related to the parcels, using a relationship class. The exact steps accomplished to create a relationship class are mentioned in Section 5.1. To capture people's comments about events, two approaches were used. The first approach allowed users to submit information to a table, and the second approach used Twitter to detect what people were saying about events.

This logical model distinguishes between three types of files: outside, temporary, and permanent. Outside files were files that were used in the web application, but never stored in the ACLB's database. Temporary files were created and used to derive final outputs. These files were automatically deleted and they were meant to be never seen by a user. Permanent files were either stored in the database from the beginning, or created when running the Twitter Search tool. These files were essential and they were not meant to be deleted at any point.

The bottom part of the logical model shows detail about the most important files that were essential when translating the conceptual model into reality. The lots were represented using parcel polygons. The events were stored in tables that were displayed as schedules. The comments that link people to events were stored in two separate files. First, a table holding user-entered information about events. Second, a table holding tweets was created each time the ACLB ran the Twitter Search tool. Running the tool also added a new record containing the summary of each search (e.g., number of returned tweets) to the existing Tweet Summary table.

\subsection{Data Sources}

Data for this project came from two sources. First, a list of A LOT Initiative events was provided by the ACLB in Excel format. Second, all geographic datasets came from the City of Long Beach. The City provided specific datasets for download on its website (Figure 4-3). Assessor parcels were downloaded for this project. Any other datasets that are consumed by the API, but not stored in the database, such as a geocoding service or basemaps, were provided by esri. 


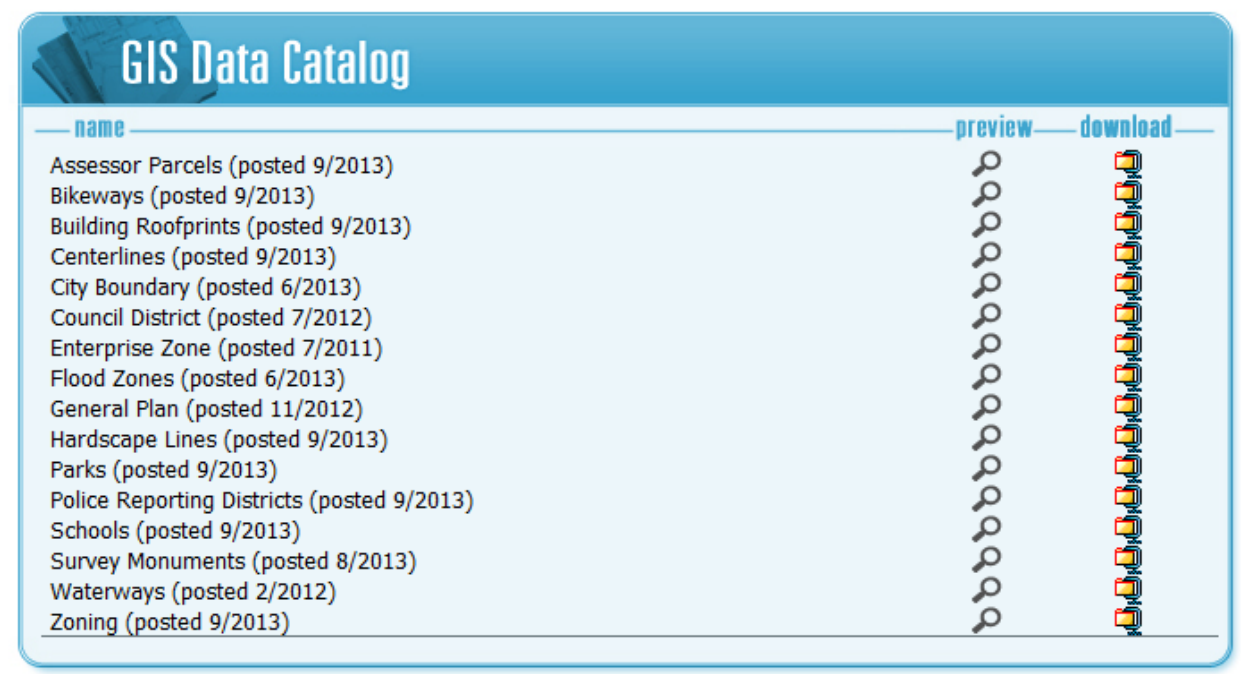

\section{Figure 4-3: City of Long Beach GIS Data Catalog}

\subsection{Data Collection Methods}

The assessor parcel datasets that are officially available from the City of Long Beach, and created for tax assessment purposes, were not optimally suited for this project. Although the parcels might have been accurate, they did not line up with the imagery that was used in this project. In the web application, the assessor parcels would potentially look confusing or inaccurate to the user when viewed with the basemaps. Figure 4-4 shows how the assessor parcel boundaries from the North Lot do not entirely coincide with the boundaries on the aerial imagery. The red rectangle indicates a gap between the assessor parcel and the adjacent sidewalk. The other two parcels had similar inconsistencies.

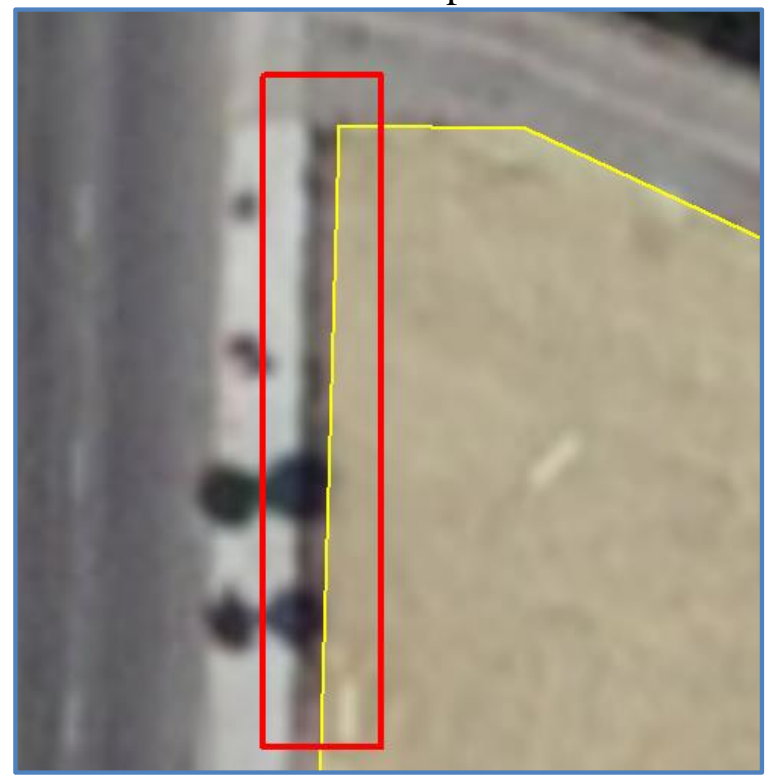

Figure 4-4: Inconsistencies between Imagery and Parcels 
To avoid these issues, and because the underlying aerial imagery cannot be moved or changed, the final boundaries were digitized on screen from the ArcGIS Online Imagery basemap, using the assessor parcels for reference only. The basemap was also used in the final application.

\subsection{Data Loading}

All of the datasets that were created or generated in this project were stored in an ArcSDE geodatabase. In addition to these files, the database also held the relationship class that linked the geographic and tabular datasets. More detail about these steps is provided in Chapter 5.

\subsection{Summary}

This chapter described the database that was used in this project as well as the logic that went into developing the database. Both the conceptual and the logical data models were used to specify the initial and final schema of the database. The chapter also explained how datasets from different sources were altered to fit the final application. 


\section{Chapter 5 - Implementation}

This chapter explains how the final product was built. Section 5.1 describes the database and how it was configured. Section 5.2 discusses publishing the datasets to the online environment, and Section 5.3 talks about how the final application was developed.

\subsection{Configuring the Database}

A database is one of the main parts of a GIS application because it holds all of the data that will be consumed by the application. In this project, an esri geodatabase with SDE technology was used.

Because the final application is required to allow user editing, a special type of database that enables editing capabilities in the online environment had to be used. Of all the different types of geodatabases offered by esri, only one fits these requirements: ArcSDE. ArcSDE is a multiuser database, which allows the editing of records by multiple users at the same time. Multiuser functionality is essential when building a web application that allows editing, because it is common that more than one user will access and attempt to alter the data at the same time. To keep the ArcSDE database clean, the original datasets were prepared in a file geodatabase. It helped testing options and at the same time avoided introducing errors into the final database. Once the datasets were ready, they were exported to the ArcSDE database (Figure 5-1).

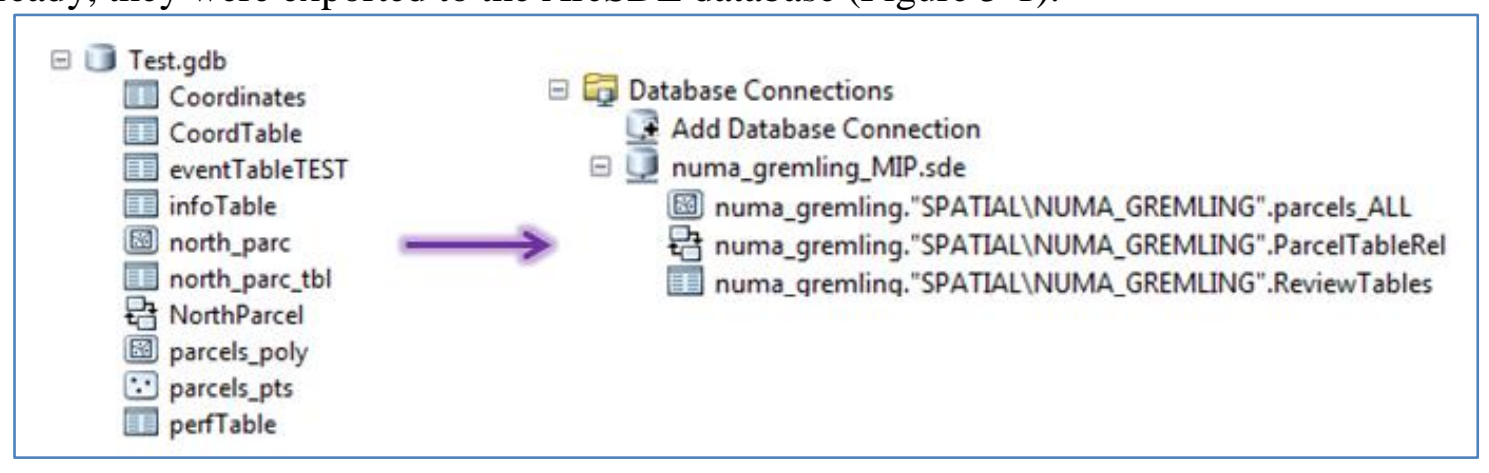

\section{Figure 5-1: Initial and Final Database}

All three parcels from this project were stored in the same feature class. The attribute table of the feature class was kept simple, with only the two required fields (FID and Geometry) and one additional field: Address. The Address field was added so that a user would be able to see the address when interacting with the web application. Field lengths in the feature class attribute table and other tables were allocated based on the expected maximum values a user would submit, as shown in Table 5-1. For instance, the Location field was kept to a length of eight characters because the longest parcel name in this project, Downtown, has eight characters. All fields for web links were kept to a maximum length of 150 characters, as that was considered a reasonable length for a web URL (Uniform Resource Locator). Long URL links that would slow down the web application are thereby automatically rejected. The Review field was kept to 250 characters because that gives a user enough space to say something substantial, yet brief. 
Table 5-1: Maximum Field Values in Table

\begin{tabular}{|lll|} 
Field & Longest expected value & Characters \\
Lot & Downtown & 8 \\
Event & Long Beach Playhouse & 20 \\
Date & September 2+ & 12 \\
links & & 150 \\
Review & & 250 \\
\hline
\end{tabular}

Because adding all of the user input to existing fields in the parcel feature class is inefficient, this project used relationship classes to solve the issue. A relationship class is a way to link geographic and tabular datasets and is determined aSt the geodatabase level. It is especially useful in relationships that have a cardinality other than one-to-one. An example of such a situation would be a state that has many counties. Instead of storing each county name in one field in the state's attribute table, it is much more efficient to store county names in tabular format and then link that table to the state feature. In this project one parcel hosts many events but each event only happens on one parcel, which establishes a one-to-many relationship. Using a relationship class is the ideal way to link the tabular information about events to the parcel feature. To set up a relationship class, it is essential to define a primary key in both the feature class and the table. A primary key is a value that uniquely identifies a specific record in a database. In this case the location was chosen as the primary key because this field is unique and exists in both datasets (Figure 5-2). Establishing a relationship class, therefore, makes it possible to click a parcel with a location and fetch all records from tables that are associated with that parcel.

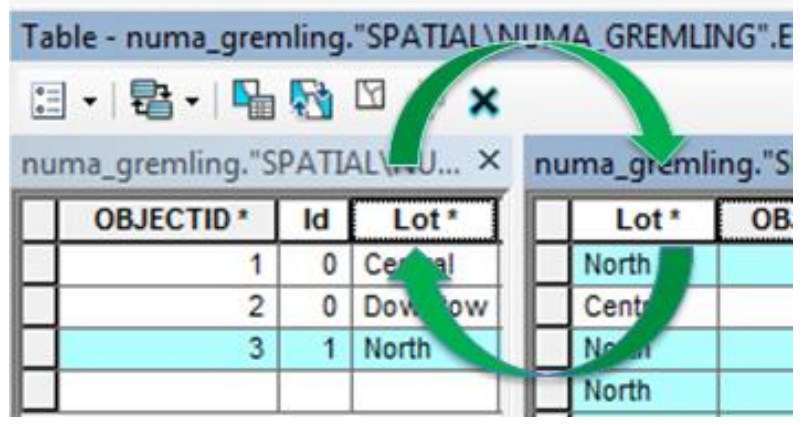

Figure 5-2: Choosing a Primary Key

Besides defining the primary key, it is also vital to specify the origin and destination datasets, the type of relationship, and the cardinality. Table 5-2 summarizes which parameters were chosen to create the relationship between the parcels and the respective tables. 


\section{Table 5-2: Summary of Relationship Class}

\begin{tabular}{|c|c|}
\hline \multirow[t]{2}{*}{ Origin: } & Parcel feature class \\
\hline & The feature that is used to trigger actions \\
\hline Destination: & Table \\
\hline \multirow{3}{*}{ Type of relationship: } & The table that will be retrieved or changed \\
\hline & Simple \\
\hline & $\begin{array}{l}\text { They are not dependent. If either one is deleted the } \\
\text { other one will not cease to exist }\end{array}$ \\
\hline \multirow[t]{2}{*}{ Primary Key: } & The parcel location \\
\hline & The field that is used to link up both datasets \\
\hline \multirow[t]{2}{*}{ Cardinality: } & $1: \mathrm{M}$ \\
\hline & $\begin{array}{l}\text { One-to-many: one parcel can link to many records in } \\
\text { the attribute table, but each record is only linked to } \\
\text { one parcel }\end{array}$ \\
\hline
\end{tabular}

\subsection{Publishing Services}

Consuming datasets that reside in a geodatabase first requires publishing these datasets as web services. ArcGIS for Server provides publishing functionality. To publish services, the datasets first had to be brought into ArcMap 10.1. For optimal results and efficient publishing, certain considerations had to be taken into account. It was very important that all basemaps were turned off by the time of publishing and transparency had to be removed from all layers. Once the files had been added and formatted and the map document was saved, it was ready for publishing. Esri offers two sharing methods: sharing as a Map Package, and sharing as a Service. In this case the datasets were shared as a service. When published, descriptions of services can be accessed from the REST Services Directory (Figure 5-3). 


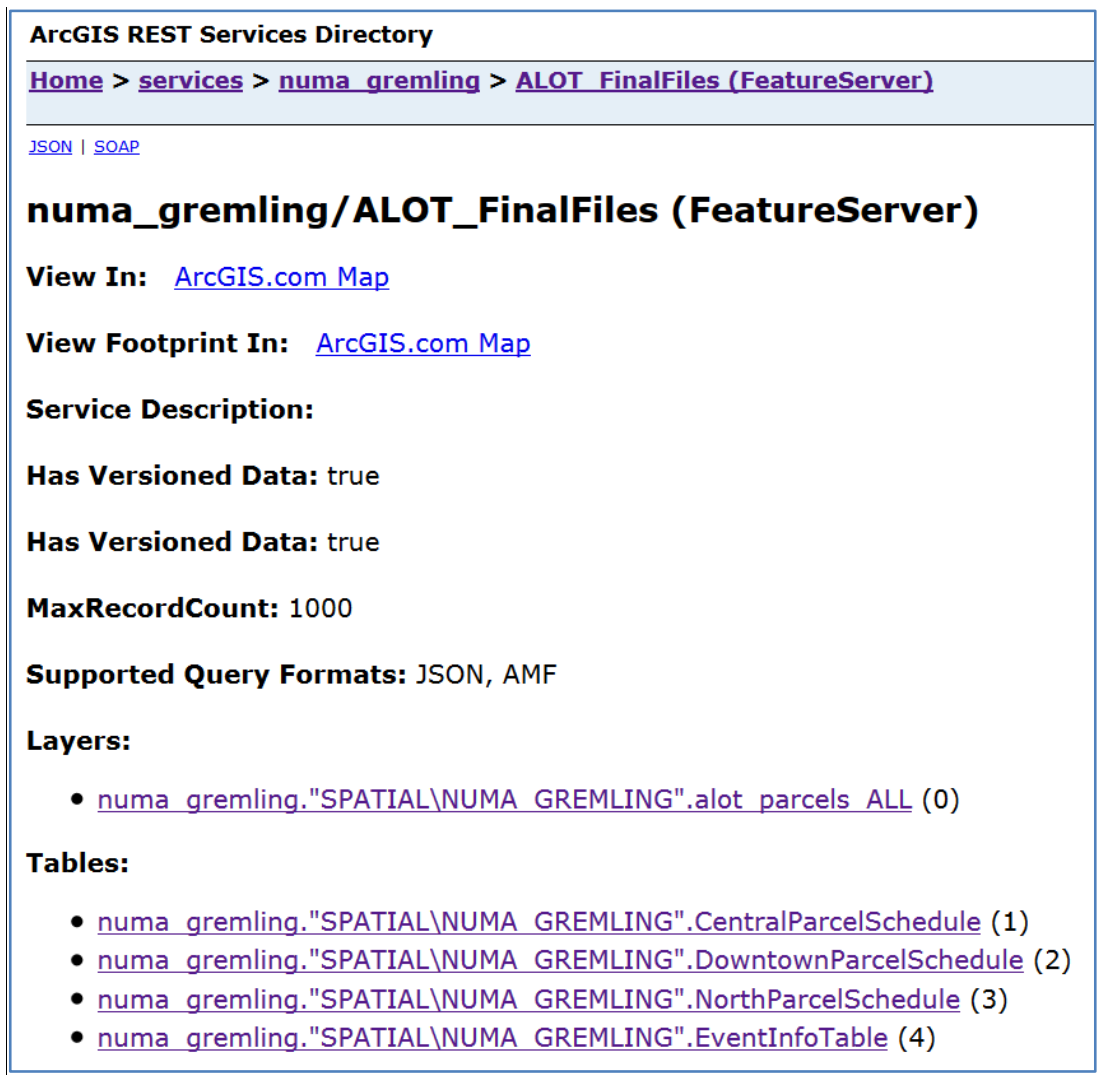

Figure: 5-3: The ArcGIS Rest Services Directory

As laid out in Section 3.3.2, the data had to be shared as a feature service because the datasets were used for editing. It was essential that the Feature Access option was checked before publishing the service. This option enables editing to the respective dataset that is consumed by a web application. Checking the option in the Service Editor unlocks a new interface which provides more control over which editing capabilities the service can be engaged in. Because ArcGIS for Server creates a map service by default, two services can be found in the REST Services Directory although only the feature service was used in the application. The published datasets were also registered as versioned, which enables them to be changed client-side after they have been published.

\subsection{Developing the Web Application}

The core of this project was the development of a user-friendly and appealing web application that can be used by anyone who is interested in the ACLB's A LOT Initiative. The following subsections discuss which languages and toolkits were used for coding, which style of coding was used, and what functionality was added to the application.

\subsubsection{Technologies Used}

Building the application relied on an API, coding languages, and two open-source libraries to facilitate coding. All of the GIS functionality was provided by the ArcGIS API for JavaScript by esri. HyperText Markup Language (HTML) was used as the 
markup language when building the website. Styling and certain effects were accomplished with Cascading Style Sheets (CSS), and interactivity was provided by JavaScript. The ArcGIS API provides the Dojo Toolkit, an open-source library which simplifies common JavaScript tasks. This project used the Dojo Toolkit to define the very basic division of the main page into three parts, also known as content panes. The table that displays query results, and the interactive Accordion Pane on the left side of the webpage, were also built using Dojo. A second open-source library, jQuery, was imported from Google. jQuery was used to simplify mouse events, as well as the movement of certain elements on the page, such as the parcel selection dropdown menu. Table 5-3 summarizes the languages, the API and the libraries, as well as their respective versions.

\section{Table 5-3: Technologies Behind the Web Application}

\begin{tabular}{|l|}
\hline \multicolumn{1}{|c|}{ Languages } \\
Markup: HTML \\
Styling: CSS \\
Programming: JavaScript \\
Application Programming Interface \\
ArcGIS API for JavaScript 3.7 \\
\multicolumn{1}{|c|}{ Open-Source Libraries } \\
Dojo Toolkit 1.9 \\
jQuery 1.10 .2 \\
\hline
\end{tabular}

\subsubsection{Asynchronous Module Definition}

The entire application was built using Asynchronous Module Definition, also known as AMD. AMD is a modern way of coding in JavaScript that loads modules asynchronously by default. That means multiple modules can be loaded at the same time, which was not the case in previous ways of coding, which were characterized by longer loading times. Esri recently switched from Legacy mode to AMD, most notably because Dojo, one of the major libraries the ArcGIS for JavaScript API relies on, will stop supporting Legacy code with its next version. The release of the next version is scheduled for early 2014. Using AMD in this project was useful because the version of Dojo could be replaced in 2014 by not requiring further translations. AMD first loads a module and then assigns it to an element in a callback function. Each element can then be used in the script.

\subsubsection{Application Interface}

Fu and others (2011, p. 45) defined user experience as the "level of satisfaction a person gets from using a product or a service" and stated that web applications should be "fast, easy, and fun to use." That approach guided the design and interface of this web application Figure 5-4 shows a sketch of the GUI (graphical user interface) which was used to guide the development of the web application. 


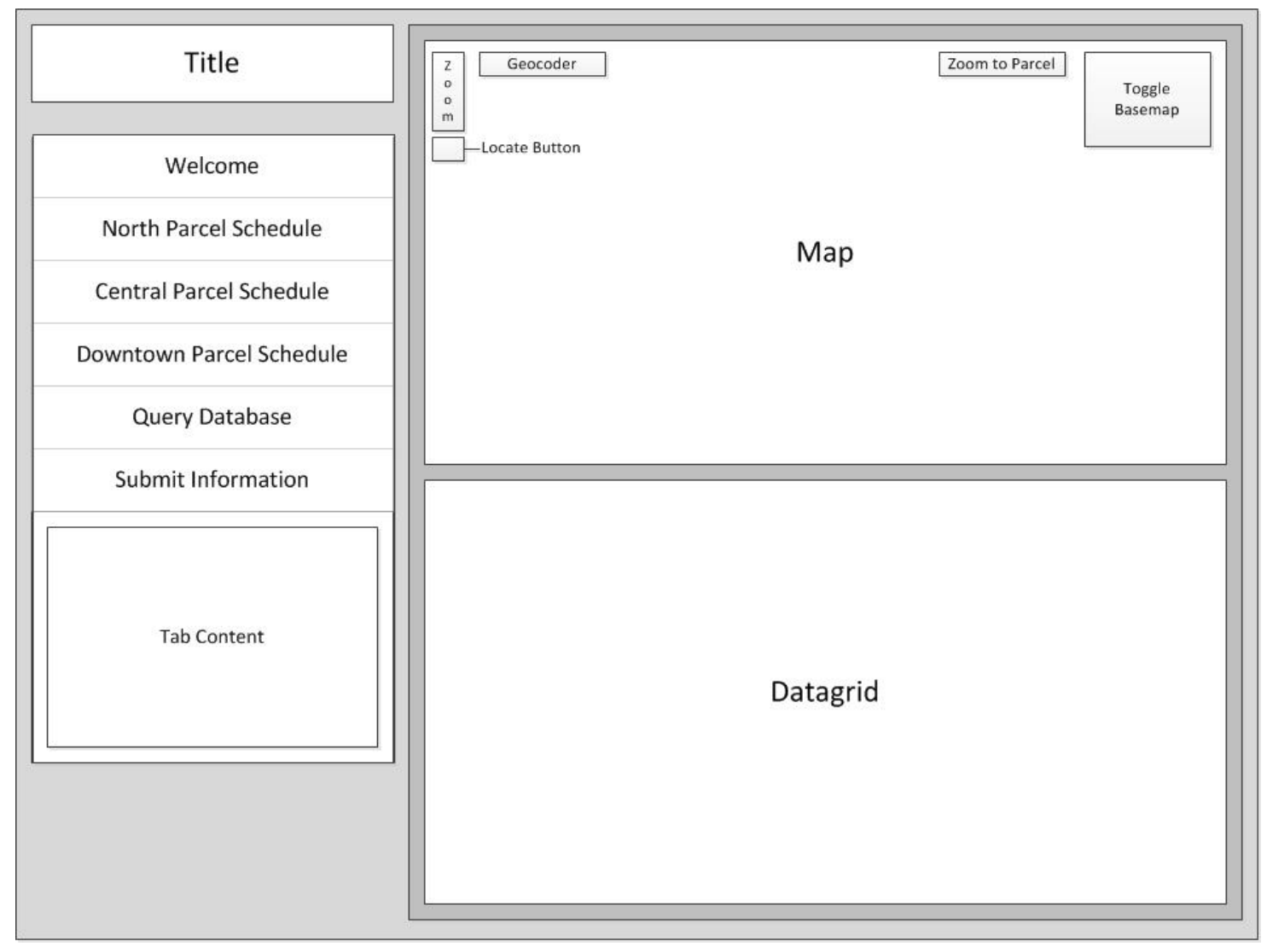

Figure 5-4: Graphical User Interface of Web Application

Most users have limited technological background and their attention needs to be caught immediately via an easy-to-use interface. Therefore, the user interface was designed so that operations are easily recognizable by anyone who has used a major web GIS before, such as Google Maps.

The map was centered on Long Beach. The coordinates were obtained by calculating the centroid of the city boundary in ArcGIS 10.1. The Topo basemap from esri was chosen as the default basemap for this project. Although the map's name indicates a scientific purpose, it is a hybrid of a topographic map and a street map; streets show up when zoomed to large scales. This map was chosen because it looks appealing yet provides all the necessary details a user needs to see. A regular street map would appear too busy for this application's purpose. Because many users are used to seeing satellite imagery as well, a Change Basemap button was added which lets the user toggle between satellite imagery and the Topo map.

Users can search addresses within Long Beach using the Geolocator widget. To simplify the use of the tool, it was programmed to automatically add 'Long Beach, CA' to any user input and display a list of closest matching addresses. Although different geocoders can be used, the standard esri World Geocoder was chosen because it is compatible with esri's ArcGIS products.

The Zoom button lets the user zoom in or out of an area, although that can also be done using the mouse wheel or the touchscreen of a smartphone. The Locator button asks 
users if they want to share their locations; if yes, the map will zoom to that location. This function is targeted toward users who will use the application on a mobile device and who might be attempting to find their way to a specific parcel that may not have an address in any address database since the lot is undeveloped. The Zoom to Parcel dropdown menu lets a user zoom to one of the three parcels hosting events. The choice of parcels only shows up when hovering the cursor over the label.

The schedule of the A LOT Initiative was added to the page so a user does not have to keep switching between the application and the A LOT Initiative website. Expanding the schedule of a specific parcel displays a list of events and centers the map around that parcel.

The table that was related to the parcels using a relationship class can be displayed when using the Query Database tab in the accordion pane. The pane offers different ways to query the table. A user can either chose one of the three parcels using a radio button, or can chose a performance using a dropdown menu. The returned information is displayed in a table on the bottom of the page. To enter new information about events, a user can refer to the Submit Information tab in the accordion pane. The tab guides a user through the input process by offering dropdown menus and input boxes.

\subsection{Developing the Twitter Search Tool}

The Twitter Search tool was developed to be used by the client only. Its purpose is to search Twitter databases based upon specific parameters. The returned results are written to a database in tabular and in geographic forms. The table holds the contents of all the tweets that were returned by a search, and the geographic files show available tweets' locations and a heat map.

\subsubsection{Technologies Used}

Python was used to develop the Twitter Search Tool. Among the different languages that can interact with the Twitter API, Python was chosen because it can be integrated into the ArcGIS environment. Python can not only be used to search Twitter databases but it can also be used to write to a geodatabase and create geographic features. ArcPy from esri was used to programmatically incorporate ArcGIS functionality in Python.

TwitterSearch, an open-source Python library provided by the Technische Universität München, was used to access the Twitter Search API. The library simplifies tasks to connect to Twitter. Table 5-4 summarizes the technologies behind the tool. 
Table 5-4: Technologies Behind the Twitter Search Tool

\begin{tabular}{|l|}
\hline \multicolumn{1}{|c|}{ Languages } \\
\hline Python \\
Application Programming Interface \\
Twitter Search API v 1.1 \\
\hline \multicolumn{1}{|c|}{ Libraries } \\
TrcPy SwitterSearch \\
\hline
\end{tabular}

\subsubsection{Limitations of the Twitter Search API}

Twitter allows programmers to retrieve information using the API, but it has to be pointed out that it is not possible to search the entirety of Twitter using the API. To avoid overburdening servers Twitter has restricted what users can query, and therefore programmatically retrieving information from Twitter differs in many ways from a manual search.

Connecting to Twitter requires authentication. Tokens and keys to connect to Twitter can be obtained from the Twitter Developers site by creating a new application. When an application is run these tokens and keys have to approved in order to connect to the Twitter database. This allows Twitter to keep track of potential abuse.

Rate limiting refers to how often one can connect to Twitter servers. The Twitter Search API has 15-minute rate limiting windows, meaning that one can only connect every 15 minutes. This helps Twitter reduce traffic and avoid servers crashing.

Twitter lets programmers retrieve 100 pages of tweets, each one containing about 180 to 200 tweets. This means that the maximum number of tweets that can be returned by a search fluctuates between 18,000 and 20,000. It is also important to know that only indexed tweets can be returned by the API. Twitter reserves the right to decide which tweets are indexed. This means that a manual search on Twitter might return results that cannot be returned by the API.

Finally, the time frame of the returned information is limited. Indexed tweets are generally made available for the API the day after they have been posted, and they are removed a week after they have been made available. At any point the programmer is therefore restricted to a selection of recent tweets.

\subsubsection{Development of the Tool}

To extract and map out relevant tweets from the Twitter database, multiple steps had to be accomplished. These steps are laid out in Figure 5-5 and are explained in the following paragraphs. 


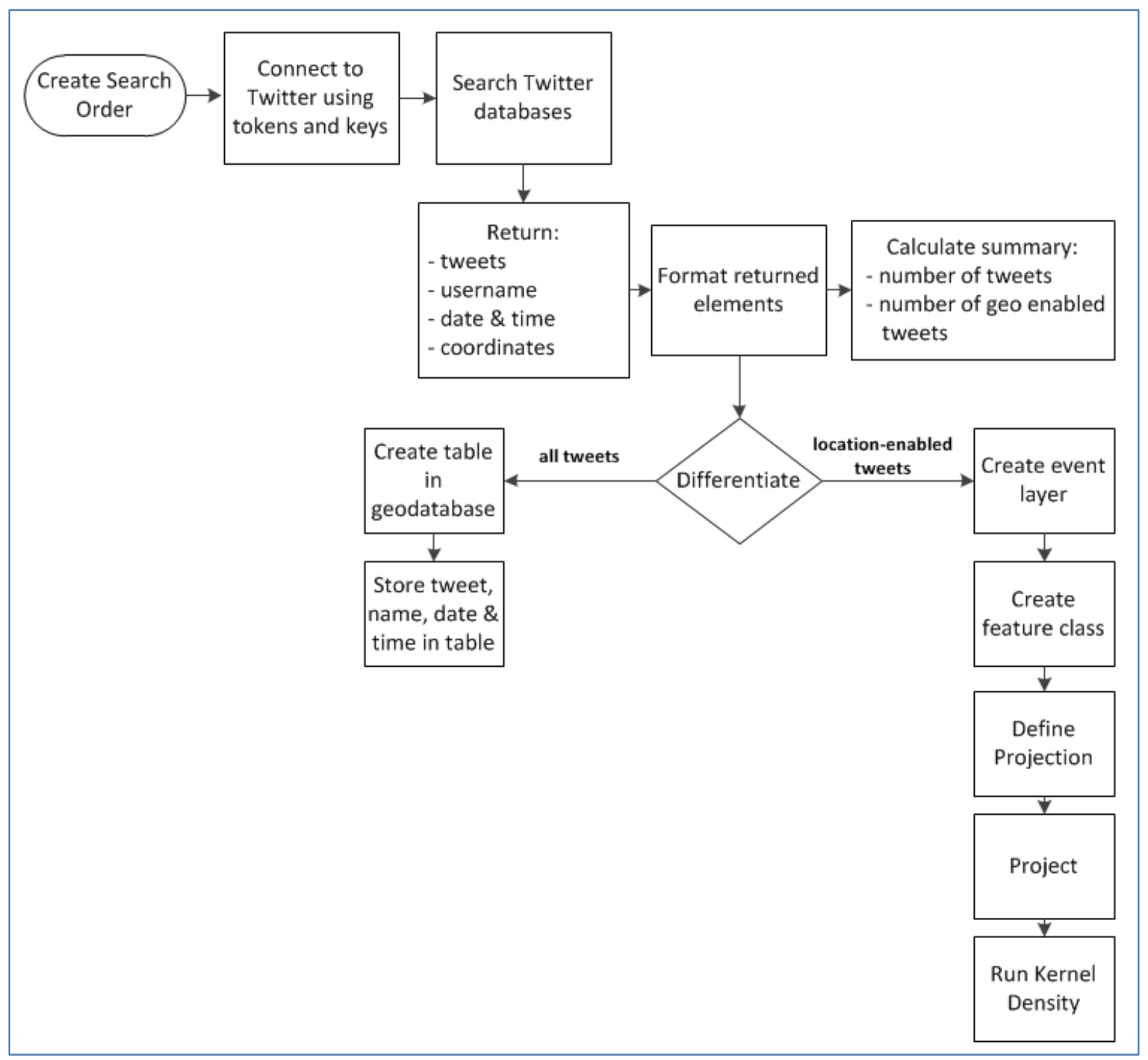

Figure 5-5: Flowchart of the Twitter Search Tool

The first step in developing an application using the Twitter Search API is creating a Twitter Developer account. The account offers different options, such as creating a new application. Creating a new application generates tokens and keys that have to be used to connect to the Twitter Search API. The tokens and keys are unique to each application and they are used by Twitter to limit the developer's behavior and become aware of potential abuse. A search order was set up to define the parameters to pass to the query that ultimately connected to Twitter. The search order included statements to search for keywords, hashtags, a page count, and a search date. The tool allows users to set all of these parameters, so the query that is sent to Twitter can be customized.

After setting up the search order, it was important to define what is returned by Twitter. This tool returns contents of tweets, the usernames who posted the tweets, the time and date they were posted, and sometimes the geographic locations of the tweets. Because certain query results were returned in a Python dictionary format, the results 
could not be directly written to a geodatabase and had to be formatted to fit the esri geodatabase schema. Coordinates, for instance, are returned in a format that cannot be understood by a geodatabase, and they also include additional information that was not useful in this project. A combination of slicing, splitting, and indexing methods were therefore used to extract only the latitude and longitude information (Figure 5-6).

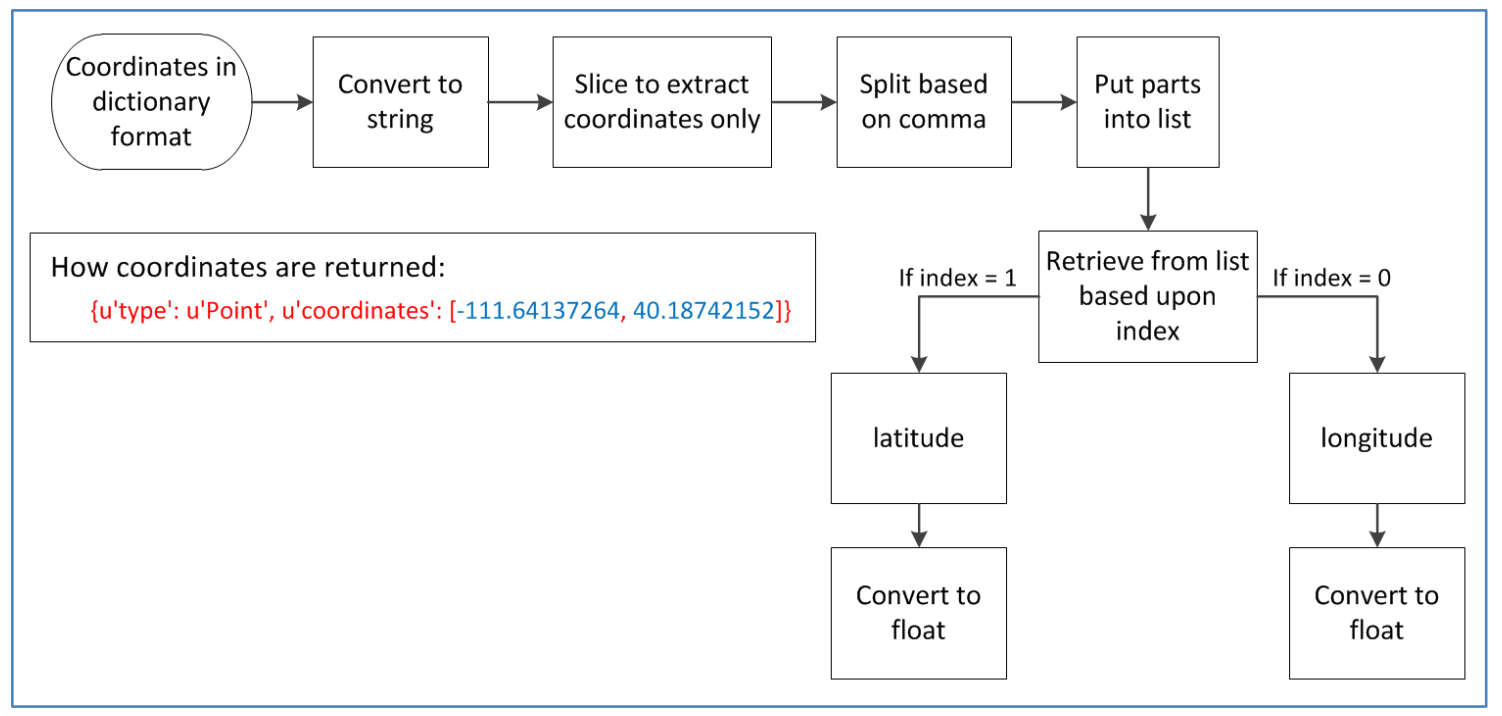

Figure 5-6: Extracting Coordinates

To iterate through multiple tweets, the search order had to be incorporated into a loop. Each iteration was passed to a list, which was then plugged into an insert cursor. The insert cursor was used to write the returned information to a newly created table in the database. To visualize the geographic aspect of the returned tweets, coordinates - if available - were converted to an event layer, which was then saved as a point feature class. The feature class was used to generate a kernel density raster layer. Because providing coordinates in a tweet is optional, the script calculates the count of returned tweets and the percentage of geo-enabled tweets. This information is also recorded in the geodatabase. The tool interface was designed by importing the final script into a custom toolbox in ArcCatalog.

\subsubsection{Tool Interface}

The tool was programmed so that a user has control over what to query from the Twitter database. The user can define keywords to directly search the content of tweets. A keyword is defined as any string that is contained in a Tweet, including hashtags and links. It has to be noted that the more keywords and hashtags are entered, the fewer results the tool will return as the Twitter API will find tweets containing all keywords. The number of returned pages and a "search until" date can also be specified. As pointed out in Section 5.4.2 the Twitter Search API does not allow searching by random time frames. Furthermore, no beginning date, but only an end date, can be set. The user can also specify the inputs and the cell size of the kernel density raster output. The Help menu, which can be toggled, explains each input field and its limitations. Figure 5-7 
shows a diagram of the tool interface.

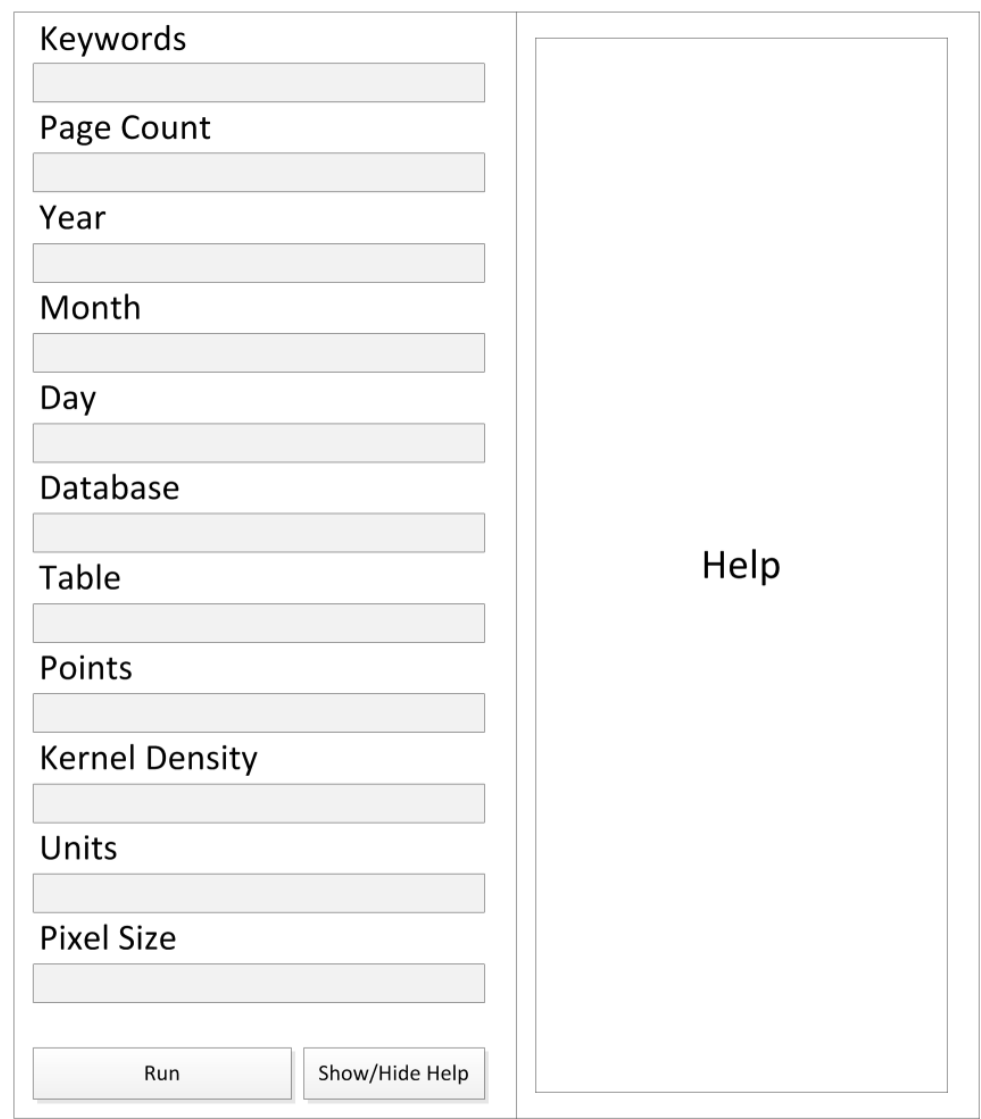

Figure 5-7: Graphical User Interface of Twitter Search Tool

\subsection{Summary}

This chapter explained how the main components of the final deliverables were set up. First, it explained how the database was designed, including database-level settings, such as relationship classes and coded value domains. After the database was ready, the datasets were shared as feature services that can be consumed by a web application. The chapter also provided a detailed explanation of the technologies and style of coding behind the web application, as well as of the functionality of the application. The second part of the chapter described the technologies, functionality, and interface of the Twitter Search tool. 


\section{Chapter 6 - Use Cases}

The two deliverables of this project have different uses. The web application has three uses: basic navigation to familiarize oneself with the A LOT Initiative, submitting information to the database, and retrieving data from the database. The Twitter Search tool's main purpose is to find people who talk about A LOT Initiative events on Twitter. The resulting tweets can be viewed in tabular form. If coordinates are available, the tool also creates a point layer and a heat map.

\subsection{Web Application}

The web application has three main purposes. It can be used to learn about when the events of the A LOT Initiative are happening and where they are located. Or it can be used to submit or retrieve information about events. All of these functionalities can be accessed by the general public and the Arts Council for Long Beach (ACLB). The following subsections will elaborate on each feature.

\subsubsection{Basic Functionality}

The web application offers basic functionalities that are nowadays shared by most web GIS applications. In addition, this application also includes basic functionality that is specifically tied to the A LOT Initiative. Figure 6-1 shows the web application and the labels point out the features mentioned in this paragraph. 


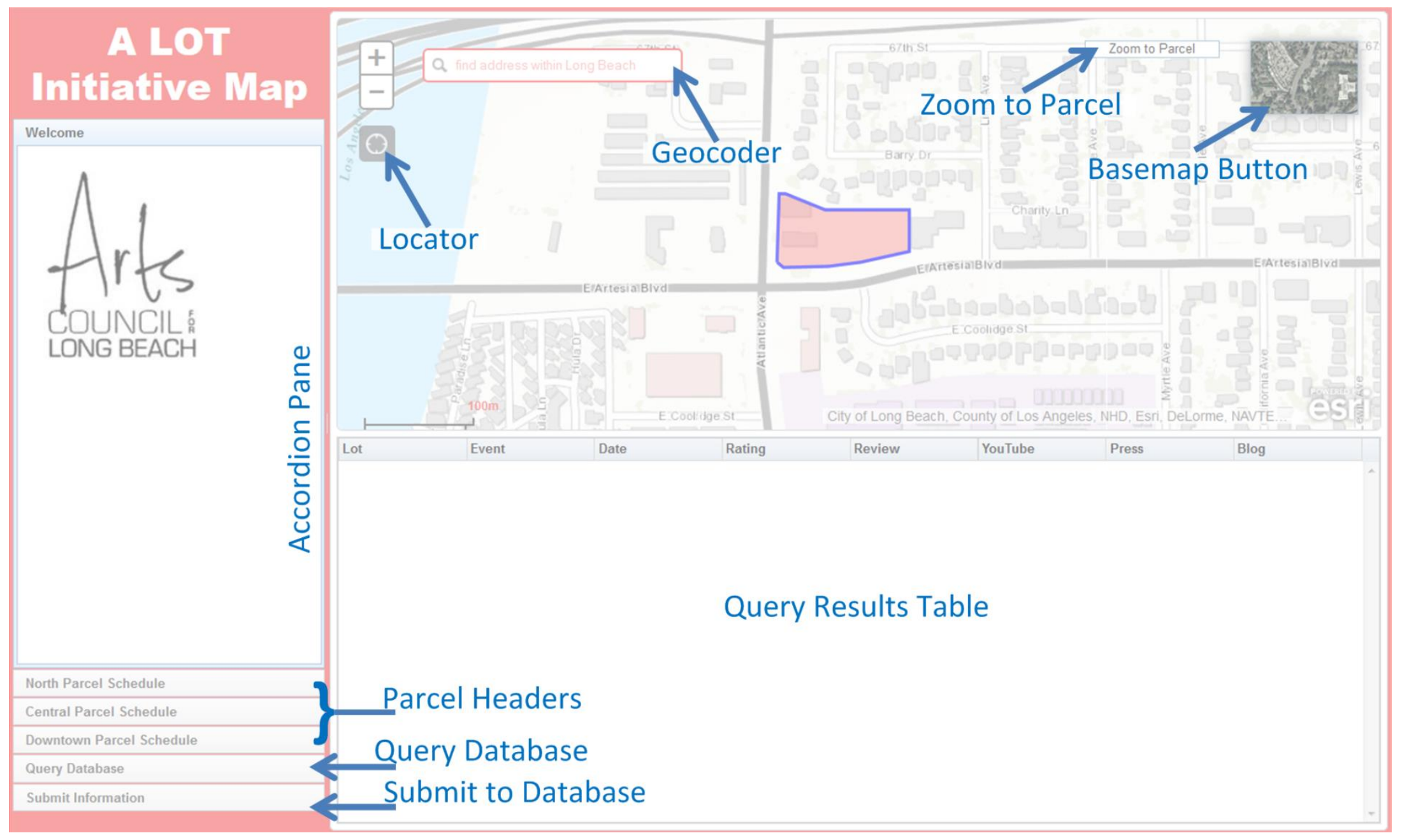

Figure 6-1: Elements of the Application 
A user might use the application to get a good idea of the A LOT Initiative and the respective events. The accordion pane on the left side of the web page includes the event schedule for each of the three lots. A user can click on a parcel header to expand a pane showing the event names as well as the dates the events are taking place (Figure 6-2). When clicking inside the pane the map will automatically center on the respective lot.

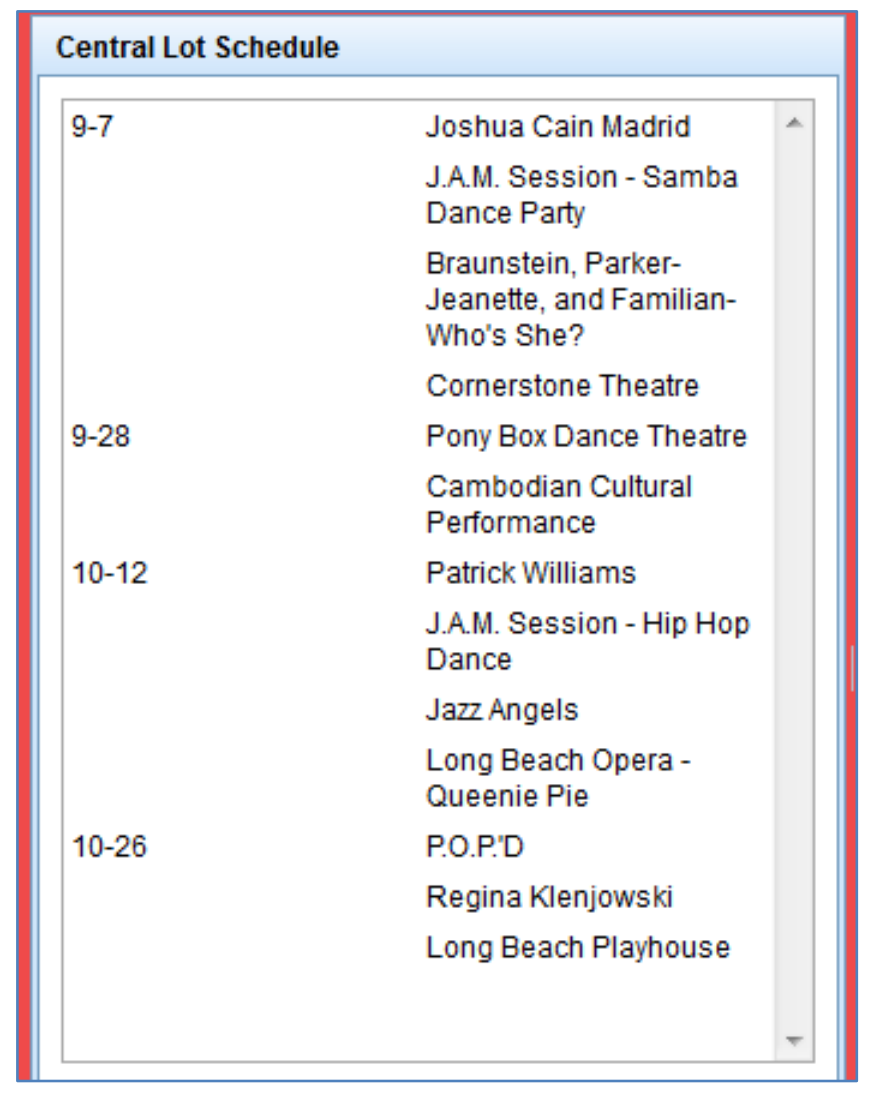

\section{Figure 6-2: The Schedule Pane for the Central Lot}

If a user wants to see the location of a parcel without opening the schedule, the user can use the Zoom to Parcel button. Once zoomed in the user might want to change the basemap. If a user is vaguely familiar with the neighborhood, then satellite imagery might be more helpful than a street network. A user can use a button to toggle between the street network and the satellite imagery. The icon on the button displays the basemap type that the user can change to when clicking. For instance, if the street network is activated then the button will display a satellite image. A user can find out his or her location in relation to the parcel using the Locator button. Clicking the button will zoom to a user's location on the map. This feature uses HTML 5 Geolocation functionality to obtain the user's position. The tool triggers an interface that asks for the user's consent to share location, and the accuracy of the location is determined by the device of the user. For instance, the location is more accurate on a smartphone using GPS than on a desktop computer using Wi-Fi. Table. Table 6-1 summarizes the accuracy of geolocation methods. 
Table 6-1: Accuracy of Geolocation Methods, adapted from Duvander (2010, p. 158)

\begin{tabular}{|l|l|}
\hline \multicolumn{1}{|c|}{ Method } & \multicolumn{1}{c|}{ Accuracy } \\
GPS & Within feet \\
Wi-Fi & Within a block \\
Cell towers & Within a few miles \\
IP address & ZIP-or city-level \\
\hline
\end{tabular}

This feature is especially helpful when the application is used on a mobile device. The current location can then be used in a routing application to navigate to one of the parcels. If a user is interested in finding an address within Long Beach, the geocoder widget can be used. When typing, an autocomplete function will compare user input to the five closest matching addresses in the geocoding service. Because the geocoder is meant to be used exclusively in Long Beach, it will automatically add "Long Beach, CA" to any input address, which helps the autocomplete process. After zooming to the location, a marker will show up. The application also supports several types of zooming and panning: a user can use the zoom buttons, mouse, keyboard, or touchpad to zoom.

\subsubsection{Submitting to the Database}

A user who returns home from an A LOT Initiative event might like to share his or her opinion about the event. Another user might have stumbled upon an article or a video about an event, and decide to share it with the Arts Council. The application was primarily built for data collection purposes, and it allows users to add four pieces of information: links to news articles, links to videos, links to blogs, and personal reviews. For each piece of information, a user can specify the event name and date.

A user can access the submission dialog by clicking on the Submit Information tab in the accordion pane (Figure 6-3). To limit typographic errors and the submission of nonexistent artists, dates, and locations, users are provided with a selection of predefined values. 


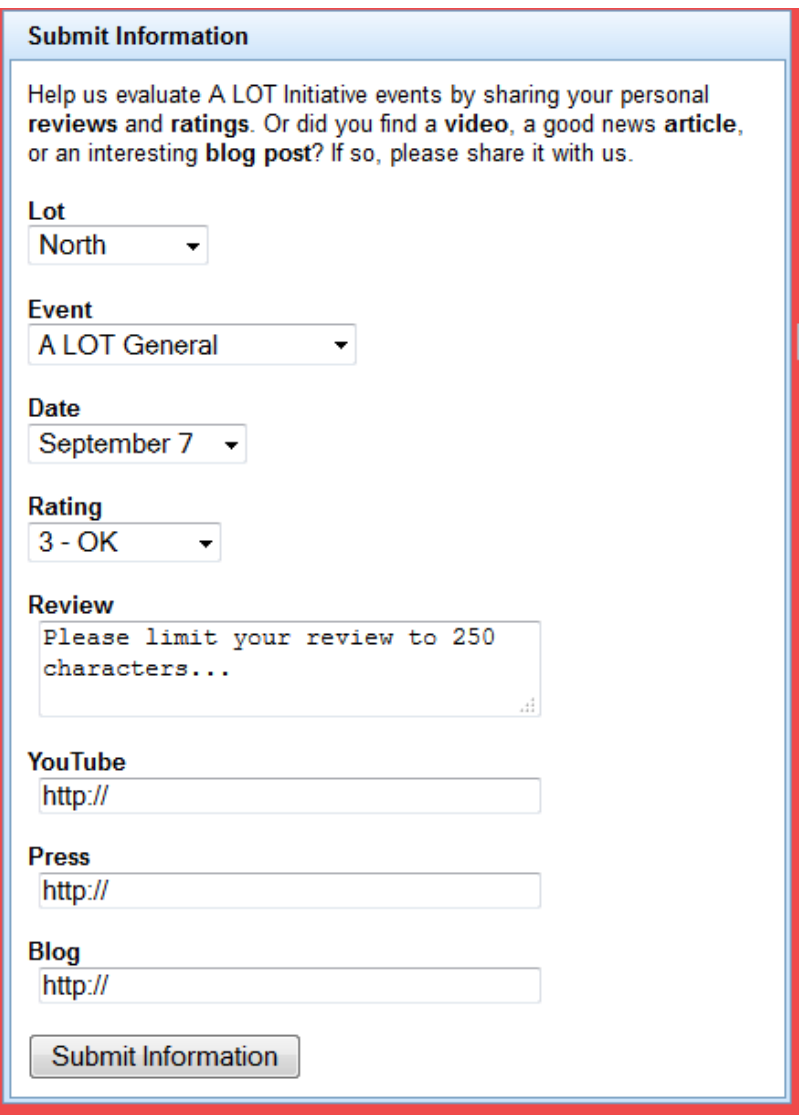

Figure 6-3: Submit Information Dialog 


\subsubsection{Querying the Database}

The general public or the ACLB might be interested in retrieving the submitted information. The Query Database tab in the accordion container can be used to search the database and return specific sets of information. To simplify the searching process, a user is offered a set of options to launch the query (Figure 6-4). Instead of typing information, a user can choose to return all the information associated with a parcel by clicking one of the three radio buttons. The user can also use the dropdown menu to return all information related to a specific event.

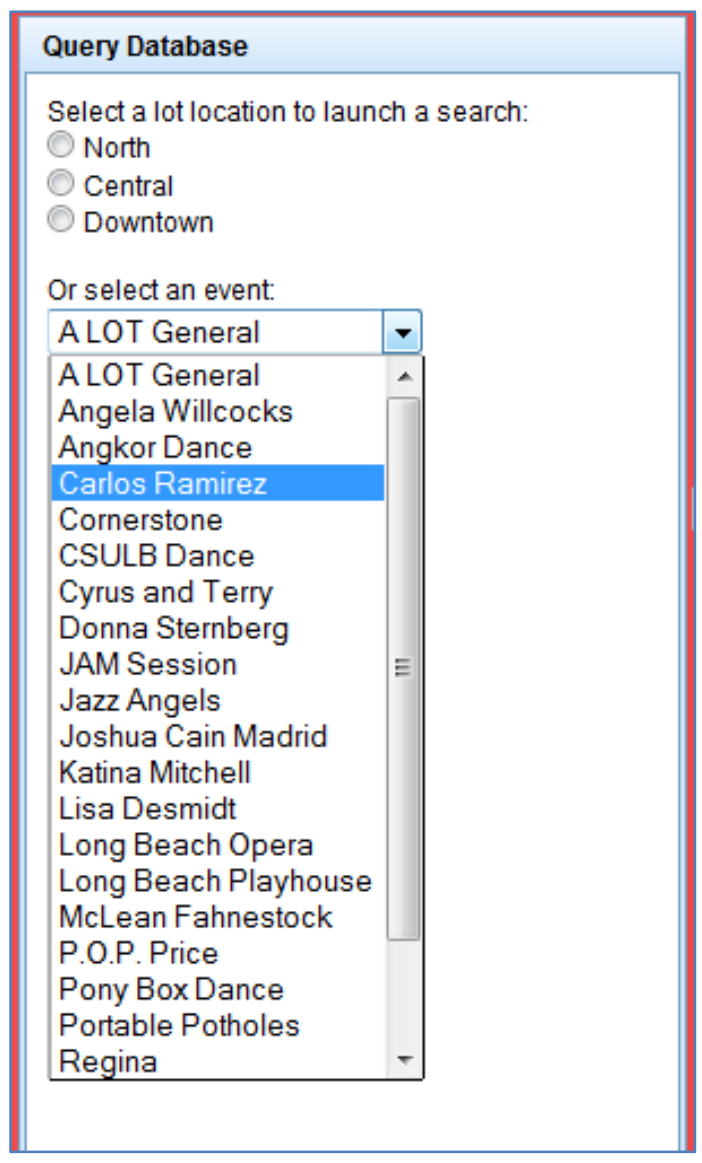

\section{Figure 6-4: Query Options}

After clicking a radio button or selecting an event, the table on the bottom of the page will populate with information retrieved from the database. Figure 6-5 shows a part of the table that has been populated after a user has chosen to see all of the information submitted for Carlos Ramirez. 


\begin{tabular}{|c|c|c|c|c|c|c|}
\hline Lot & Event & Date & Rating & Review & YouTube & Pre \\
\hline Downtown & Carlos Ramirez & September 28 & 5 & $\begin{array}{l}\text { My favorite A LOT event so } \\
\text { far! Let Carlos play again } \\
\text { next year and you will } \\
\text { attract a large crowd! }\end{array}$ & $\begin{array}{l}\text { http://www.youtube.com } \\
\text { /watch?v=x71uD9ybrzk }\end{array}$ & $\begin{array}{l}\text { http } \\
\text { cultı } \\
\text { lit-m }\end{array}$ \\
\hline Downtown & Carlos Ramirez & September 28 & 5 & $\begin{array}{l}\text { This was awesome; Carlos } \\
\text { rocked it! Wow! }\end{array}$ & $\begin{array}{l}\text { http://www.youtube.com } \\
\text { /watch?v=01s7DTwHqsl }\end{array}$ & $\begin{array}{l}\text { http } \\
\text { /foru } \\
\text { qual } \\
\text { arts }\end{array}$ \\
\hline
\end{tabular}

Figure 6-5: Query Results for Carlos Ramirez

\subsection{Twitter Search Tool}

The Twitter Search tool lets the user specify a number of parameters to search Twitter databases. The returned tweets will be written to a geodatabase and mapped out if the location is enabled. Unlike the web application, this tool is intended to be used only by the client.

Supposed that the ACLB wants to find out what people tweeted in reference to Donna Sternberg's performance, as shown in Figure 6-6, the user can specify a number of parameters to detect tweets. In this case the user decides to search for tweets that contain "Donna Sternberg", "event", "concert", and "Long Beach". The user also wants to check for two hashtags: "ALOTInitiative" and "ALOTLongBeach". The user submits 100 for the Count field. Count refers to the number of tweet pages that will be returned, and the default is 100, with about 200 tweets per page, or a total of approximately 20,000 tweets. The user then specifies the cell size at which the raster will be created, as well as the area units of the output density values. After pointing to the correct databases, the tool can be run. 


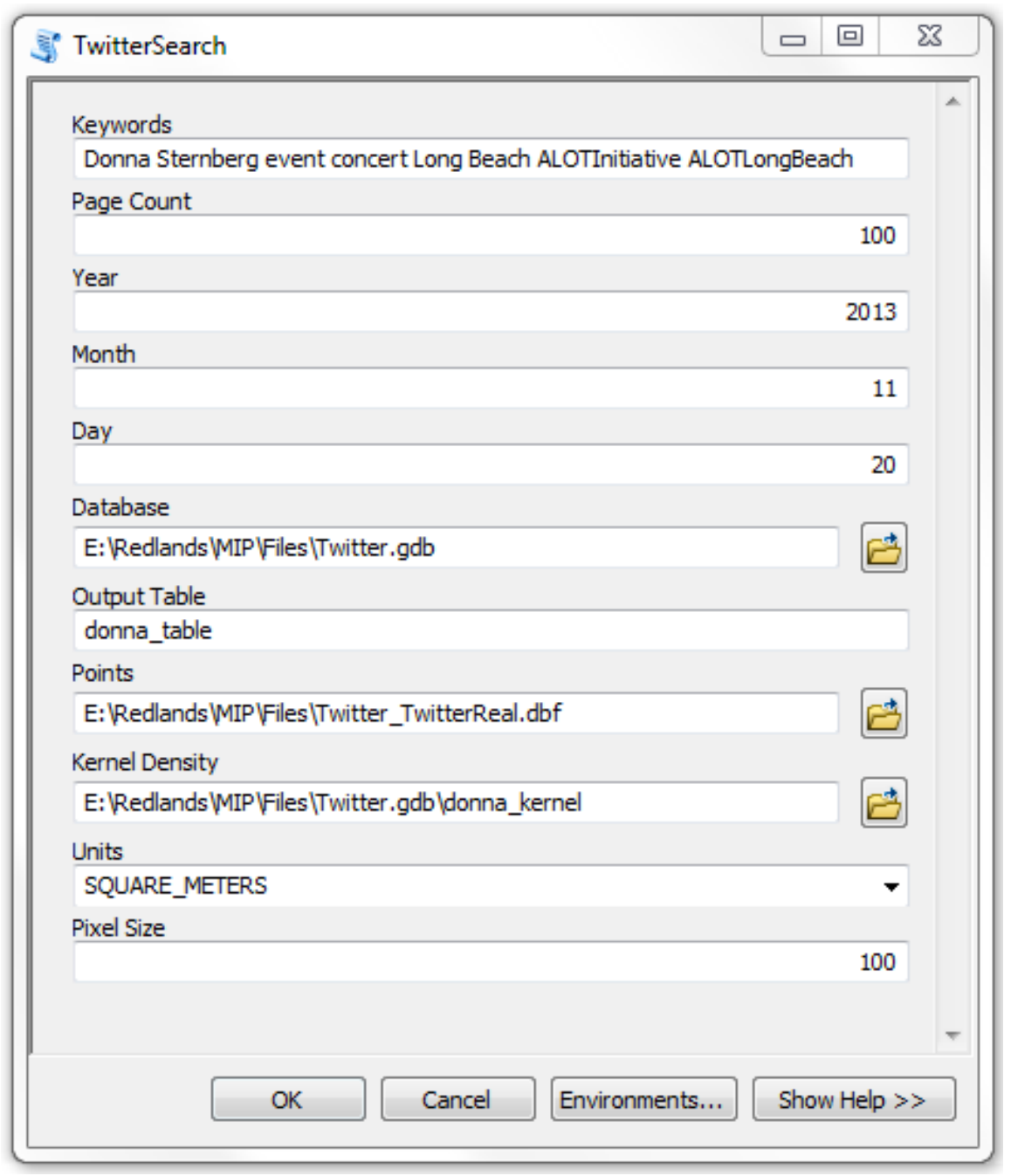

\section{Figure 6-6: Twitter Search Tool}

In this case the tool did not return any results. This suggests that either no one tweeted about that event or it suggests that the user should query using different keywords. The fewer words the user enters and the more talked-about a word is in a given period of time, the more results will be returned. For instance, using "Thanksgiving" as a keyword in mid-November returns over 17,900 tweets, although only about 400 of these tweets had a location attached to them. Figure 6-7 shows the resulting kernel density raster, brought into ArcMap and laid on top of a basemap. The user now has a visual representation of the distribution of tweets. It suggests that Thanksgiving is an especially popular topic to tweet about in the Northeast and the Southwest of the United States. 


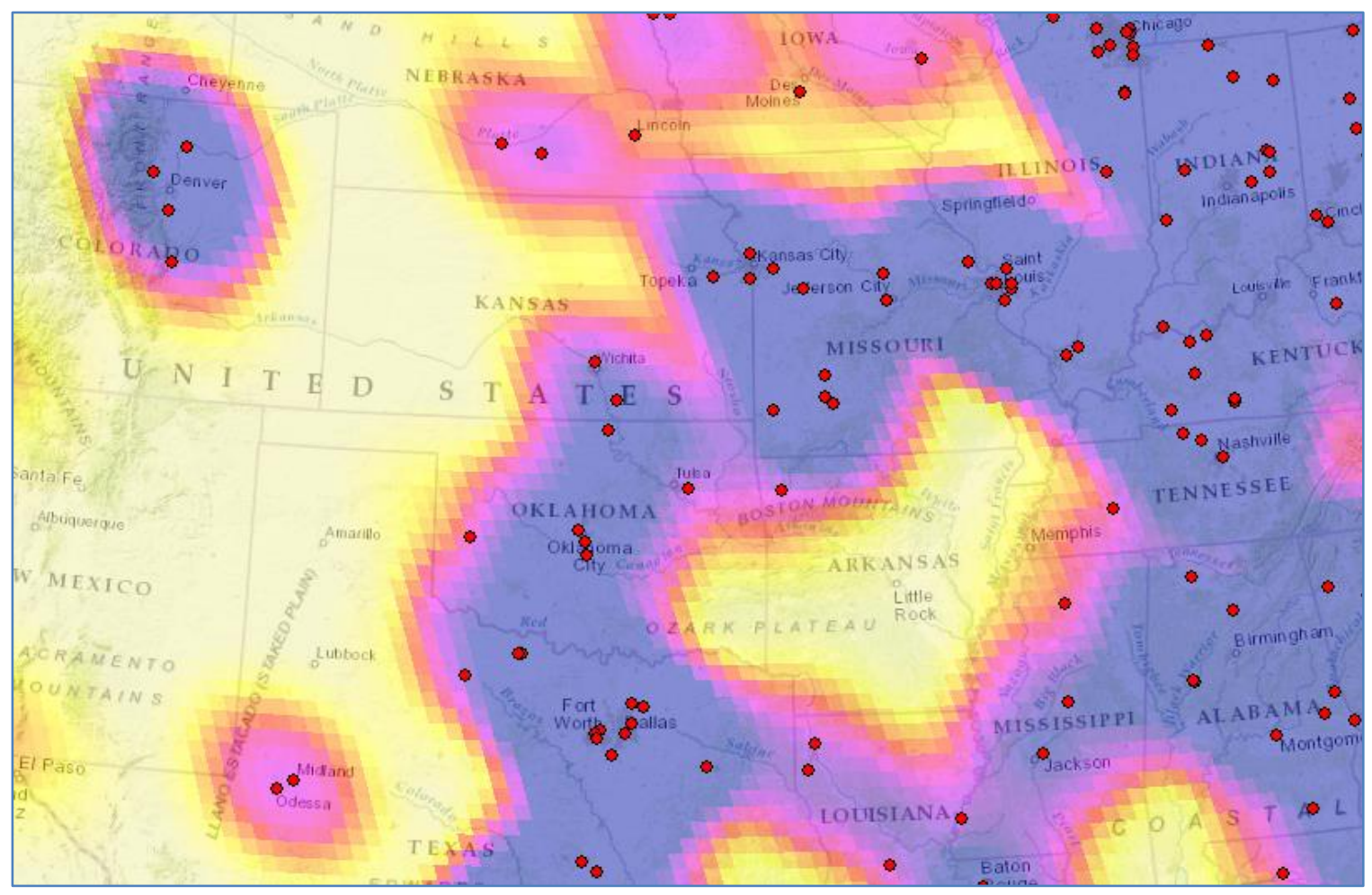

Figure 6-7: Heat Map Result from Searching "Thanksgiving"

\subsection{Summary}

This chapter showed how the two deliverables of this project can be used in real-world scenarios. Section 6.1 elaborated on the uses of the web application, which has three main purposes: familiarizing oneself with the A LOT Initiative, submitting information, and retrieving information. Section 6.2 showed how the Twitter tool can be used to return and map out specific tweets from Twitter databases. 



\section{Chapter 7 - Conclusions and Future Work}

This project was accomplished for the Arts Council for Long Beach (ACLB), a non-profit organization based in Long Beach, California. The ACLB is involved in a cultural project, called A LOT Initiative. The A LOT Initiative is an attempt to reverse the issue of empty urban lots in the City of Long Beach. Over a period of two years the ACLB hosted events in three lots across the city. This project resulted in two deliverables - a web application and a tool to search Twitter databases - which both helped the ACLB track the success of its A LOT Initiative.

A wealth of information about many of the A LOT Initiative events is available on the internet. It was impossible for the ACLB, however, to gather all that information by itself. A web application was built that lets users submit relevant information to a database. The user was able to submit links to blogs, links to news articles, links to YouTube videos, as well as personal reviews and ratings. Anyone who is passionate about the A LOT Initiative can now easily look up or share valuable information with the ACLB.

Based on specific keywords, the Twitter Search tool searches tweets from Twitter databases. The resulting tweets are written to a database, and if locations are available, they are mapped. The rationale behind the Twitter Search tool was that the ACLB could query Twitter databases after an event to see what people tweeted about it. Ideally all of the returned tweets contain geographic location, which would help the ACLB visualize where in Long Beach specific events had an impact. It turned out that it can be difficult to use Twitter to find such specific and local information. To make the tool useful, the ACLB could ask visitors to share their location of events to use a specific hashtag when tweeting about the A LOT Initiative (.e.g., \#ALOTInitiativeLongBeach).

Future work could consist of combining the deliverables, such that the Twitter tool could be accessed from the web application. By opening the tool to the public and keeping track of the entered keywords, the ACLB would find out which events users are, or were, most interested in. The ACLB would know which artists should be hired again, and which areas in Long Beach should be invested in more. It would be interesting as well to have a map that is connected to Twitter using the Twitter Streaming API. 



\section{Works Cited}

Carver, S., Evans, A., Kingston, R., \& Turton, I. (2001). Public participation, GIS, and cyberdemocracy: evaluating on-line spatial decision support systems. Environment and Planning B, 28(6), 907-922.

DuVander, Adam. Map Scripting One Hundred One. No Starch Press, 2010.

Elwood, S., \& Leitner, H. (2003). GIS and spatial knowledge production for neighborhood revitalization: Negotiating state priorities and neighborhood visions. Journal of Urban Affairs, 25(2), 139-157.

Fu, P., \& Sun, J. Web GIS: principles and applications. Esri Press, 2010.

Goodchild, M. F. (2007). Citizens as sensors: the world of volunteered geography. GeoJournal, 69(4), 211-221.

Guetzkow, J. (2002). How the arts impact communities. Centre for Arts and Cultural Policy Studies.

Kelling, G. L., \& Wilson, J. Q. (1982). Broken windows. Atlantic Monthly, 249(3), 2938.

Kunstler, J. H. (1998). Home from nowhere: remaking our everyday world for the 21 st century. Touchstone Press.

Markusen, A., \& Gadwa, A. (2010). Arts and culture in urban or regional planning: A review and research agenda. Journal of Planning Education and Research, 29(3), 379-391.

McKay, D.A., (2007). Redeveloping Greyfields in the Greater Toronto Area [Current Issues Paper]. Retrieved from http://www.geog.utoronto.ca/graduate/planning/student-work/cip/2006-07Redeveloping-Greyfields-MCKAY.pdf

Northam, R. M. (1971). Vacant urban land in the American city. Land Economics, 47, 345-355.

O'Reilly, T. (2007). What is Web 2.0: Design patterns and business models for the next generation of software. Communications \& strategies, (1), 17.

Pagano, M. A., \& Bowman, A. O. M. (2000). Vacant land in cities: An urban resource. Brookings Institution, Center on Urban and Metropolitan Policy. 
Peng, Z. R. (2001). Internet GIS for public participation. Environment and Planning B, 28(6), 889-906.

Sieber, R. (2006). Public participation geographic information systems: A literature review and framework. Annals of the Association of American Geographers, 96(3), 491-507.

Stanziola, J. (1999). Arts, government and community revitalization. Brookfield, VT: Ashgate.

Steinacker, A. (2003). Infill development and affordable housing patterns from 1996 to 2000. Urban Affairs Review, 38(4), 492-509.

Strom, E. (2002). Let's put on a show! Performing arts and urban revitalization in Newark, New Jersey. Journal of Urban Affairs, 21(4), 423-435. 


\section{Appendix A. Web Application Code}

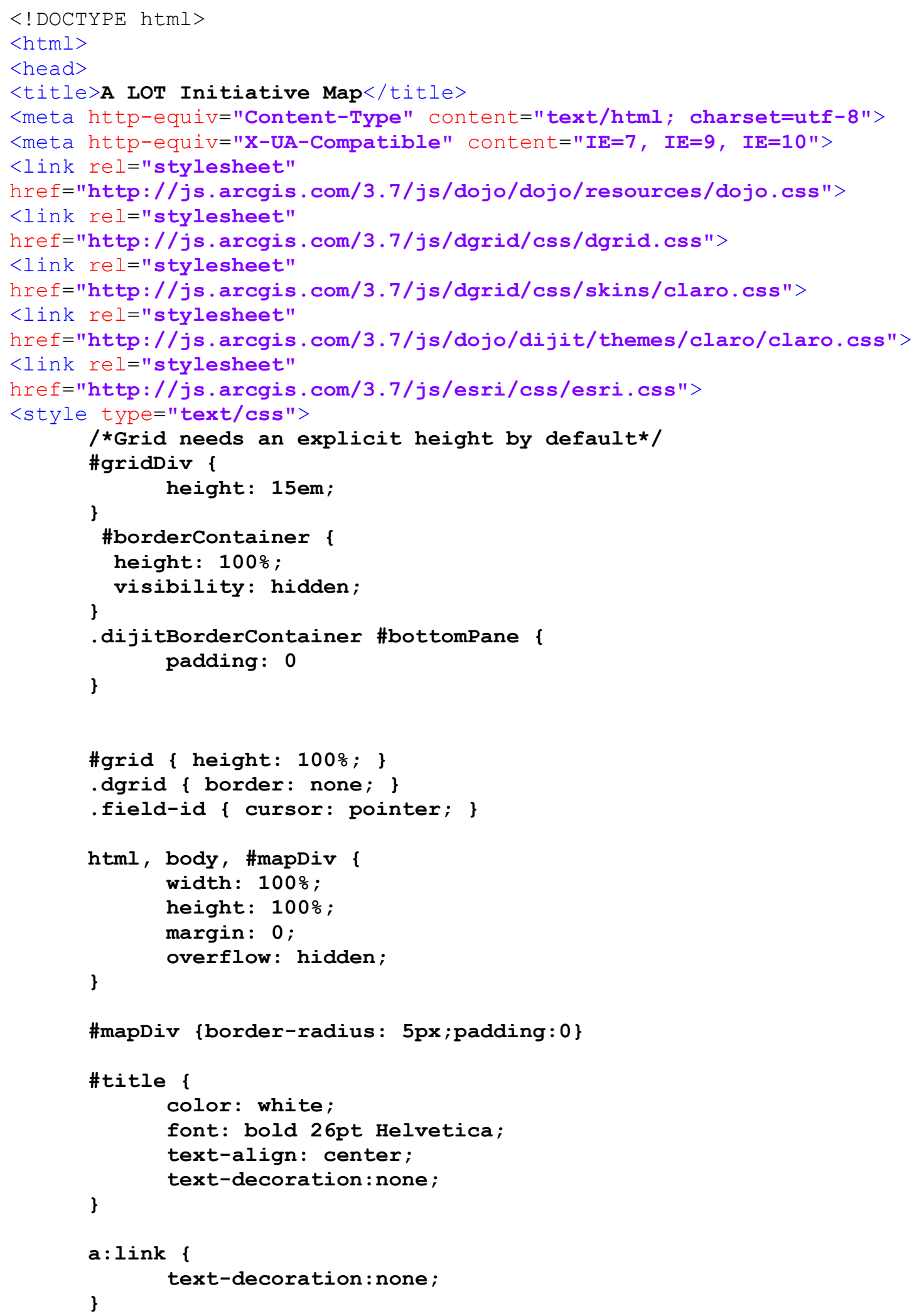




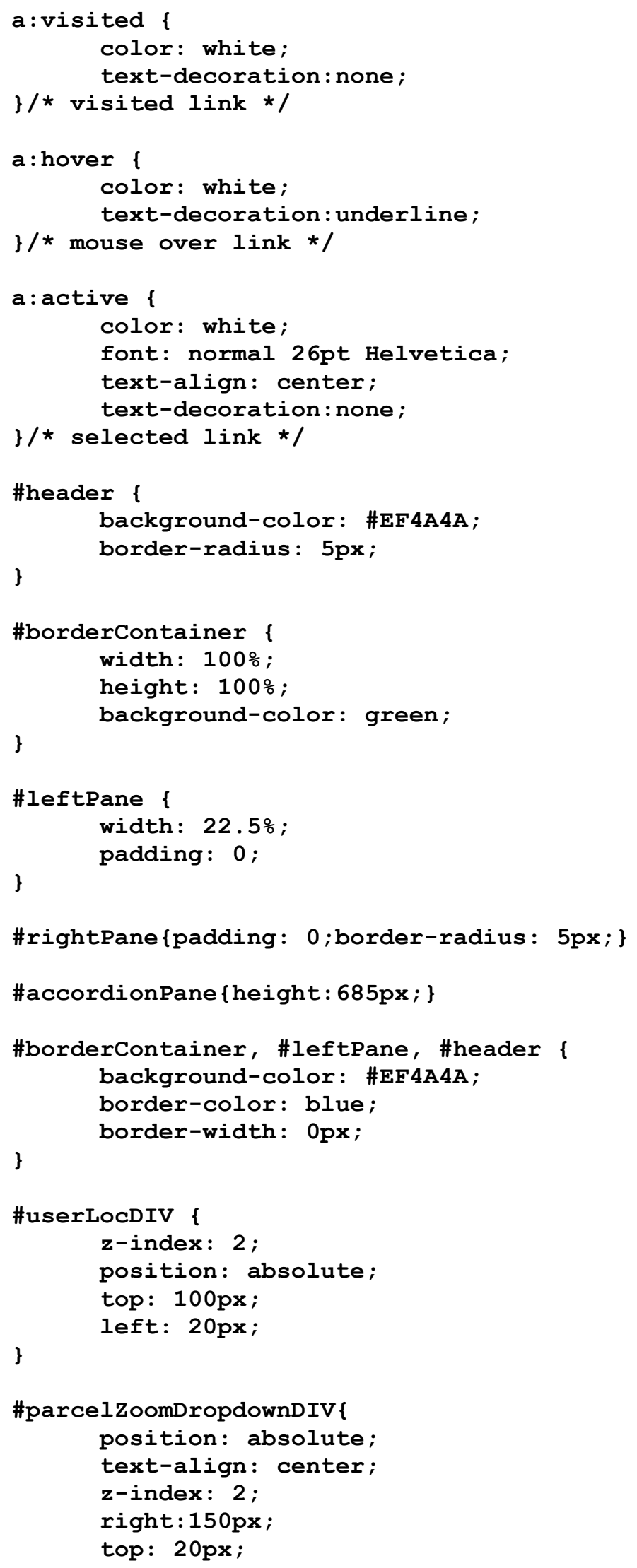




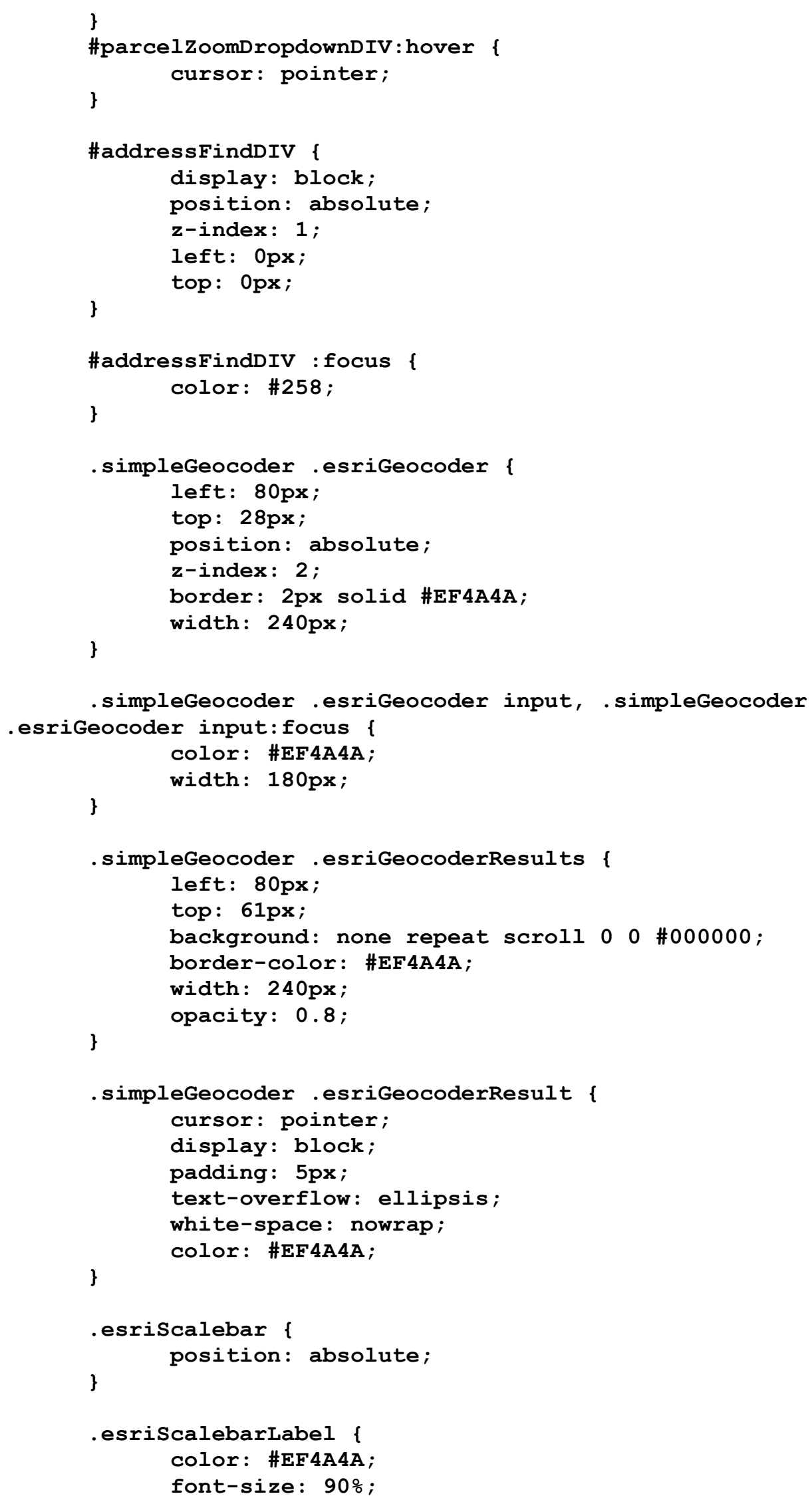




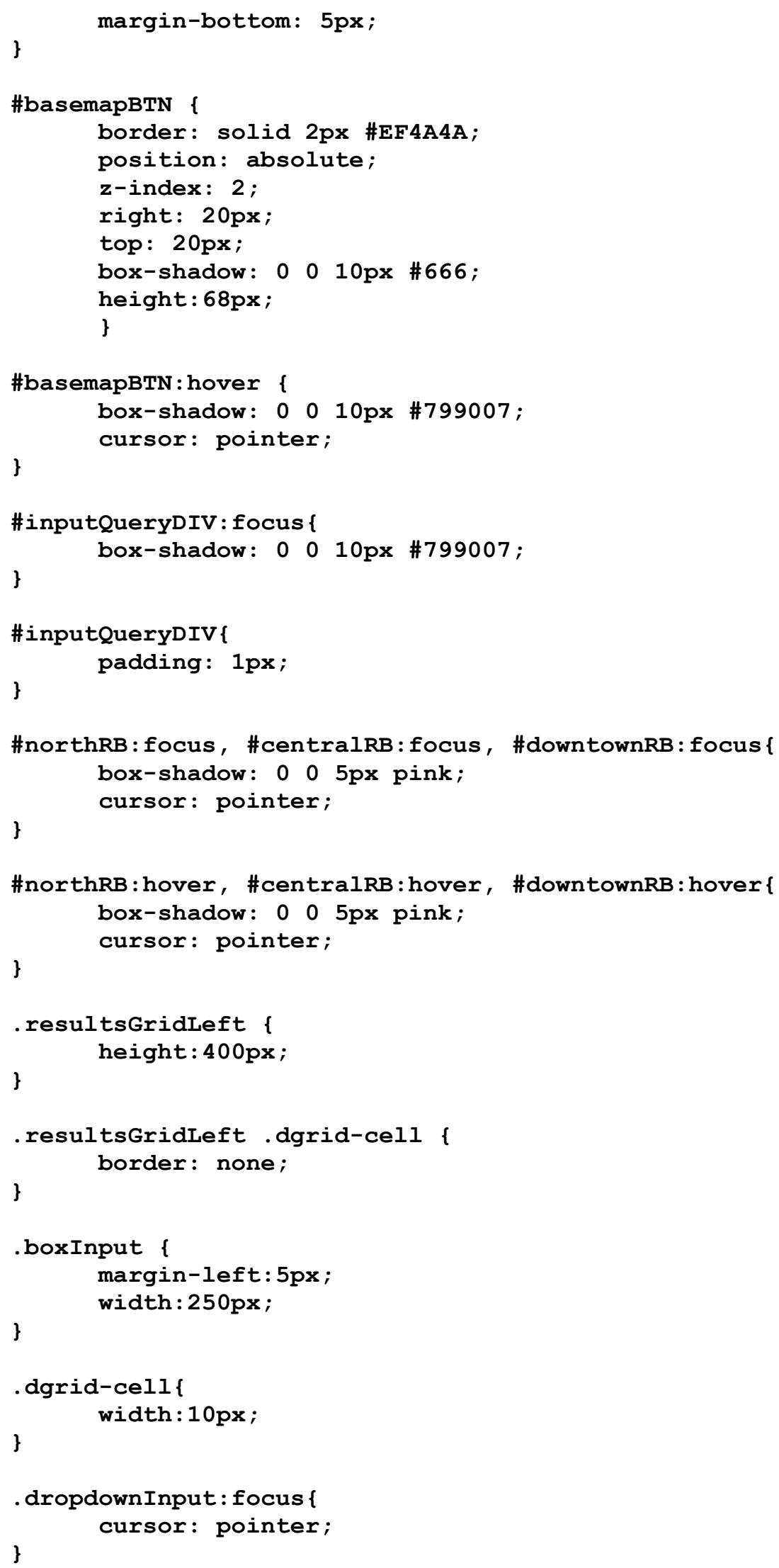




\section{.dropdownInput: hover \{ \\ cursor: pointer; \\ \}}

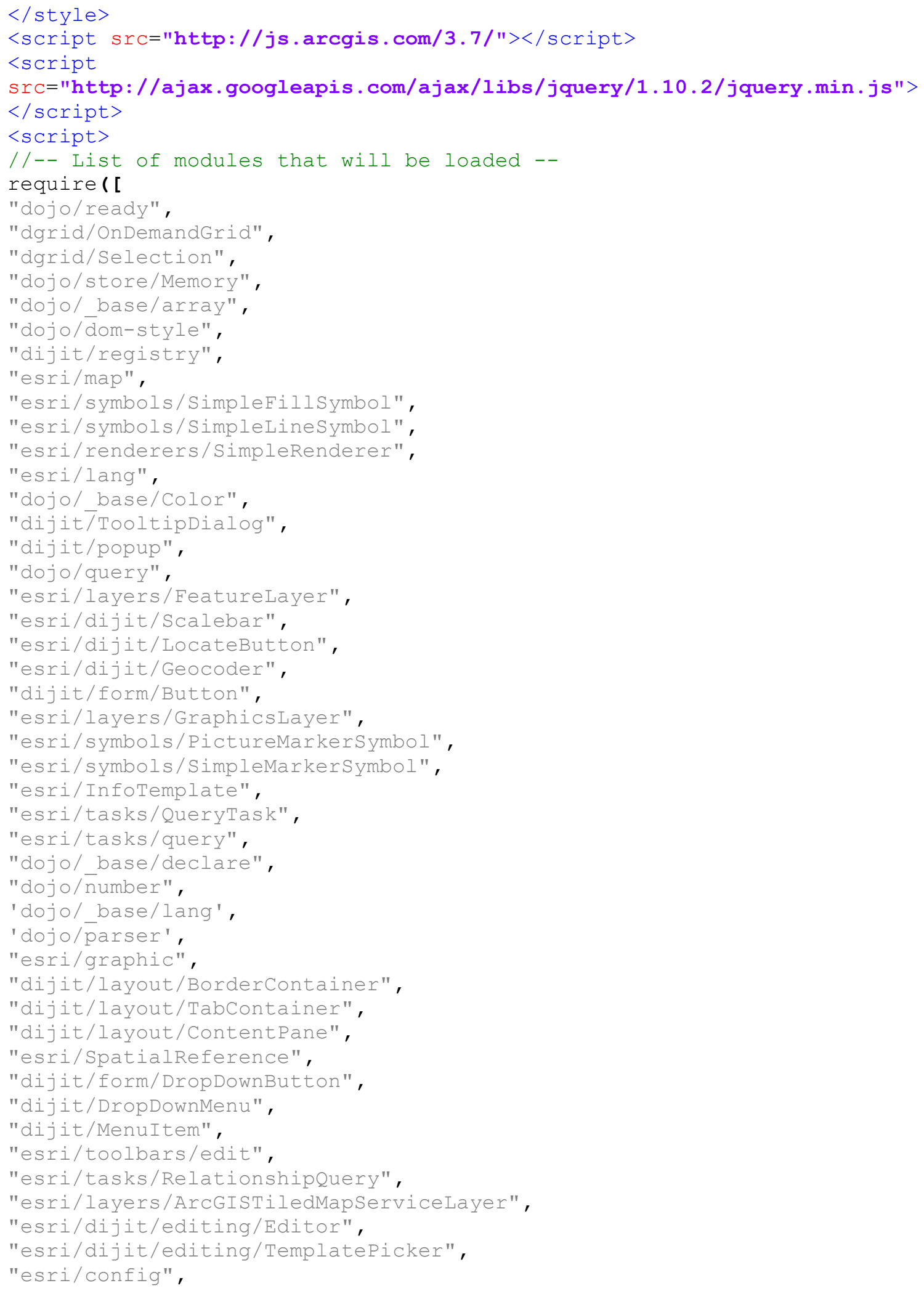




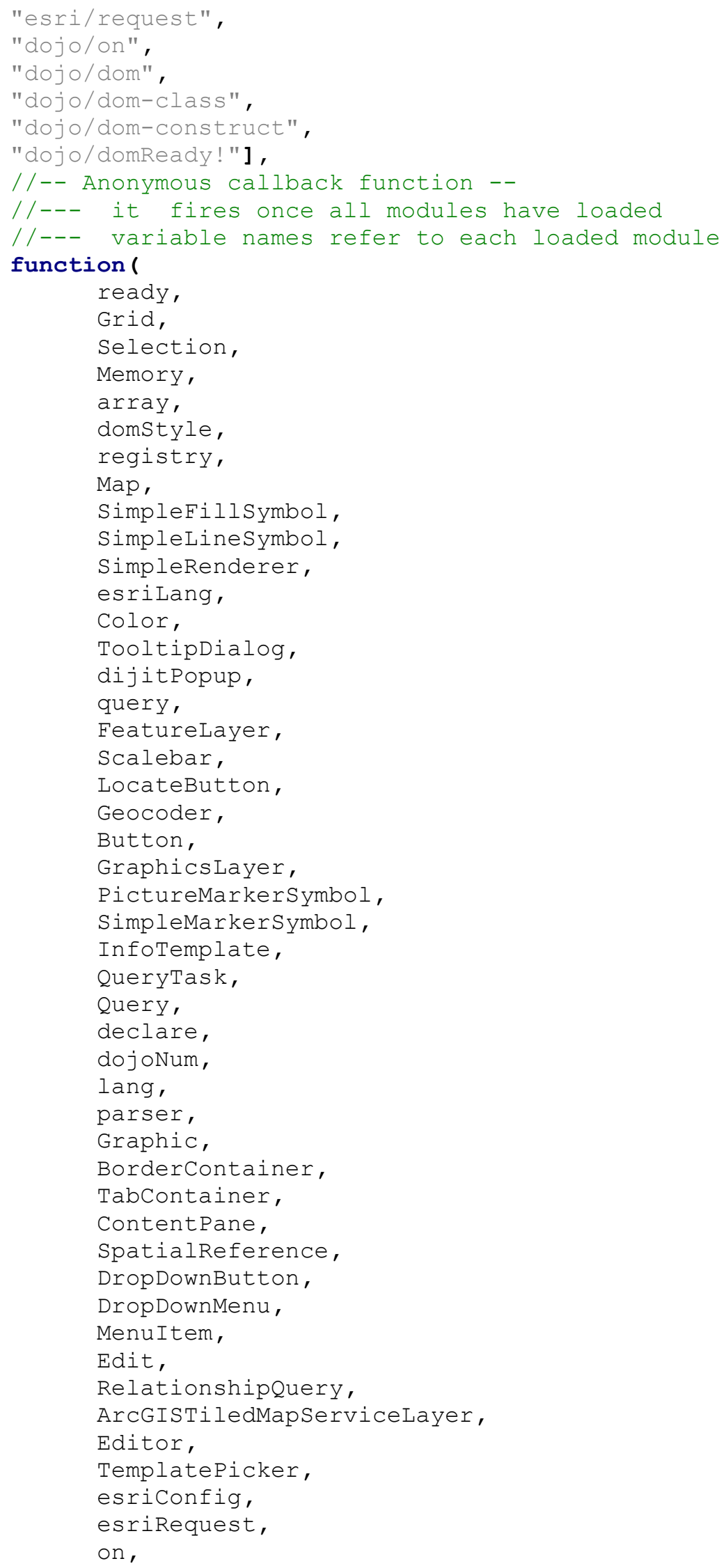




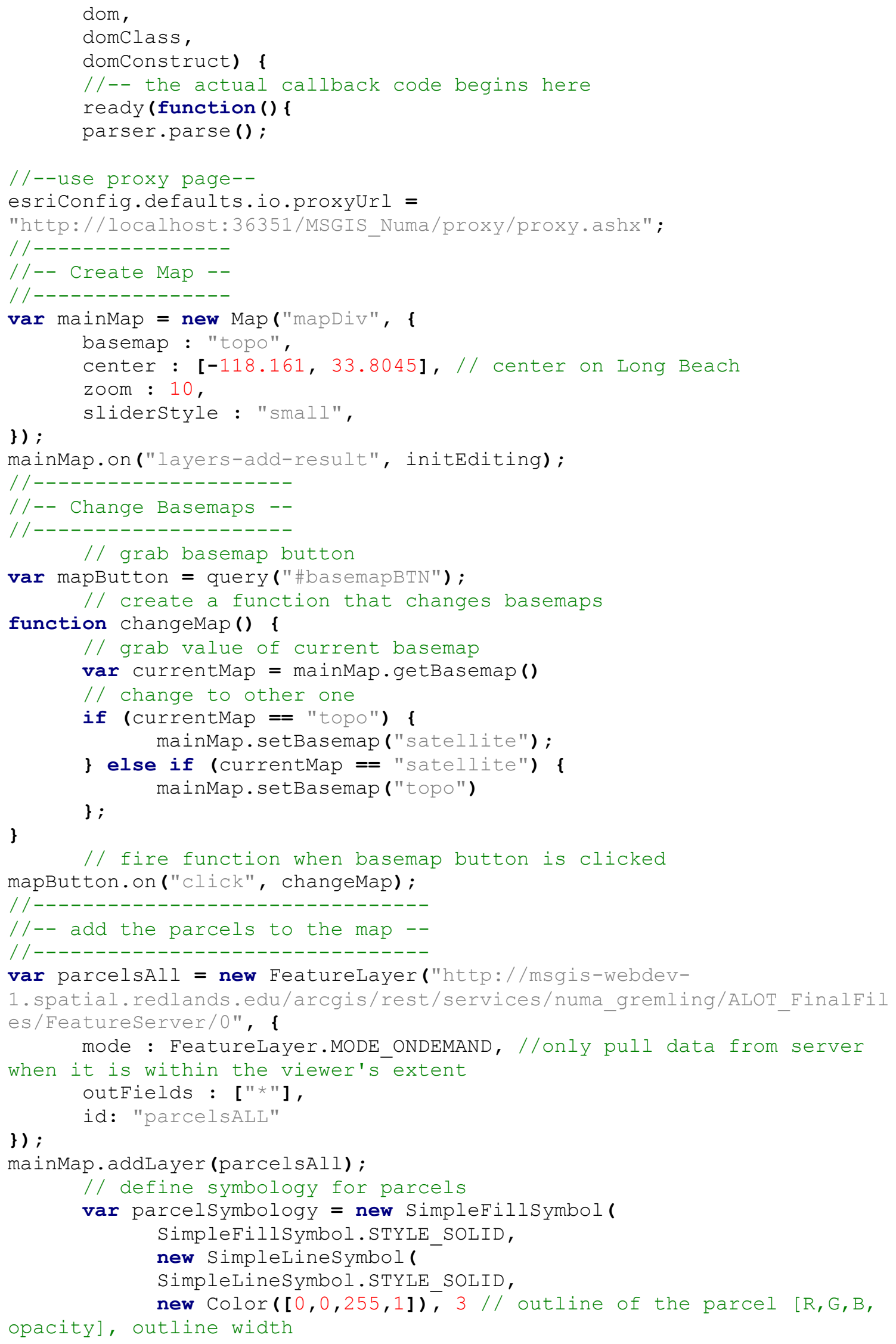




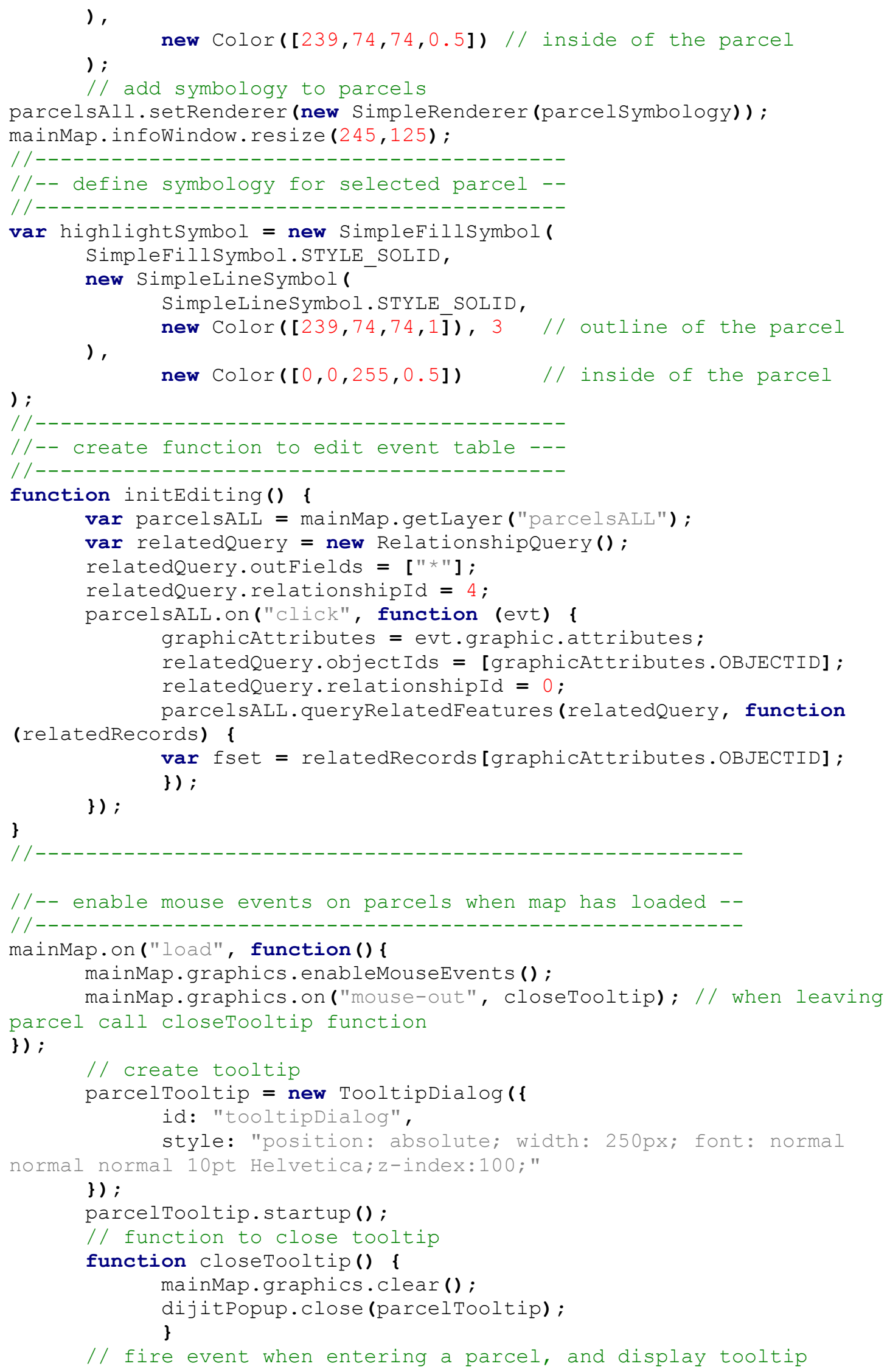




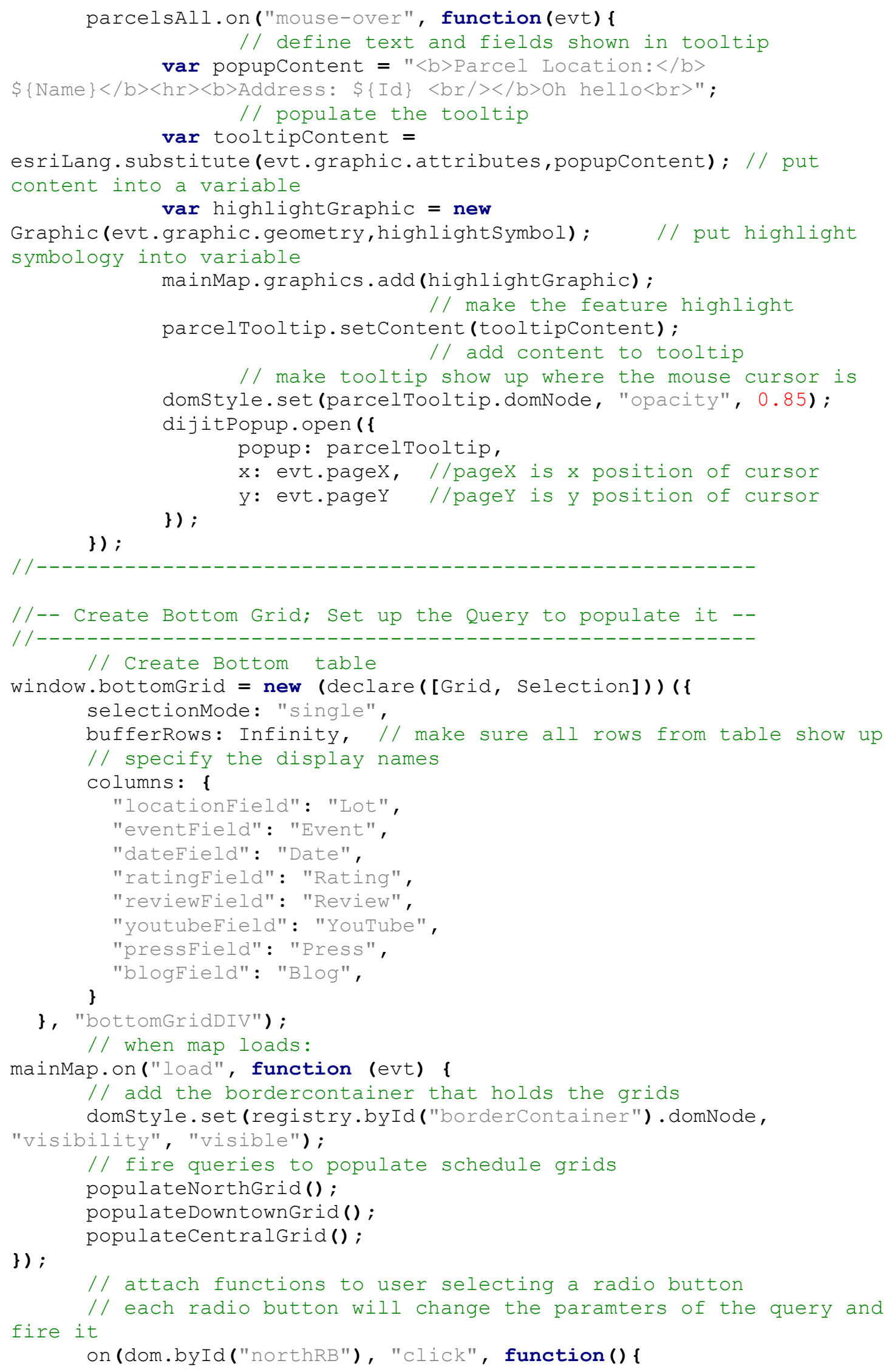




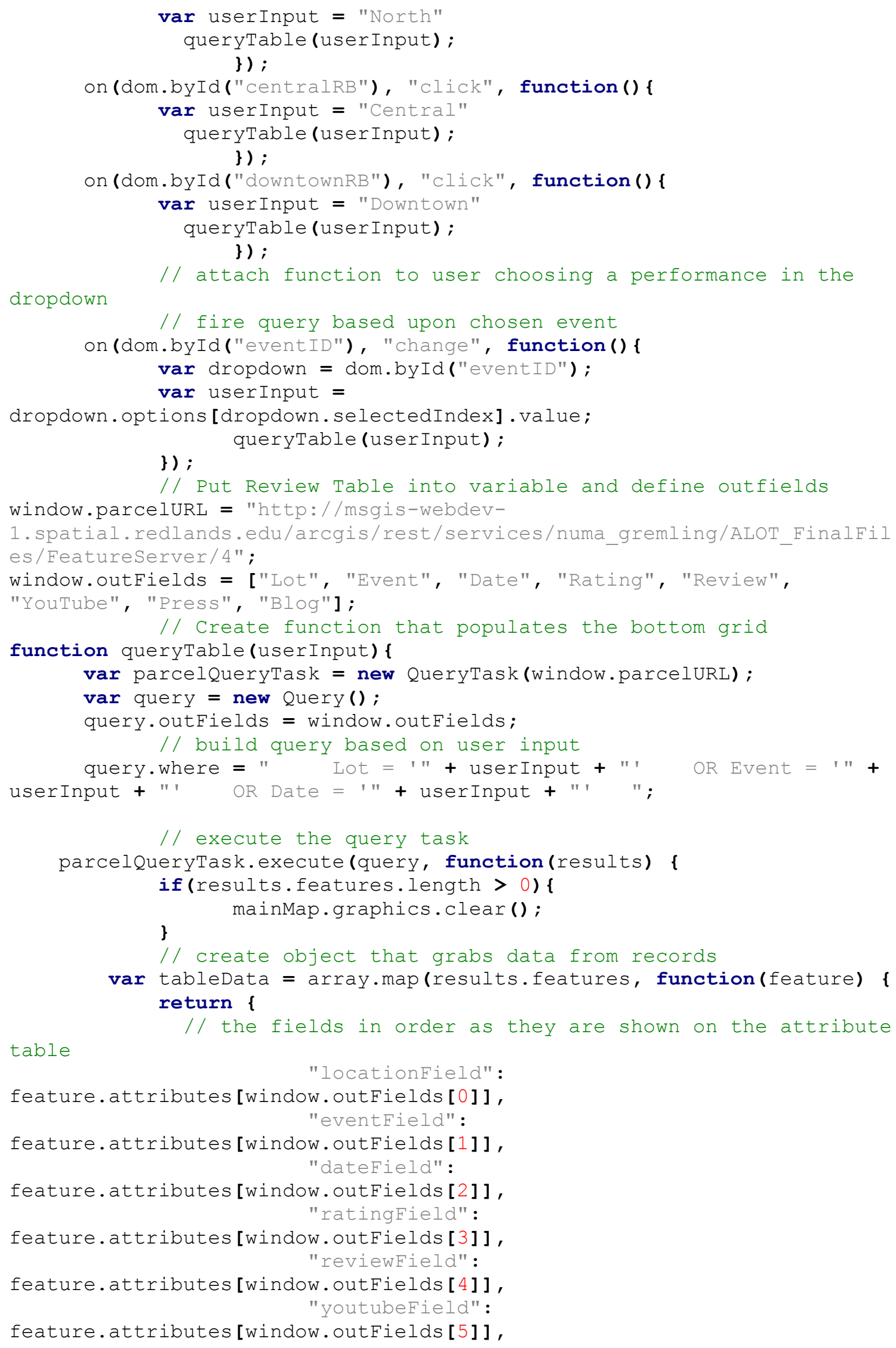




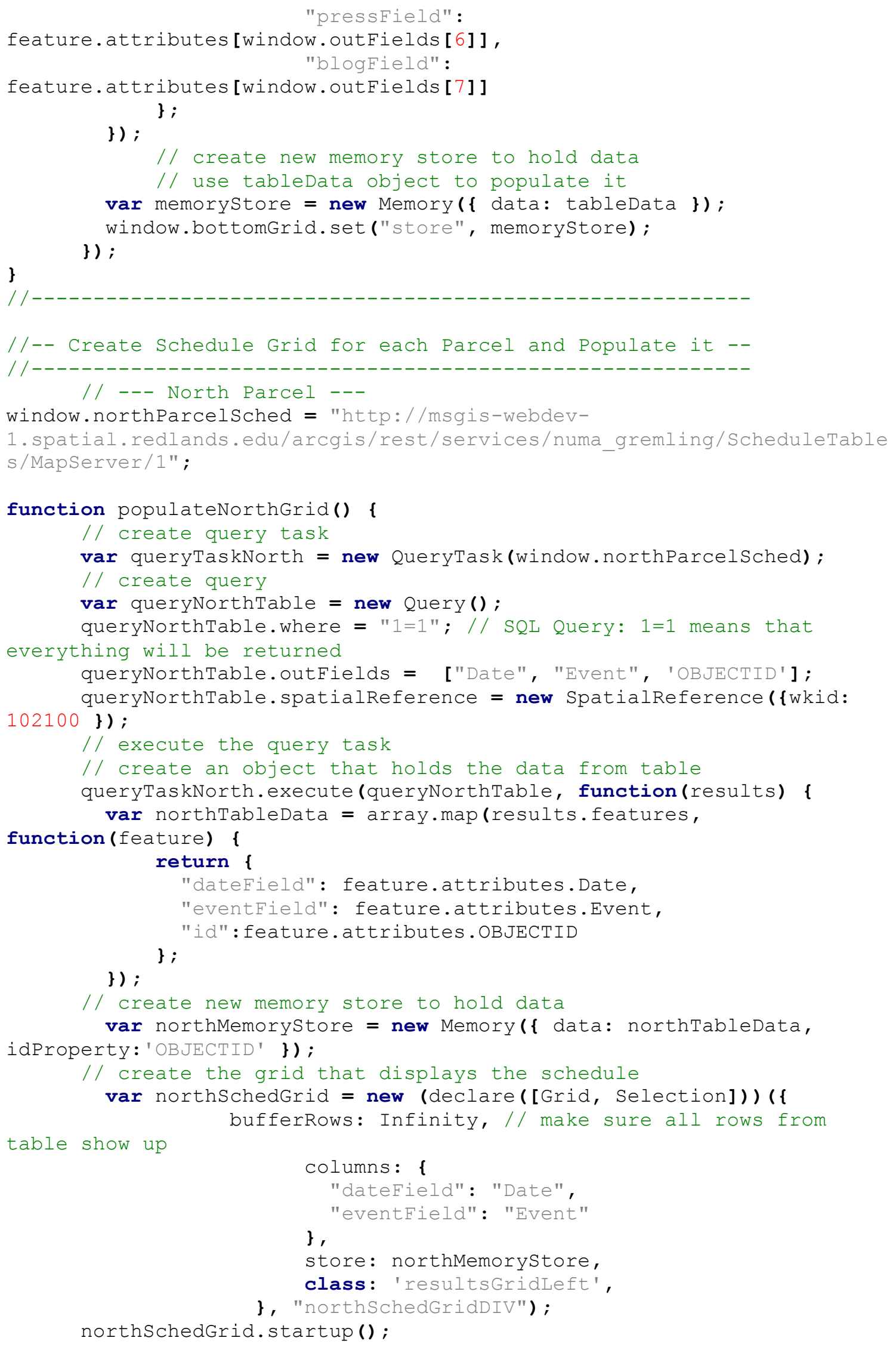




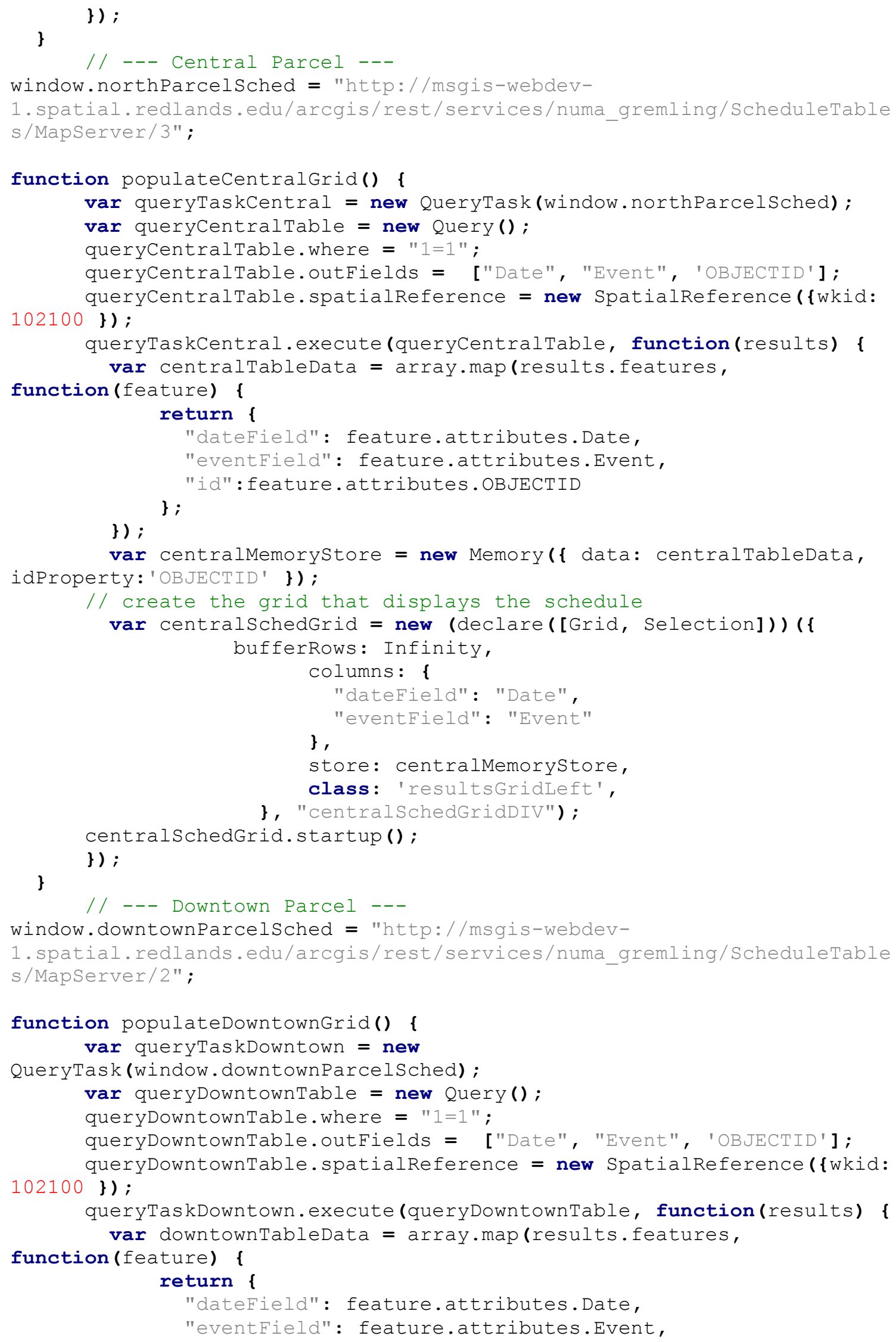




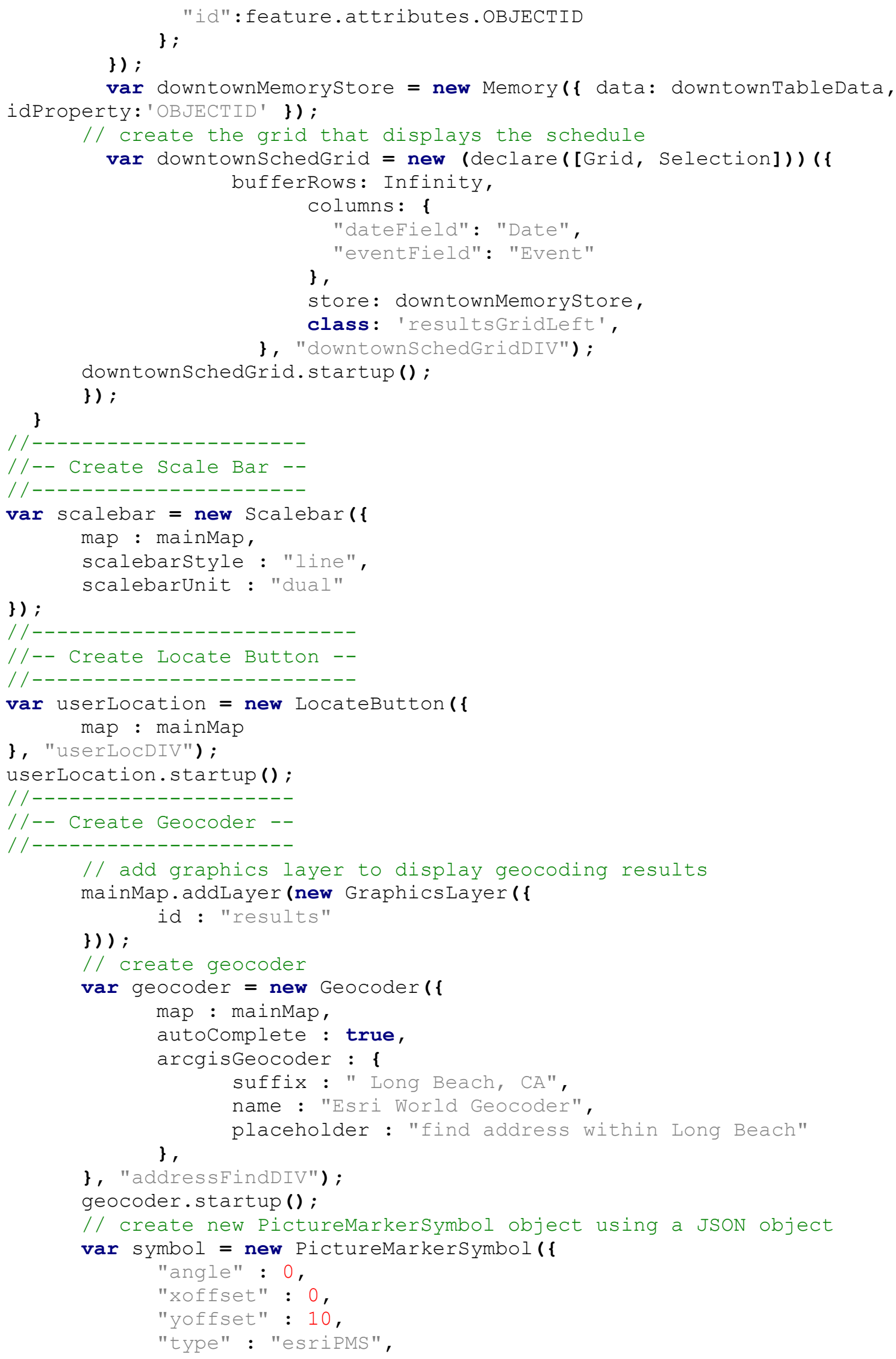




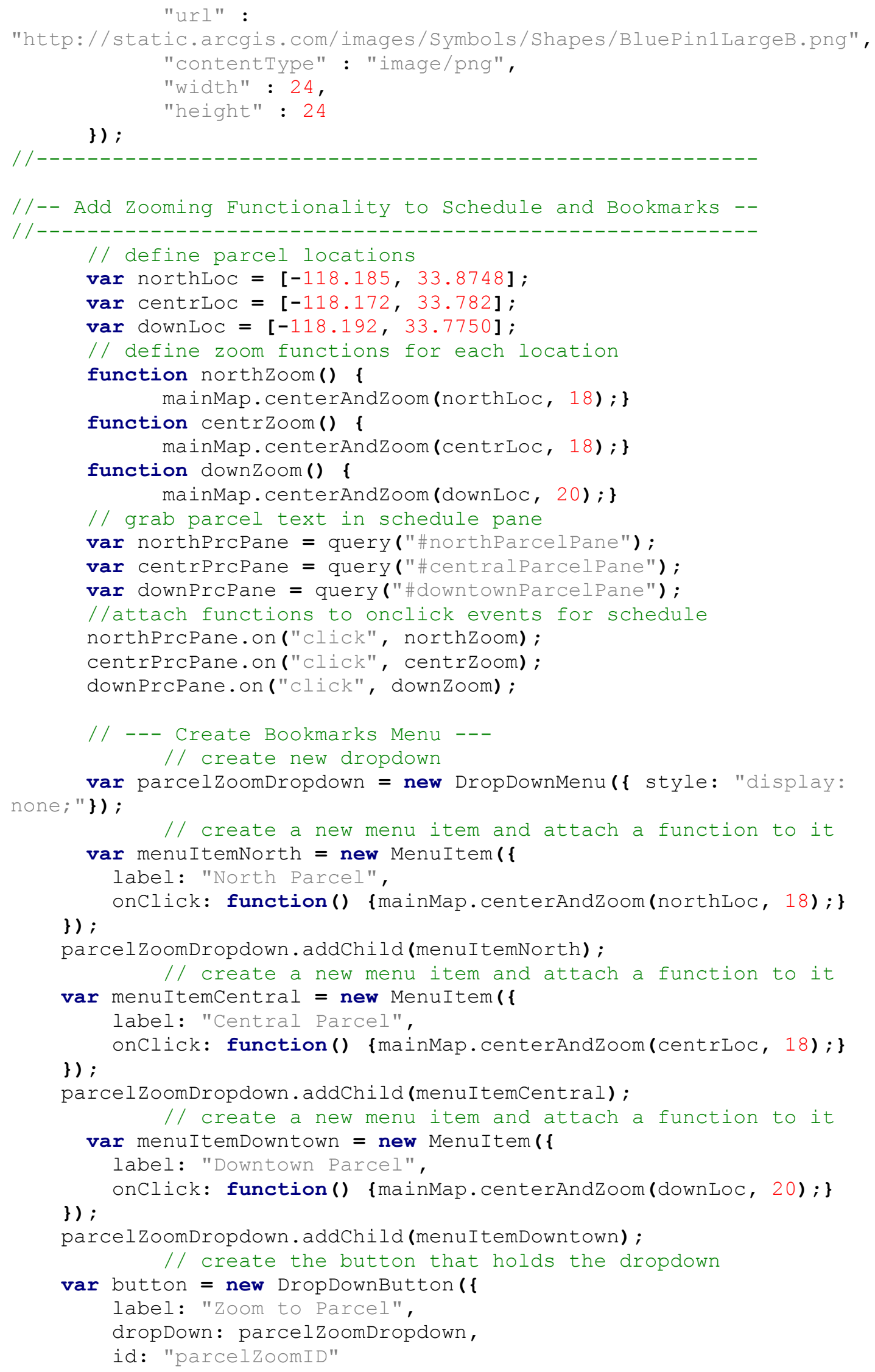


\}) ;

dom.byId ("parcelZoomDropdownDIV") . appendChild (button.domNode);

// -- Function and Require end here --

\});

\});

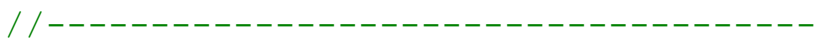

//---------------------------------------

//-- Function that Edits the Review Table --

function updateRelatedTable() \{

require( [

"esri/layers/FeatureLayer",

"dojo/on",

"dojo/dom",

], function (Featurelayer, on, dom) \{ // get value from YouTube input box

youtubeLink = document.getElementById('youtubeInputID').value; // get value from Blog input box

blogLink = document.getElementById('blogInputID').value;

// get value from Review input box

reviewText $=$ document.getElementById('reviewInputID').value;

// get value from Press input box

presslink $=$ document.getElementById('pressInputID').value;

// get value from selected Event in dropdown

var eventDropdown $=$ dom.byId("eventInputID");

eventInput $=$

eventDropdown. options [eventDropdown. selectedIndex].value;

// get value from selected Parcel Location in dropdown

var locationDropdown = dom.byId("locationInputID");

locationInput $=$

locationDropdown.options [locationDropdown.selectedIndex] .value;

// get value from selected Date in dropdown

var dateDropdown = dom.byId("dateInputID");

dateInput $=$

dateDropdown.options [dateDropdown.selectedIndex] .value;

// get value from selected Rating in dropdown

var ratingDropdown $=$ dom.byId("ratingInputID");

ratingInput $=$

ratingDropdown.options [ratingDropdown. selectedIndex] . value;

// array that holds user input

alert ("Updating...") ;

var comments $=\{$

attributes: \{

Lot: locationInput,

Event: eventInput,

Date: dateInput,

Rating: ratingInput,

Review: reviewText,

YouTube: youtubeLink,

Press: presslink, 


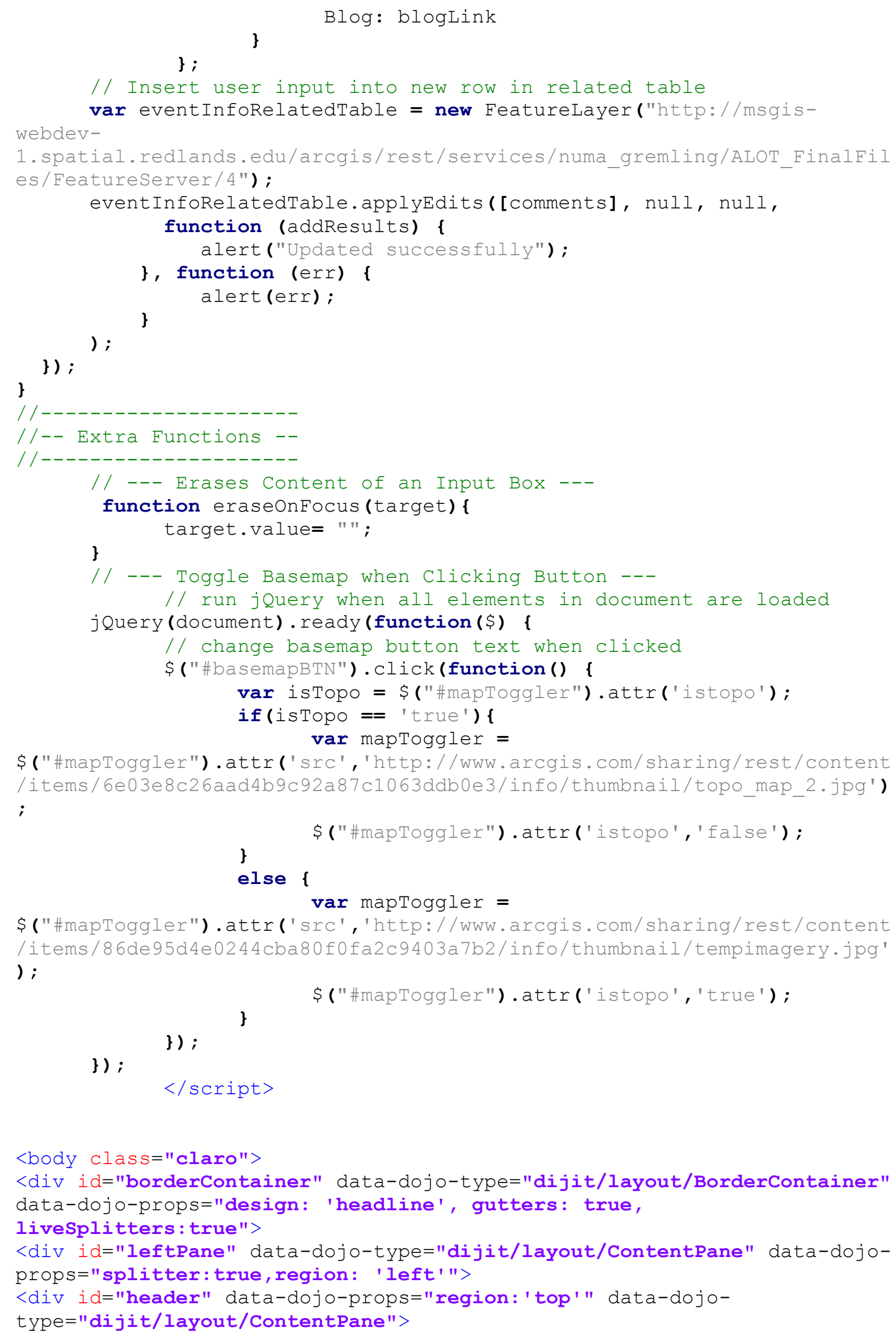




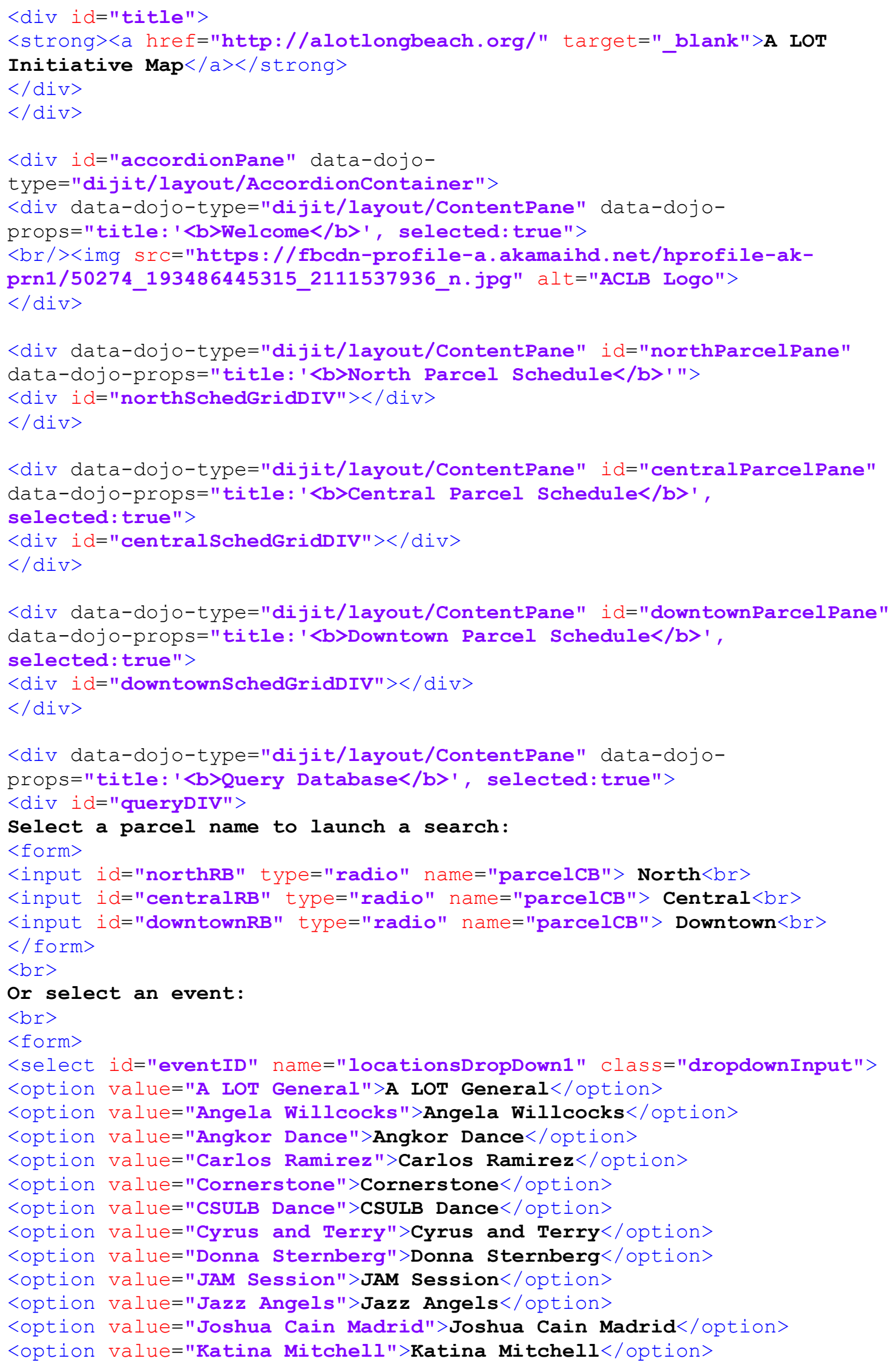




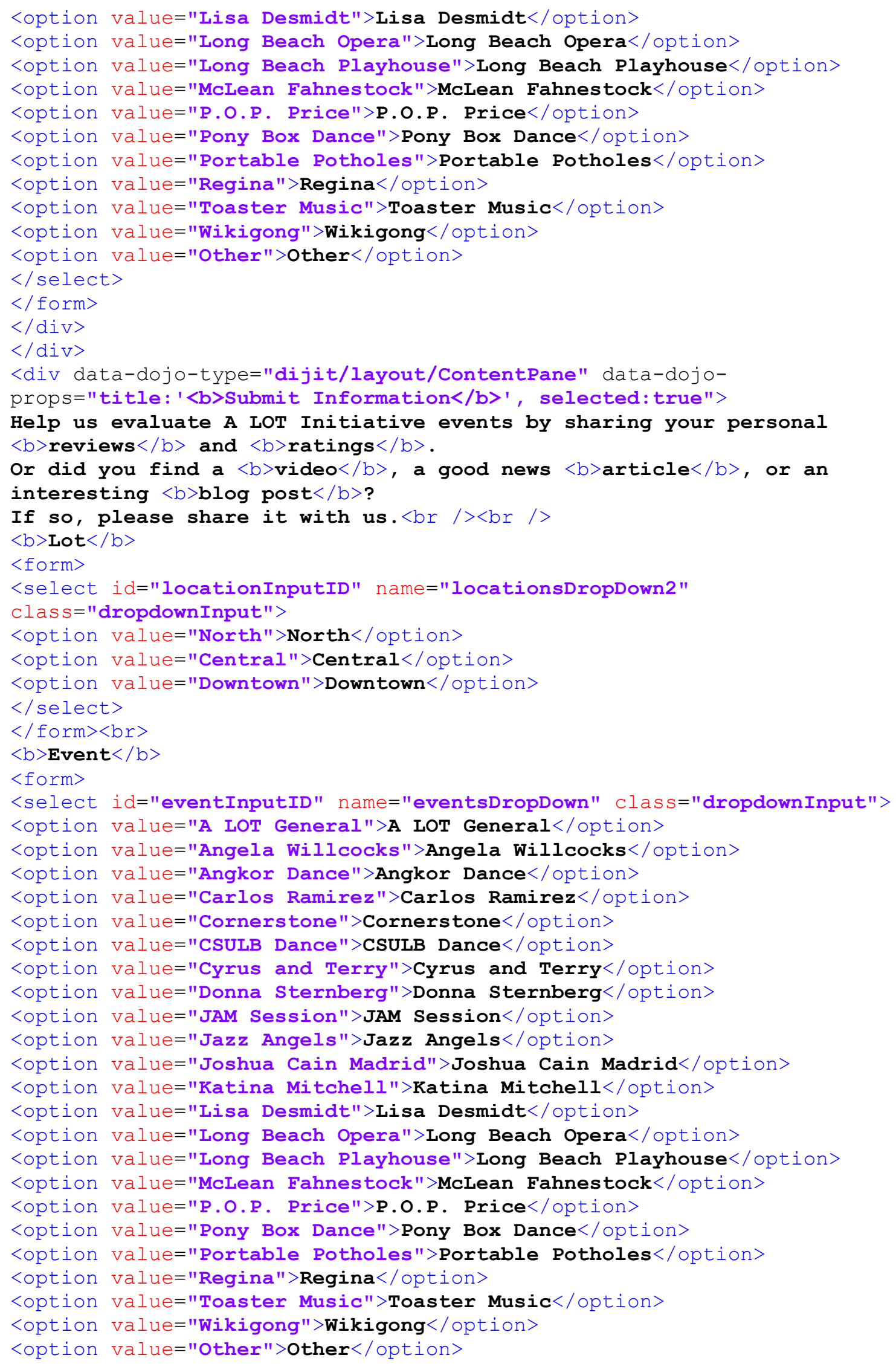




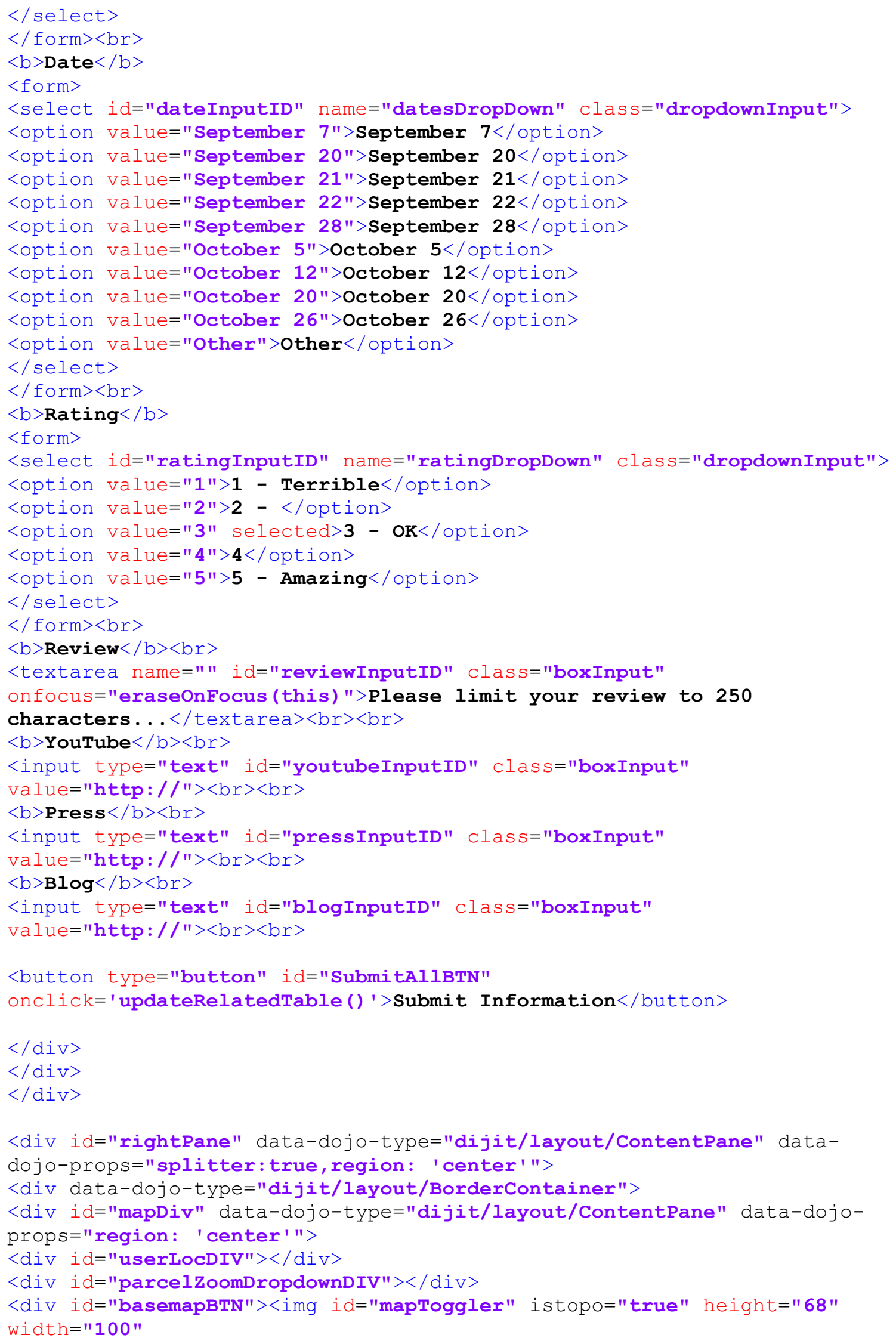


$\mathrm{srC}=$ ' http: //www.arcgis.com/sharing/rest/content/items/86de95d4e $0244 \mathrm{cba} 8$ of0fa2c9403a7b2/info/thumbnail/tempimagery.jpg ' $/></$ div $\rangle$

$<$ div id="addressFindDIV" $></$ div $>$

$</$ div $>$

<div id="bottomPane" data-dojo-type="dijit/layout/ContentPane" datadojo-props="region: 'bottom'" $>$

$<$ div id="bottomGridDIV" $></$ div $>$

$</$ div $>$

$</$ div $>$

$</$ div $>$

$</$ div $>$

$</$ body $>$

$</$ html $>$ 


\section{Appendix B. Twitter Search Tool Code}

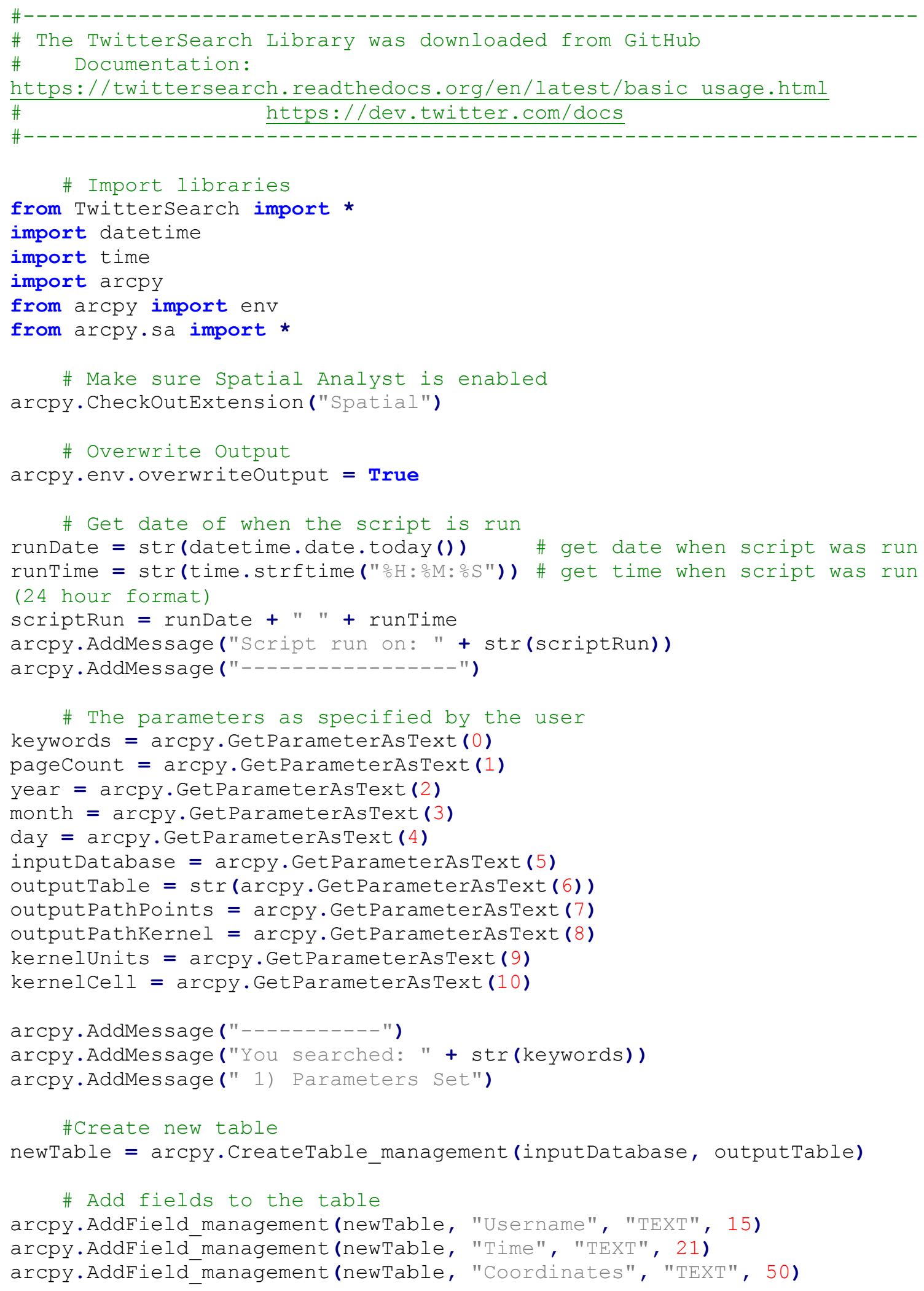




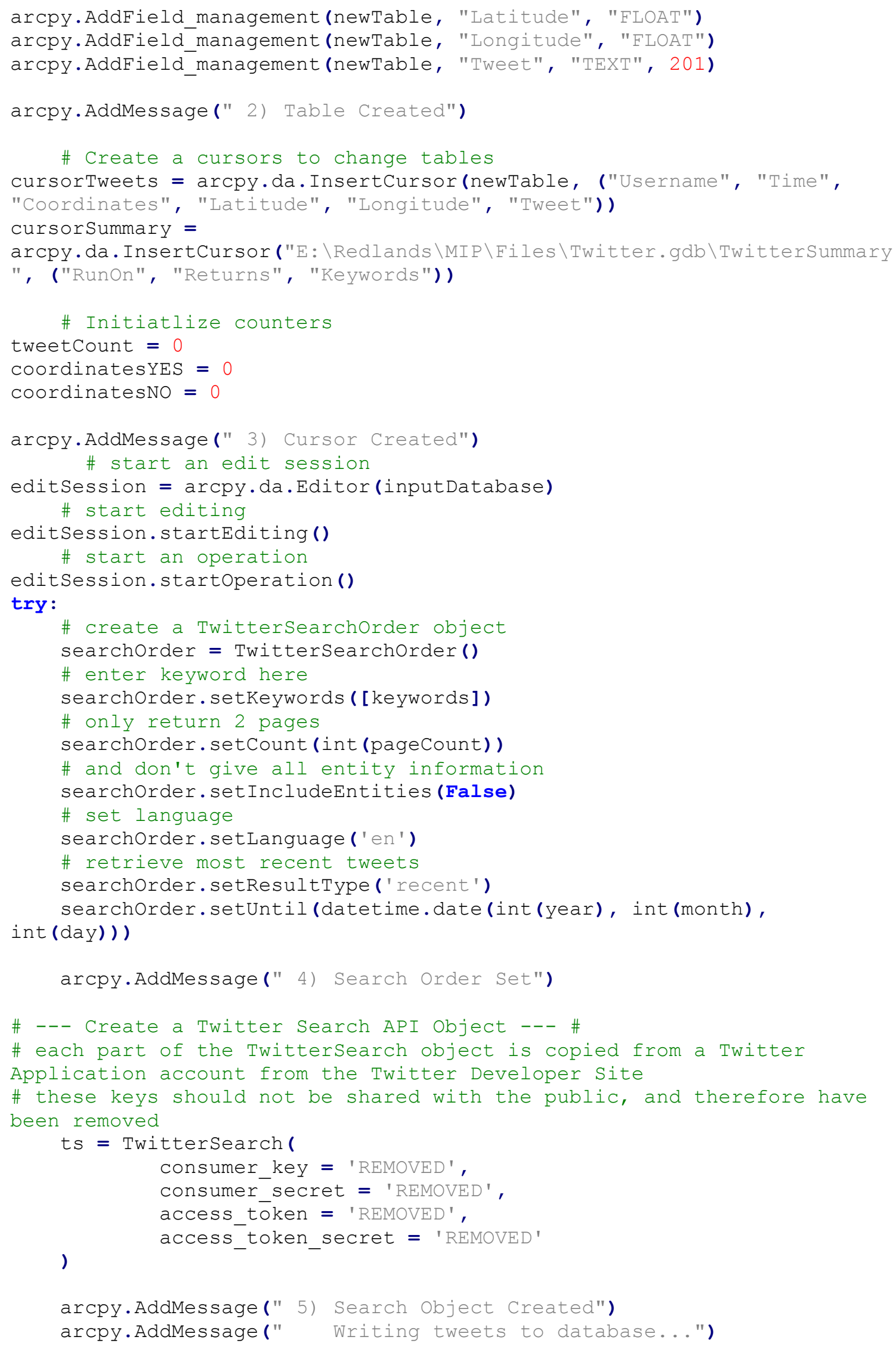


\# Search tweets as defined on top

for find tweet in ts.searchTweetsiterable (searchorder):

username $=\operatorname{str}($ find_tweet ['user'] ['screen_name']) \# extract user name

userCoordRaw $=\operatorname{str}($ find_tweet ['coordinates']) \# get coordinates information

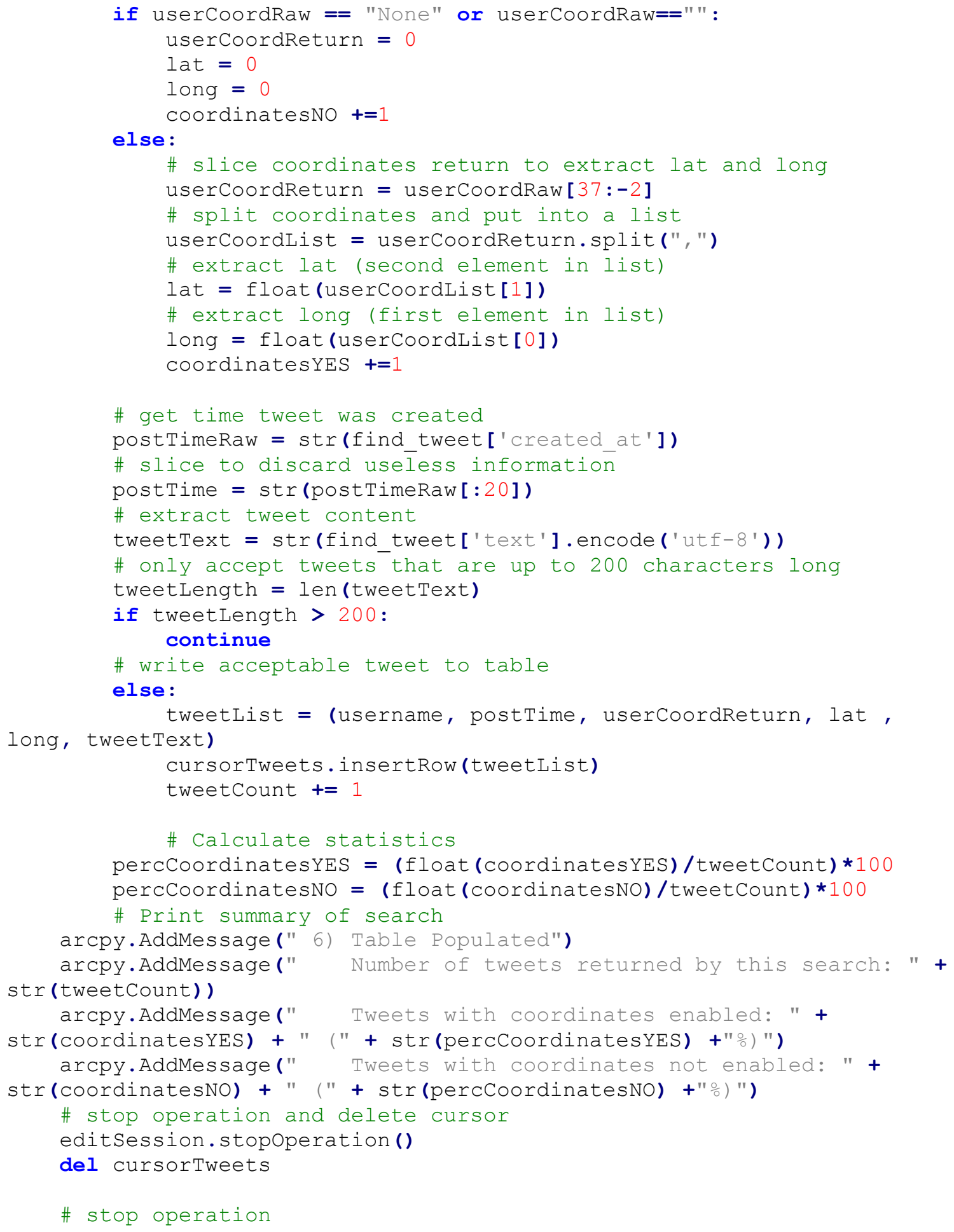




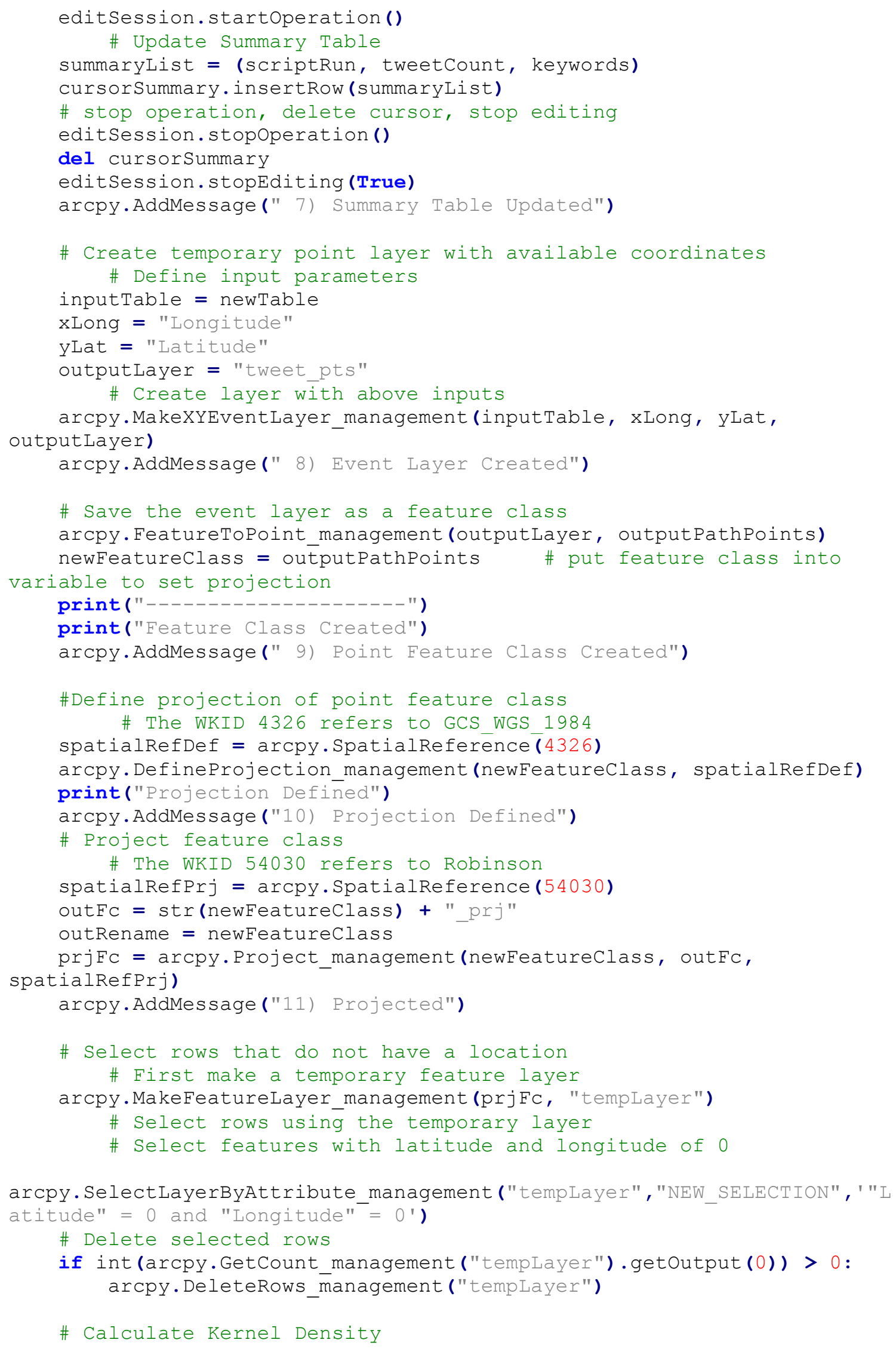




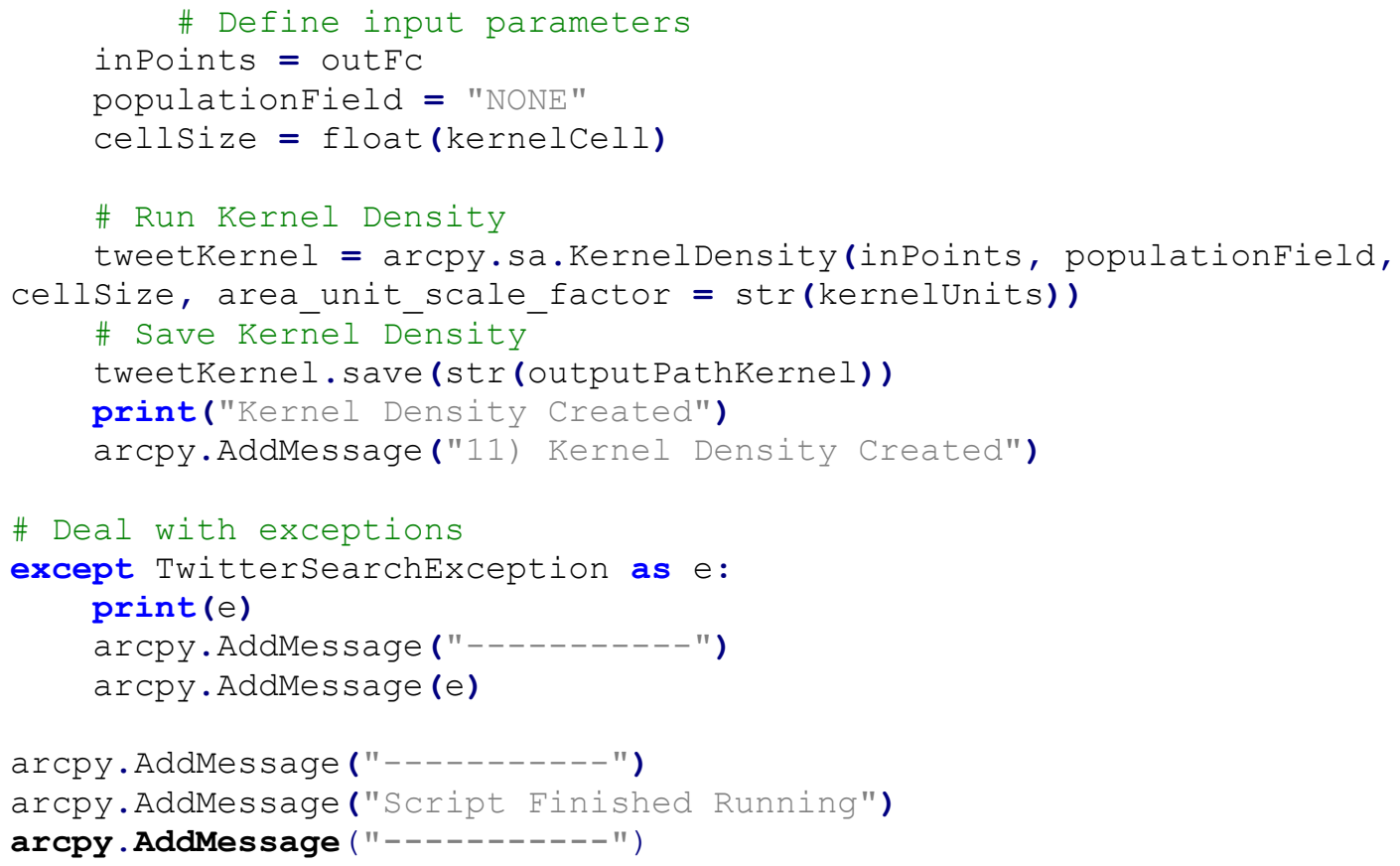

